UNIVERSIDADE DE SÃO PAULO

FACULDADE DE ECONOMIA, ADMINISTRAÇÃO E CONTABILIDADE DEPARTAMENTO DE CONTABILIDADE E ATUÁRIA PROGRAMA DE PÓS-GRADUAÇÃO EM CIÊNCIAS CONTÁBEIS

FATORES LIMITANTES EM IMPLEMENTAÇÕES DE SISTEMAS DE CUSTOS EM EMPRESAS DE PORTE MÉDIO: UM ESTUDO DE CASO

Roberto Suzuki

Orientador: Prof. Dr. Welington Rocha

SÃO PAULO 
Prof. Dra. Suely Vilela

Reitora da Universidade de São Paulo

Prof. Dr. Carlos Roberto Azzoni

Diretor da Faculdade de Economia, Administração e Contabilidade

Prof. Dr. Fábio Frezatti

Chefe do Departamento de Contabilidade e Atuária

Prof. Dr. Gilberto de Andrade Martins

Coordenador do Programa de Pós-Graduação em Ciências Contábeis 


\title{
FATORES LIMITANTES EM IMPLEMENTAÇÕES DE SISTEMAS DE CUSTOS EM EMPRESAS DE PORTE MÉDIO: UM ESTUDO DE CASO
}

\author{
Dissertação apresentada ao Departamento de \\ Contabilidade e Atuária da Faculdade de \\ Economia, Administração e Contabilidade da \\ Universidade de São Paulo para qualificação \\ como requisito parcial para a obtenção do \\ título de Mestre em Ciências Contábeis.
}

Orientador: Prof. Dr. Welington Rocha

\section{SÃO PAULO}


Suzuki, Roberto

Fatores limitantes em implementações de sistemas de custos em empresas de porte médio: um estudo de caso / Roberto Suzuki. -São Paulo, 2008.

$158 \mathrm{p}$.

Dissertação (Mestrado) - Universidade de São Paulo, 2008 Bibliografia.

1. Sistemas de informação gerencial 2. Sistemas de informação 3. Custo industrial 4. Pequenas e médias empresas I. Universidade de São Paulo. Faculdade de Economia, Administração e Contabilidade II. Título. 
A meus pais,

por todo sacrifício e valores.

A minha esposa,

pelo apoio e compreensão.

A batian (in memorium),

pelo carinho e amor incondicionais. 
Agradeço a meu professor e orientador Welington Rocha, que desde o início, sempre encorajou, apoiou e confiou.

A minha esposa Erika e a tia Mitiam, que sempre acreditaram em meu potencial.

A minha família, sem os quais seria impensável estar aqui.

A meus professores, pelos ensinamentos passados.

A todos que de alguma forma colaboraram para que este trabalho tornasse possível. 


\section{RESUMO}

No atual ambiente competitivo das empresas, é necessário que elas utilizem artefatos para manter a sua continuidade. A Gestão Estratégica de Custos é um desses artefatos e, portanto, é necessário que haja um sistema de custeio que oriente as decisões dos gestores dentro de uma organização, que passam a demandar informações cada vez mais elaboradas e com maior agilidade. A implantação desses sistemas, que são cada vez mais complexos, é comum a grandes empresas e, somando-se à importância do mesmo, entende-se o motivo de ter sido muito estudado no decorrer do tempo. Com as mudanças decorrentes da evolução tecnológica, sua diminuição nos custos, e o aumento de competitividade, as pequenas e médias empresas também perceberam a necessidade de se ter um sistema de custeio para suportar suas decisões. Porém, as características dessas empresas são distintas das demais, podendo supor que suas necessidades de informação, assim como as dificuldades de implantação desse tipo de sistema também sejam diferentes. Este estudo tem como objetivo principal identificar as dificuldades de implantação do sistema de custos em uma empresa de médio porte analisada através de estudo de caso. Como objetivos secundários estão: a categorização em grupos do material encontrado na revisão bibliográfica; verificar se as dificuldades encontradas no estudo de caso estão de acordo com a literatura. As dificuldades encontradas pelos diversos autores foram inicialmente segregados em dificuldades e fatores críticos para a implementação de sistemas. Posteriormente foram categorizados em comportamentais, administrativos e de escassez de recursos, sendo que os dois últimos foram novamente classificados em subgrupos. A empresa analisada no estudo de caso é uma indústria de médio porte do ramo de embalagens plásticas. O estudo mostra que as principais dificuldades encontradas pela empresa estavam relacionadas com insuficiência de treinamentos, limitações de linguagem e critérios contábeis, uma vez que o modelo implantado foi determinado pela matriz situada em outro país. Além destas, a maioria das dificuldades constantes da literatura também foram identificadas pela empresa em sua implantação, em menor ou maior escala. Considerando as categorias utilizadas, a maioria está relacionada com o grupo de dificuldades administrativas e com o de escassez de recursos. As soluções utilizadas pela empresa não tiveram um projeto específico para suas realização, sendo aplicadas de acordo com as possibilidades que o contexto da época permitia. 


\begin{abstract}
In the current companies' competitive environment, it is necessary that they use tools to keep their continuity. The Strategic Cost Management is one of these devices and, therefore, a cost system is necessary to guide the managers' decision of an organization, which starts to demand faster more elaborated information. These systems' implementation, which are more and more complex, are usual in big companies and, also considering its importance, it is understandable the motive of why it has been studied along the time. With the changes from technology evolution, the lower costs, and the higher competitiveness, the small and medium companies also seemed the necessity of having a cost system to support their decision. But these companies' characteristics are different of the others, supposing that their needs of information, as their system implementation difficulties are also different. This study's main objective is to identify the difficulties of cost system implementation in one medium size company through a case study. As secondary objectives are: the categorization of the material found in the bibliographical revision in groups; verify if the difficulties founded in the case study are similar with the literature. First, the founded difficulties by the many authors were separated between difficulties and critical factors for the implementation of systems. They were after categorized in behavior, management and insufficiency of resources, and the last two were reclassified in other subgroups. The analyzed company is a medium size industry in the branch of plastic packings. The study shows that the mainly difficulties of the company were related with lack of training, language limitations and accounting standards, once the implanted model was ordered by the headquarter located abroad. Beyond these, the most of difficulties in the literature were also identified by the company in its implementation, in different levels. Considering the used categories, most of them are related with the management difficulties group and with the insufficiency of resources group. The solutions utilized by the company hadn't a specific project for its realization, been applied in agreement with the possibility that the context allowed in that time.
\end{abstract}




\section{SUMÁRIO}

LISTA DE QUADROS 3

1. INTRODUÇÃO

1.1. Contextualização 5

1.2. Situação problema 10

1.3. Questão de pesquisa 12

1.4. Objetivo 12

1.5. Relevância 13

1.6. Divisão do trabalho 14

2. METODOLOGIA 15

2.1. Método de estudo de caso 15

2.2. Componentes do projeto de pesquisa 17

$\begin{array}{ll}\text { 2.2.1. Questões de estudo } & 17\end{array}$

2.2.2. Proposições 18

$\begin{array}{ll}\text { 2.2.3. } & 19\end{array}$

2.2.4. Lógica da união dos dados às proposições $\quad 21$

2.2.5. Critérios para interpretar as constatações 21

2.3. Desenvolvimento de teoria 21

2.4. Limitações da Pesquisa 22

2.5. Protocolo 23

2.5.1. Questionário 26

2.5.2. Roteiro de entrevista 27

3. SISTEMAS DE INFORMAÇÃO 31

3.1. Sistemas 31

3.2. Informação 33

3.3. Sistemas de informação $\quad 35$

$\begin{array}{ll}\text { 3.3.1. Sistemas de custos } & 38\end{array}$

3.3.2. Sistemas ERP 42

4. DIFICULDADES DE IMPLANTAÇÃO DE SISTEMAS DE CUSTOS E DE SISTEMAS ERP $\quad 47$

4.1. Implantação de sistemas 49

4.2. Dificuldades $\quad 54$

4.3. Classificação do porte das empresas 55

4.4. Dificuldades na implantação de sistemas de custos 59

4.4.1. Em empresas de pequeno porte 60

4.4.2. Em empresas de grande porte 63

$\begin{array}{ll}\text { 4.5. Dificuldades de implantação de sistemas ERP } & 67\end{array}$

4.5.1. Em empresas de pequeno porte 68

4.5.2. Em empresas de médio porte $\quad 70$

$\begin{array}{ll}\text { 4.5.3. } & \text { Em empresas de grande porte } \\ \end{array}$

5. CATEGORIZAÇÃO 77

5.1. Dificuldades e Fatores Críticos

5.2. Comportamentais, administrativas e escassez de recursos 78

$\begin{array}{ll}\text { 5.2.1. Dificuldades } & 81\end{array}$

$\begin{array}{ll}\text { 5.2.1.1. Comportamentais } & 82\end{array}$

5.2.1.1.1. Nas empresas de pequeno porte $\quad 82$

5.2.1.1.2. Nas empresas de médio porte 83

5.2.1.1.3. Nas empresas de grande porte 85 
5.2.1.2. Administrativas 86

5.2.1.2.1. Nas empresas de pequeno porte 87

5.2.1.2.2. Nas empresas de médio porte $\quad 88$

5.2.1.2.3. Nas empresas de grande porte $\quad 90$

$\begin{array}{ll}\text { 5.2.1.3. De Escassez de Recursos } & 91\end{array}$

$\begin{array}{ll}\text { 5.2.1.3.1. Nas empresas de pequeno porte } & 91\end{array}$

5.2.1.3.2. Nas empresas de médio porte $\quad 94$

5.2.1.3.3. Nas empresas de grande porte 95

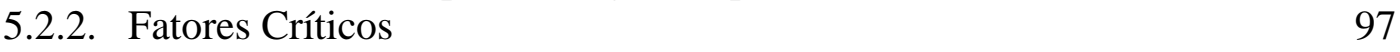

5.2.2.1. Comportamentais 98

5.2.2.1.1. Nas empresas de pequeno porte 98

5.2.2.1.2. Nas empresas de médio porte $\quad 99$

5.2.2.1.3. Nas empresas de grande porte 99

$\begin{array}{ll}\text { 5.2.2.2. Administrativos } & 99\end{array}$

5.2.2.2.1. Nas empresas de pequeno porte $\quad 99$

5.2.2.2.2. Nas empresas de médio porte 100

$\begin{array}{ll}\text { 5.2.2.2.3. Nas empresas de grande porte } & 101\end{array}$

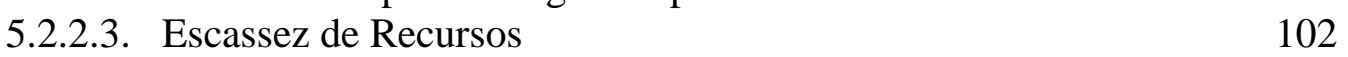

5.2.2.3.1. Nas empresas de pequeno porte 102

5.2.2.3.2. Nas empresas de médio porte 102

5.2.2.3.3. Nas empresas de grande porte 103

5.3. Análise dos grupos 104

6. ESTUDO DE CASO 107

6.1. A empresa 107

6.2. Situação anterior à implantação 107

6.3. A implantação do sistema 107

6.3.1. Fase pré-implementação 108

6.3.2. Fase de implementação 108

6.3.3. Fase pós-implementação 108

6.4. Dificuldades 108

$\begin{array}{ll}\text { 6.4.1. Principais dificuldades } & 109\end{array}$

6.4.2. Demais dificuldades 111

6.4.2.1. Comportamentais 112

6.4.2.2. Escassez de recursos 112

6.4.2.3. Administrativos 114

7. CONCLUSÕES E RECOMENDAÇÕES 117

$\begin{array}{ll}\text { 7.1. Conclusões } & 117\end{array}$

7.2. Recomendações de estudos posteriores 118

REFERÊNCIAS 119

APÊNDICES 127 


\section{LISTA DE QUADROS}

Quadro 1 - Utilização dos termos: "Sistema de Custos" e "Sistemas de Custeio" 39

Quadro 2 - Definições de sistemas ERP.

Quadro 3 - Incidência dos termos "implantação" e "implementação". 50

Quadro 4 - significados dos termos implantação, implantar, implementação e implementar . 50

Quadro 5 - Aspectos relevantes ao sucesso na implantação de ERP .... 54

Quadro 6 - Características qualitativas das PMEs 55

Quadro 7 - Dificuldades encontradas na implementação de sistemas de custos em pequenas empresas

Quadro 8 - Dificuldades encontradas na implantação de sistemas ABC em empresas de grande porte. 65

Quadro 9 - Dificuldades encontradas na implantação de sistemas ABC em empresas de grande porte.

Quadro 10 - principais dificuldades de implementação de sistemas ERP em pequeno porte

- Valente

Quadro 11 - principais fatores críticos de sucesso em sistemas ERP de pequeno porte Valente. 70

Quadro 12 - dificuldades de implementação de sistemas ERP em empresas de pequeno porte

Quadro 13 - dificuldades de implementação de sistemas ERP em empresas de médio porte.71

Quadro 14 - dificuldades encontradas na implementação de sistemas ERP em empresas de médio porte

Quadro 15 - fatores críticos de sucesso em implementações de sistemas ERP em empresas de grande porte

Quadro 16 - dificuldades de implmentação de sistemas ERP em empresas de grande porte .. 75 


\section{INTRODUÇÃO}

\subsection{Contextualização}

No atual ambiente globalizado, existe um constante aumento de concorrência para as empresas, tanto no âmbito nacional como internacional. No campo da economia nacional, aproximadamente 470 mil empresas são abertas anualmente desde 1985, ou cerca de dez por cento do número de empresas em atividade (DNRC, 2007). Além desse aumento de concorrência nacional, é percebido o aumento da influência do mercado internacional, refletida nos números referentes importações. Comparando-se os números de dois períodos recentes, no ano de 2006 as empresas nacionais importaram o dobro do que se importava em 2002 (BRASIL, 2007).

Devido esse aumento de concorrência, o mercado torna-se mais competitivo, ocorrência observada pelo fato de que o equivalente a vinte por cento do número das empresas que iniciam suas atividades anualmente extingue-se no mesmo período (BRASIL, 2007). Diante desse ambiente competitivo, as empresas têm a necessidade de estarem preparadas para continuarem atuando no mercado. Por isso, caso não encontrem alternativas nesse ambiente que passa por constante transformação, podem colocar em risco a sua continuidade.

Para um adequado planejamento e controle, assim como para a escolha adequada das decisões, as empresas utilizam diversos artefatos de Contabilidade Gerencial. Apesar do baixo grau de utilização de novas técnicas e conceitos de Contabilidade Gerencial (Guerreiro et al., 2006, p.8), Soutes (2006, p.87) analisou a utilização de diversos artefatos pelas empresas brasileiras, e se essa utilização implica em um desempenho diferenciado. Os resultados mostram que, das empresas por ela analisadas, a maioria utiliza algum tipo de artefato. Além disso, verificou que as empresas que os utilizam têm um desempenho diferenciado das demais. Dessa forma, percebe-se que o uso de artefatos pode ser um fator importante para a continuidade das empresas.

A análise de custos faz parte desse grupo de artefatos, que tem evoluído, assim como os sistemas de informação, para atender as necessidades dos seus usuários. Esses usuários, por 
sua vez, passam a demandar informações cada vez mais elaboradas e com maior agilidade. Para Scramim (2002, p.15), os sistemas de custeio estão entre as técnicas gerenciais mais importantes para a competitividade das organizações. Dessa forma, a utilização dos sistemas de custeio, que orientem as decisões dos gestores, é importante para a sobrevivência das empresas, pois permite um conhecimento que auxilia no seu desenvolvimento e competitividade. Posição semelhante tem Pompermayer (2004, p. 19), para quem o sistema de gestão de custos é uma das principais tecnologias de gestão, e o conhecimento dos custos influi na posição competitiva e na sobrevivência da empresa. Na opinião de Roztocki et al. (2004, p.19), os administradores devem ter informações de custos precisas e atualizadas para tomar as decisões apropriadas. De forma semelhante, Famá (2000, p. 24) comenta de importância dos custos para o desenvolvimento e acompanhamento dos negócios, principalmente em um mercado sem fronteiras e de concorrência internacional, e que a administração eficaz dos custos pode melhorar seu desempenho. Diante das afirmações, percebe-se que o sistema de custos é um dos importantes artefatos que devem ser utilizados pelas empresas.

Num ambiente competitivo, as empresas precisam de estratégias para atingir seus objetivos. "Passa assegurar que sejam selecionadas e executadas as atividades corretas, é essencial que exista um planejamento estratégico.” (Kotler \& Keller, 2007, p. 40). Muitas dessas estratégias dependem de um sistema adequado de custos, que forneça as informações necessárias de seus produtos e estruturas. Sobre isso, Pompermayer (1999, p. 27) comenta que quanto maior a competição incidente numa empresa, maior a importância de conhecer os custos, de forma a encontrar uma posição competitiva vantajosa frente aos competidores. Com isso, pode-se tentar obter vantagens competitivas que englobem decisões como: onde e como investir, estratégias de preço, estratégias de mercado, planejamentos de curto e longo prazo, entre outros. Martins (2003, p. 21-22) comenta que o auxílio à tomada de decisões é uma das funções relevantes da contabilidade de custos, e que passou a ser uma importante arma de controle e decisões gerenciais.

Nos últimos tempos, houve uma grande evolução tecnológica e, ao mesmo tempo, o custo dessa tecnologia diminuiu consideravelmente, fazendo com que aumentasse a sua acessibilidade pelas empresas de menor porte. Zwicker (2008, p. 16) comenta sobre essa mudança do ambiente tecnológico, quando diz que “a tecnologia também abriu possibilidades que até então eram limitadas por seus custos”. Dessa forma, empresas de menor porte, que 
antes tinham limitações para aquisição de tecnologia, passaram a ter uma possibilidade de acesso maior. DeLone (1988, p. 51) comenta que o custo de sistemas de informação para pequenas empresas tem reduzido, a ponto de todas as empresas poderem adquirir um sistema para suas necessidades. Aliando a maior acessibilidade ao aumento de competitividade, as pequenas e médias empresas também perceberam a necessidade de se ter um sistema de custeio para suportar suas decisões.

Al-Ahmari (2002, p. 122) comenta que pequenas e médias empresas por todo mundo estão procurando meios de resolver problemas e tomar ações para garantir vantagens competitivas e que “[...] o mercado altamente competitivo forçam as pequenas e médias empresas a procurar por novos métodos, estratégias e tecnologias [...]”. Fassoula \& Rogerson (2003, p. 1143) apresentam opinião semelhante quando comentam que para sobreviver num crescente ambiente competitivo, as empresas de pequeno e médio porte têm que gerenciar questões como redução de custo e contínua melhoria de performance. Para que essas empresas consigam atingir esses objetivos elas utilizam um adequado sistema de custos.

O sistema de custos é um subsistema do sistema de informações de uma empresa (Bio, 1987, p. 133; Padoveze, 1998, p. 188; Vieira, 2004, p. 23; Sussmann, 2005, p. 45) e, muitas vezes, faz parte de um sistema ERP, estando intrinsecamente a ele conectado. Além disso, ambos têm características semelhantes, como: ser um centro de processamento onde se acumulam, organizam e produzem informações gerenciais; servem para gerar informações para decisões estratégicas; integra várias áreas da empresa; envolvem pessoas e treinamento para coleta de dados, precisam de um planejamento para sua implementação; podem utilizar modelos de implementação semelhantes, entre outras. Vieira (2004, p. 20-23), aborda a definição de ERP por diversos autores, onde Losinsky, Saccol e Caon incluem o módulo de custos como sendo parte do sistema ERP. Dessa forma, apresenta-se a seguir alguns comentários sobre os sistemas ERP e sua relação com as empresas de médio porte.

Sobre esse tipo de sistemas, Ozaki \& Vidal (2008, p. 302), afirmam que eles são imprescindíveis para a gestão e sobrevivência das pequenas e médias empresas. Riccio (2001, p. 48) comenta que, antes, as empresas de pequeno e médio porte não utilizavam sistemas ERP, e que estes começaram a ser adaptados ou criados para esse tipo de empresas recentemente. Além disso, devido à saturação do mercado desses sistemas para as grandes empresas, seus fornecedores direcionaram-se para as empresas de pequeno e médio porte 
(Mendes \& Escrivão Filho, 2008, p. 243; Ozaki \& Vidal, 2008, p. 301; Sussmann, 2005, p. 55).

Apesar do aumento de utilização dos sistemas de informação pelas empresas de médio porte, suas características são distintas das demais em diversos aspectos, como: nos recursos, que podem ser mais escassos (Roztocki, 2004, p.20; Fassoula \& Rogerson, 2003, p. 1143, Mendes \& Escrivão Filho, 2008, p.253; Ozaki \& Vidal, 2008, p.286) ou na dificuldade de mudança organizacional, ser menos profissionalizadas e com processos diferentes das melhores práticas administrativas (Ozaki \& Vidal, 2008, p.286). Massuda (2003, p.26) classifica as diferenças entre vantagens e desvantagens, citando nesse caso: falta de preparo administrativo dos proprietários; informalidade dos processos e falta de planejamento. Por outro lado, podem ter autoridade centralizada e serem mais ágeis e flexíveis (Farias, p.46-48), ou capacidade de maior adaptação às condições do mercado (Massuda, 2003, p.25), que podem ser pontos favoráveis.

Em relação às características distintas dessas empresas, Gunasekaran \& Grieve (1999, p. 407) fazem uma colocação interessante, quando afirmam que, considerando-se o porte e a estrutura de seus negócios, as empresas de pequeno e médio porte são flexíveis e inovadoras, o que faz com que tenham um potencial de melhorar seu desempenho, que por sua vez melhoram sua competitividade. Isso reforça ainda mais a importância das informações fornecidas pelos sistemas de custos a essas empresas, considerando os benefícios que estes podem oferecer. Da mesma forma que as características dessas empresas são distintas das de maior porte, pode-se supor que suas necessidades de informação, assim como as dificuldades de implantação desse tipo de sistema também sejam diferentes, decorrentes, como por exemplo, dos tipos de decisões a serem tomadas, ou mesmo recursos humanos, físicos, tecnológicos e financeiros disponíveis. Também devido às suas características diferenciadas, elas podem enfrentar problemas de gestão específicos, distintos dos das empresas de portes diferentes.

Apesar das diferenças com as grandes, as menores empresas têm grande importância para a economia. Se considerarmos as micros, pequenas e médias empresas, essas representam 99,69\% da quantidade das empresas brasileiras e 66,97\% das pessoas empregadas (SEBRAE, 2007). Excluindo-se as micro-empresas, que compõem sua maioria, temos as pequenas e médias, que representam aproximadamente vinte vezes a quantidade de grandes empresas, e empregam juntas, 35\% mais trabalhadores (em torno de nove milhões de pessoas) do que as 
grandes empresas (BRASIL, 2007, p.45). Considerando somente as empresas de médio porte, dentro dos critérios do RAIS - relatório anual de informações sociais, seu número representa quase cinco vezes o número das grandes empresas, e empregam mais da metade de pessoas que elas. Outro fator a considerar é de que muitas das grandes empresas originam-se dessas menores (Kassai, 1997 p.60), tornando-as ainda mais importantes para a economia nacional.

As empresas de médio porte constituem um grupo à parte, e a justificativa para a análise de empresas desse porte, além da importância econômica citada, baseia-se em suas características peculiares como: a) não serem tão burocratizadas como as grandes, e ao mesmo tempo não serem tão flexíveis como as micros e pequenas; b) por não serem tão estruturadas como as grandes, mas têm a necessidade de uma maior organização do que as empresas menores; c) ao contrário das grandes, que na sua maioria já têm à sua disposição uma grande quantidade de informações, passa a demandar maior quantidade e qualidade de informações, que até então não eram obtidas ou o eram com pouco detalhamento; d) estão em uma fase em que, caso não se modifique e organize, podem estar destinadas a um declínio que culmine em sua descontinuidade; e) estão em uma fase onde os custos da estrutura necessária para sua operacionalização passam a representar grande parte da receita, obrigando-as a encontrar soluções para manter a rentabilidade e conseqüente continuidade.

Apesar da importância das médias empresas, existem poucos estudos referentes sistemas de custos voltados especificamente a elas. A implantação desses sistemas, que são cada vez mais complexos, é comum a grandes empresas e a literatura aborda vastamente a implantação de sistemas de custeio pelas empresas com grandes faturamentos e grandes números de empregados (Roztocki, 2004, p. 19; Duran \& Radaelli, 2000, p. 119). Por outro lado, a utilização de sistemas de custos, especialmente o ABC, pelas PME tem sido pequena (Afonso, 2002, p.176; Roztocki, 2004, p.19). Assim como sua utilização prática, as dificuldades de implementação dos sistemas de custos são escassas na literatura quando relacionadas a empresas de médio porte. Para essas empresas, as quais representam o foco deste trabalho, existem estudos de implantação de sistemas ERP, como Souza \& Zwicker (2008), Chien et al. (2007), Mendes \& Escrivão Filho (2008), entre outros, assim como estudos que tratam de sistemas de custos nas médias empresas, mas pouco material que trate especificamente das dificuldades de implementação de sistemas de custos. 
Apesar de não haver estudos específicos nesse sentido, verifica-se que, na prática, a dificuldade na implantação de um sistema de custos em empresas de porte médio é um problema enfrentado por grande número delas, desde a definição dos modelos conceitual e lógico mais apropriados até a finalização da implantação, que pode ser originada por problemas de recursos (financeiros, materiais ou de pessoal), de comportamento, de conhecimento técnico, de planejamento, entre outros.

\subsection{Situação problema}

Considerando-se as situações anteriormente relacionadas, inicia-se pela importância na economia das empresas de médio porte, seja pela sua quantidade, pelo número de pessoas empregadas por elas, ou pelo potencial de se transformarem em grandes empresas. Muitas delas, inclusive, estão no limiar entre as de porte médio e as de grande porte, as quais têm importância reconhecida. Na seqüência, considera-se o ambiente competitivo em que elas estão inseridas, que se torna a cada dia mais acirrado, e que demanda ações e atitudes para manter-se no mercado. Dentre essas ações, encontra-se a adoção de artefatos de contabilidade, que contribuem para que essas empresas tenham um desempenho diferenciado das demais. Os sistemas de custeio fazem parte desses artefatos, mas são encontradas diversas dificuldades na implantação desses e de outros tipos de sistemas. Principalmente nas empresas de menor porte, que têm características distintas das demais, seja em sua cultura ou dinâmica, ou em recursos técnicos, financeiros ou de pessoal, que muitas vezes são agravantes aos problemas comumente encontrados.

Apesar da relevância, não foram encontrados estudos que analisassem as variáveis que têm relativa importância no sucesso ou fracasso na implantação de um sistema de custos em empresas de médio porte, ou as dificuldades para sua implantação. Dentre os estudos analisados, encontram-se trabalhos que tratam de dificuldades de implantação de sistemas de custos para empresas de pequeno e grande porte, mas nenhum específico para empresas de médio porte. Para este segmento, há vários trabalhos que tratam das dificuldades de implantação de sistemas ERP, que, apesar de não tratar especificamente de sistemas de custos, pode ser útil ao estudo quando analisados por analogia. Devido à escassez de estudos que tratam das dificuldades relacionadas a sistemas de custos para essas empresas, o trabalho 
abordará estudos próximos ao tema para tentar inferir sobre as dificuldades levantadas, além de utilizar-se de estudo de caso.

Tratando-se de sistemas de custos, e ao porte de empresa analisado, de porte médio, alguns autores tratam de implantações de sistemas de custos focando o processo de implantação em si, mas sem abordar as dificuldades ou problemas encontrados. Como exemplos dos trabalhos que têm essa característica podem-se citar:

a) Nascimento (2002) apresentou um modelo de sistema de custo para pequenas confecções baseado em planilhas eletrônicas, mas sem nenhuma menção às dificuldades de implantação;

b) Em trabalho semelhante, Santos (2002), também apresentou um caso de implantação de sistemas de custos numa pequena confecção, mas sem abordar as dificuldades.

c) Scramim (2002), que aborda o desenvolvimento e a implantação de um sistema de custos para um laticínio de médio porte, onde somente identificou como dificuldade o desencontro de informações, que divergiam em diferentes relatórios;

d) Pinotti (2003), também apresentou um modelo teórico de sistema de custos para pequenas e médias empresas de confecções, e também não listou nenhuma dificuldade encontrada por se tratar de um modelo teórico e não haver a implantação efetiva, mas cita que o "principal requisito para o sucesso de um sistema deste tipo é a percepção gerencial de sua necessidade";

e) Kassai \& Kassai (1998) mostram a experiência de uma implantação em uma editora e os resultados obtidos através das informações do sistema, sem também focar as dificuldades de implementação.

Mesmo que nesses estudos o foco não sejam as dificuldades de implementação, apenas um deles refere-se especificamente à empresa de porte médio. Por outro lado, quando se trata de empresas de grande porte, é possível encontrar mais estudos que tratem de dificuldades de implementação de sistemas de custos, mesmo essas dificuldades não sejam seu foco, como em Pompermayer (2004). Outros, como Gosselin (2007) e Medeiros (1999), têm uma abordagem maior sobre essas dificuldades.

Dessa forma, a situação-problema objeto de pesquisa reside no fato de que, mesmo considerando-se a relevância das empresas de médio porte para a economia, aliada: à 
necessidade de um sistema de custeio que suporte suas atividades; e à sua importância na continuidade dessas empresas; não se encontram estudos sobre as dificuldades de implementação desse tipo de sistema nas empresas de médio porte, ao contrário do que acontece com as de pequeno e grande porte, mesmo que também escassos.

Para este trabalho, são considerados alguns pressupostos para o seu desenvolvimento. Dentre eles pode-se citar: que as empresas de médio porte têm características específicas que as diferem das demais; que existem semelhanças entre as dificuldades de implementação nos sistemas de custeio e nos sistemas ERP.

\subsection{Questão de pesquisa}

Diante da contextualização apresentada e da situação problema descrita, apresenta-se a questão de pesquisa, que o estudo pretende esclarecer e que norteará toda a trajetória de pesquisa, que trata de identificar as dificuldades de implementação de sistemas de custos, encontradas na empresa de porte médio analisada através de estudo de caso, qual seja:

Quais foram as principais dificuldades encontradas na implementação do sistema de custos, suas causas e soluções, na empresa de porte médio objeto do estudo?

\section{$1.4 \quad$ Objetivos}

O objetivo do estudo é identificar as principais dificuldades encontradas na implantação de sistemas de custeio na empresa de médio porte analisada no estudo de caso.

Como objetivo intermediário, pretende-se identificar na literatura e apresentar de forma categorizada: as dificuldades de implementação de sistemas de custos e sistemas ERP, assim como fatores considerados importantes na implementação desses sistemas.

Ainda como objetivo intermediário, pretende-se verificar se as dificuldades de implementação de sistemas de custos identificadas no estudo de caso estão de acordo com a literatura. 


\section{$1.5 \quad$ Relevância}

A relevância do tema pode ser verificada se analisados fatores como: ser atual; estar relacionado com problemas práticos; atingir ampla população; haver lacuna científica e ser importante para a continuidade das empresas. No âmbito científico, o estudo é relevante a partir do momento em que não foram encontrados estudos específicos que analisassem os fatores críticos de sucesso na implantação desse tipo de sistema, na classificação de empresas do porte escolhido. Em relação à amplitude da população atingida, além da representatividade apresentada no início do trabalho, Gunasekaran \& Grieve (1999, p. 407) lembram que a participação das empresas de pequeno e médio porte nas economias nacionais tem sido enfatizada no mundo todo, considerando sua contribuição para a produção industrial e oportunidades de empregos.

Por ser um problema encontrado por diversas empresas desse porte, tem grande relevância prática, podendo auxiliar muitas empresas que pretendam ou estejam em processo de implantação de sistemas de custos, identificando e indicando possíveis ações para o sucesso da implementação. Não só as empresas desse porte encontram dificuldades na implementação de sistemas de custos. Gosselin (2007, p. 642) afirma que várias organizações que o adotaram e implementaram encontraram dificuldades no processo de implementação, sendo que muitas abandonaram seus projetos.

Com isso, dependendo do estágio em que se encontre a empresa, esse conhecimento pode ser importante para o seu desenvolvimento e continuidade, uma vez que permite uma melhora na gestão de custos, na vantagem competitiva e na administração estratégica. Pois, como afirma Famá (2000, p. 24): “A alocação dos custos de uma empresa ou entidade representa, portanto, um fator extremamente importante para o desenvolvimento e acompanhamento dos negócios, ainda mais quando se pensa em um mercado sem fronteiras e de concorrência internacional.”.

Além disso, com a identificação das principais dificuldades de implantação, assim como com uma maior compreensão desses problemas, espera-se contribuir para que, quando futuros envolvidos em implantação de sistemas de custos em empresas de médio porte, possam 
realizá-lo de forma mais eficiente, assim como contribuir para a ampliação do conhecimento sobre esta área.

Pelo âmbito acadêmico, a relevância deste estudo é observada pelo fato de que, para a realização deste trabalho, foi realizado um rastreamento na literatura que identificou praticamente todos os fatores que podem limitar, restringir, dificultar ou enfraquecer o processo de implementação de sistemas de custeio. Isso serve como um verdadeiro guia, quase um manual, para se evitar esses problemas em futuras implantações, e não só em empresas de médio porte.

Outra contribuição importante é a análise efetuada nos itens, de forma a detalhar e aumentar a compreensão dos mesmos. Da mesma forma, contribuem as categorizações apresentadas, que permitem uma organização dos diversos materiais disponíveis.

\subsection{Divisão do trabalho}

O estudo está organizado da seguinte forma: A primeira parte (Capítulo 1) refere-se a esta introdução, onde fazemos uma breve contextualização do tema, sua relevância e objetivos do trabalho. Na segunda parte (Capítulo 2) é abordada a metodologia utilizada do trabalho. Em seguida (Capítulo 3) é feita uma revisão de conceitos necessários para uma maior compreensão do trabalho. Na parte seguinte (Capítulo 4) são tratadas as dificuldades encontradas na literatura, baseada principalmente em teses e artigos, principais materiais disponíveis, referente de implementação de sistemas de custos e de sistemas ERP. Após a revisão de literatura, no Capítulo 5 é apresentada a categorização proposta. Na seqüência (Capítulo 6) são apresentados os resultados referentes ao estudo de caso, que são analisados em conjunto com as considerações obtidas através da revisão de literatura. Por fim, no Capítulo 7, é apresentada a conclusão do estudo, onde são apresentadas as percepções do caso relacionando-as com a base teórica, e onde são sugeridos estudos posteriores. 


\section{METODOLOGIA}

Uma vez que os sistemas de custos fazem parte do sistema de informação gerencial das organizações, a plataforma teórica deste estudo está baseada nos sistemas de informação de gestão, assim como no conjunto de obras que tratam dos problemas encontrados na implementação de sistemas de custos. No capítulo seguinte serão apresentados conceitos sobre sistemas de informações, necessários para uma maior compreensão do estudo, assim como outros conceitos e definições utilizados no decorrer do trabalho.

A metodologia utilizada é a revisão de literatura e o método de estudo de caso. A primeira servirá para o levantamento de estudos anteriores, que forneçam informações para a elaboração de uma base teórica, na qual os estudos práticos possam orientar-se. Os principais materiais utilizados foram artigos nacionais e internacionais, teses, dissertações e publicações nacionais e internacionais.

\subsection{Método de estudo de caso}

Neste estudo será realizada uma revisão de literatura do material disponível sobre dificuldades de implantação de sistemas de informação, além do método de estudo de caso, com o objetivo de apresentar detalhes de situações reais, contribuindo para a compreensão do funcionamento de uma unidade social. Yin (2005, p.20) comenta que para "contribuir com o conhecimento que temos dos fenômenos individuais, organizacionais, sociais, políticos e de grupo, além de outros fenômenos relacionados”, utiliza-se o estudo de caso como estratégia de pesquisa, estratégia essa que é comum nas áreas de psicologia, sociologia, ciência política, administração, entre outras. Martins (2006, p. xi) afirma que o estudo de caso pede uma avaliação qualitativa, e que esta é caracterizada pela descrição, compreensão e interpretação de fatos e fenômenos, tendo como objetivo o estudo de uma unidade social que se analisa profunda e intensamente. O autor ainda afirma que:

Trata-se de uma investigação empírica que pesquisa fenômenos dentro de seu contexto real (pesquisa naturalística), onde o pesquisador não tem controle sobre eventos e variáveis, buscando aprender a totalidade de uma situação e, criativamente, descrever, compreender e interpretar a complexidade de um caso concreto. (MARTINS, 2006:xi) 
Yin (2005, p. 23) apresenta com as cinco principais estratégias de pesquisa nas Ciências Sociais: experimentos; levantamentos; análise de arquivos; pesquisas históricas e estudos de casos. O autor ainda comenta que, apesar do estudo de caso conter técnicas também utilizadas pelas pesquisas históricas, tem adicionalmente duas fontes de evidência: a observação direta do que está sendo estudado; e as entrevistas das pessoas envolvidas. Além disso, outra diferença sobre as pesquisas históricas, “é a sua capacidade de lidar com uma ampla variedade de evidências - documentos, artefatos, entrevistas e observações - além do que pode estar disponível no estudo histórico convencional”.

Yin (2005, p. 109) afirma que as evidências para um estudo de caso podem vir de seis fontes distintas. A entrevista de pessoas nele envolvidas é uma delas. Martins (2005, p. 23), por sua vez, apresenta dez técnicas de coleta de dados que podem ser utilizadas em um estudo de caso, estando entre elas a entrevista e o questionário. Em relação ao questionário, o autor comenta que, quando em um estudo de caso, ele é aplicado pelo próprio pesquisador e que, mesmo não sendo tão comum nessas situações, ele pode ser um dos instrumentos de coleta dependendo da situação e dos propósitos. Para este trabalho, serão utilizadas duas técnicas: i) a entrevista, a qual objetiva, segundo Martins (2005, p. 27), “entender e compreender o significado que os entrevistados atribuem a questões e situações”; e ii) o questionário, por dois motivos: para realizar a triangulação de métodos e; pela possibilidade de medição em escalas que esta técnica proporciona.

Em relação à técnica de entrevista, Andrade (2002, p. 34) comenta que é uma técnica de observação direta intensiva muito empregada na pesquisa das ciências sociais. Ela ainda comenta que, mesmo não sendo a mais fácil de ser aplicada, é um instrumento eficaz na recolha de dados fidedignos para uma pesquisa. Dentre os objetivos desta técnica apresentados pela autora, aqueles que condizem com este estudo são: (a) averiguar fatos ou fenômenos; (b) identificar opiniões sobre fatos ou fenômenos. Em relação ao tipo de entrevista utilizado neste trabalho, será uma padronizada ou estruturada, por ser composta por uma série de perguntas conforme um roteiro preestabelecido, e aplicado da mesma forma a todos os informantes.

Em relação ao confronto entre a literatura e a prática pelo método de estudo de caso, Martins (2006, p. 2) confirma essa relação quando afirma que um estudo de caso pode ser considerado uma investigação exemplar se as proposições e teses puderem ser defendidas a partir de uma 
sólida plataforma teórica e dos achados empíricos da pesquisa. Yin (2005, p. 49) também se refere ao assunto quando comenta que é essencial no desenvolvimento da teoria do estudo de caso, saber se o seu propósito é de desenvolver ou testar a teoria. Dessa forma, justifica-se a utilização desta técnica para poder confrontar os achados da revisão bibliográfica com os dos estudos de caso.

Yin (2005, p. 42) apresenta cinco componentes de um projeto de pesquisa que considera como especialmente importante para os estudos de caso. Dessa forma, serão abordados a seguir alguns desses componentes adequando-os aos propósitos deste estudo.

1. "as questões de um estudo;

2. suas proposições, se houver;

3. sua(s) unidade(s) de análise;

4. a lógica que une os dados às proposições; e

5. os critérios para interpretar as constatações.”

(YIN, 2005, p. 42)

\subsection{Componentes do projeto de pesquisa}

\subsubsection{Questões de estudo}

Em relação às questões de estudo, conforme apresentado no capítulo de introdução, a investigação está direcionada para responder à seguinte questão de pesquisa:

Quais são as principais dificuldades encontradas na implementação de sistemas de custos nas empresas de porte médio objeto do estudo?

Entende-se que estudo de caso é uma estratégia de pesquisa adequada ao trabalho, uma vez que atende às três condições apresentadas por Yin (2005 p.23): i) referentes às questões de pesquisa, que pretende compreender o funcionamento das implantações de sistemas, ou o “como" e "o porquê", conforme citado pelo autor; ii) da não exigência de controle que o pesquisador tem sobre os eventos comportamentais; e iii) o enfoque do problema a acontecimentos contemporâneos. 


\title{
2.2.2 Proposições
}

Sem uma proposição, por mais bem formuladas que sejam, as questões não apontam um caminho para o que se deveria estudar. (Yin, 2005, p. 42; Martins, 2005, p. 68). Segundo Yin (2005, p.42), "somente se for obrigado a estabelecer algumas proposições, você irá à direção certa”. Martins (2005, p. 68) corrobora com a afirmação ao mencionar que "as proposições teses expostas para serem demonstradas e defendidas - permitem a correta direção para o desenvolvimento de um estudo de caso.” Outras observações sobre as proposições em estudos de casos, que são apresentadas por Martins (2005, p. 68):

\begin{abstract}
"As proposições, no contexto de um estudo de caso, refletem explicações teóricas formuladas a partir de algum conhecimento do caso e reflexões do pesquisador. [...] podem ser entendidas com uma teoria preliminar, criada pelo autor, que buscará, ao longo do trabalho, defender e demonstrar.[...] buscam-se condições para explicar, demonstrar uma teoria específica sobre o caso a partir dos resultados obtidos. [...] Em um estudo de caso, parte-se de uma teoria preliminar, que pode ser aperfeiçoada [...] ao longo do estudo, buscando evidências e dados [...] que possam demonstrar, e defender as teses previamente formuladas. [...] em um estudo de caso buscam-se elementos e evidências para demonstrar uma teoria - construir uma teoria [...] sobre o caso".
\end{abstract}

Dessa forma, neste estudo são apresentadas as seguintes proposições:

a) Assim como as características das empresas de médio porte são distintas das de diferentes portes, algumas das dificuldades de implementação também são específicas para empresas de médio porte;

b) Algumas das dificuldades de implementação de sistemas de custeio em empresas de pequeno e grande porte podem ser encontradas em empresas de médio porte.

Yin (2005, p. 42) comenta sobre a necessidade de haver finalidades e critérios para avaliação do sucesso em alguns tipos de estudos. Neste trabalho, ambos estão presentes, sendo que sua finalidade é identificar, nos estudos de caso analisados, quais são as dificuldades de implementações em sistemas de custeio encontradas na empresas analisadas. Em relação aos critérios para avaliar o sucesso do estudo, é feita a triangulação de dados e triangulação metodológica. Além disso, os resultados encontrados serão interpretados, analisados e comparados com a revisão de literatura, parte do embasamento teórico deste estudo, em relação a situações análogas de sistemas de custos e sistemas ERP em empresas de demais porte. 


\subsubsection{Unidade de análise}

Yin (2005, p. 43) comenta da importância da definição da unidade de análise. Para ele, quanto mais proposições específicas um estudo contiver, mais permanecerá dentro de limites exeqüíveis. Pode-se fazer uma comparação com as delimitações do tema proposto, pois da mesma forma, caso não haja essas delimitações, o estudo pode tornar-se muito amplo e inviável.

Ao especificar corretamente a questão de pesquisa, segundo Yin (2005, p. 44), traz como conseqüência a seleção da unidade apropriada de análise. Ele comenta que, se as questões não derem preferência a uma unidade de análise, elas estão vagas demais ou em número excessivo.

Neste estudo, conforme citado no capítulo de introdução, a unidade de pesquisa envolve as empresas de médio porte, e que tenham envolvimento com sistemas de custeio. De forma a melhorar a especificação da unidade de análise utilizada, pode-se complementar como sendo as empresas que atendam às características a seguir:

a) Sejam de médio porte. Como a definição para médio porte pode variar muito, conforme apresentado no item 4.3 deste trabalho, basicamente dois critérios serão utilizados nessa classificação, sendo o número de empregados e o faturamento bruto anual. Dentre esses dois, o critério de número de empregados é o mais uniforme entre os diversos países, e a faixa média mais utilizada fica entre cinqüenta e duzentos e cinqüenta empregados. Dessa forma, a unidade de análise deste trabalho utiliza-se deste mesmo critério para definição de empresa de médio porte em relação ao número de empregados. Quanto ao critério de valor do faturamento bruto anual, a sua utilização pelos países não é tão uniforme como o outro. O valor utilizado para este estudo, para classificar as empresas de médio porte, fica entre o equivalente a quatro e vinte milhões de dólares de faturamento bruto anual. Esses valores forma utilizados por estarem próximos dos valores utilizados pelo MERCOSUL, pelo banco mundial e por diversos países como a Itália e o Reino Unido; 
b) Apesar dos limites estabelecidos no tópico anterior para a classificação de empresas de médio porte, este estudo pretende focar nas empresas que estejam no limite superior desse intervalo, para que não haja dúvidas de sua exclusão do grupo de pequenas empresas. Quanto à proximidade ao limite superior, essa se justifica para que se encontrem as características esperadas descritas nos próximos tópicos;

c) Empresas que não tenham restrições quanto a recursos financeiros necessários para a aquisição de software, hardware e consultoria para implementação. Tal divisão faz-se necessária para que essa característica contingenciais típica de micro e pequenas empresas, que é a falta de recursos, não seja o fator limitante para a implementação do sistema de custos, pois esse fato não propiciaria agregação acadêmica;

d) Estejam numa etapa de crescimento onde apresentem ou apresentaram, para a apuração de seus custos, a necessidade de um sistema específico para este fim, e que passaram pela fase de transição onde existem diversos controles paralelos e em planilhas eletrônicas. Essa delimitação justifica-se para que se obtenham empresas onde os processos operacionais tenham sido elevados em volume e complexidade, de forma que os antigos controles não atendam mais às necessidades de informação da organização;

e) Empresas que tenham em seu quadro de colaboradores, pessoas com conhecimentos técnicos suficientes para a implantação do projeto. Com essa delimitação a restrição por falta de pessoas qualificadas tecnicamente também é excluída, pois essa dificuldade não propicia evoluções acadêmicas.

Em relação à localização das empresas, não se pretende fazer nenhuma delimitação em função de área geográfica ou do ramo de atividade. Porém, encontra-se relacionado às empresas industriais, maior quantidade de estudos e utilização de sistemas de custos. Dessa forma, utiliza-se o pressuposto de que as dificuldades encontradas na revisão de literatura têm maior aderência às empresas do ramo industrial.

Dessa forma, espera-se que a unidade de análise esteja bem definida, para que haja uma maior compreensão do problema envolvido e, como comenta Yin (2005, p.46), estando bem definida, possa auxiliar outros pesquisadores na comparação das descobertas com pesquisas anteriores, deixando explícitas as semelhanças ou diferenças entre os estudos. 


\subsubsection{Lógica da união dos dados às proposições}

Yin (2005, p.48) afirma que o projeto de pesquisa deve informar o que deve ser feito após os dados terem sido coletados, considerando os dois últimos tópicos: a lógica da união dos dados às proposições; e os critérios para interpretação das constatações; etapas estas que prenunciam as etapas de análise de dados.

\subsubsection{Critérios para interpretar as constatações}

Yin (2005) comenta da importância dos critérios para a interpretação dos dados, para que os resultados realmente representem os achados da pesquisa. Para que isso seja possível, Yin (2005, p.168) apresenta várias estratégias para analisar os estudos de caso. Ele as divide em estratégias gerais e analíticas. No primeiro grupo, ele apresenta três estratégias para analisar os dados, que são baseadas em: proposições teóricas, explanações concorrentes e estruturas descritivas. No segundo grupo, das estratégias analíticas, ele apresenta cinco estratégias, que são: adequação ao padrão; construção da explanação; análise de séries temporais; modelos lógicos e síntese de casos cruzados.

\subsection{Desenvolvimento de Teoria}

Yin (2005, p. 49) comenta que, com a definição dos cinco componentes analisados, deve haver a formulação de uma teoria preliminar antes do início da coleta de dados. Martins (2006, p. 18) também comenta que, “definido o tema, colocadas as questões orientadoras da pesquisa e enunciadas as proposições para o estudo”, deve-se efetuar uma revisão bibliográfica e a construção da plataforma teórica da pesquisa, para dar suporte ao caso a estudar. Para Yin (2005, p. 49), nessa etapa é essencial definir se o estudo de caso pretende desenvolver ou testar a teoria formulada. Martins (2005, p. 68) por sua vez, entende que "Em um estudo de caso, parte-se de uma teoria preliminar, que pode ser aperfeiçoada ao longo do desenvolvimento do estudo”, sendo esta a abordagem adotada neste estudo. 
Neste trabalho, devido à questão de pesquisa, existem estudos que de alguma forma estão relacionados com o tema, como, por exemplo, a implementação de sistemas de custos para empresas de pequeno e grande porte e a implementação de sistemas ERP para as de médio porte. Com as proposições anteriormente citadas sobre o conhecimento decorrente desses estudos, estes serão utilizados para que se possam fazer comparações de forma análoga, nas situações que sejam semelhantes. Com isso, espera-se desenvolver uma base na qual os achados poderão ser analisados e comparados. Maiores detalhes sobre essa plataforma teórica serão apresentados nos capítulos três e quatro seguintes.

Ainda assim, Eco (1998, p. 29) comenta que “... pode haver uma boa tese que não seja tese de investigação, mas tese de compilação.” O autor detalha ainda que numa tese de compilação existe um exame crítico da maior parte da literatura existente e a expõe de forma clara, relacionando os pontos de vista, “oferecendo assim uma inteligente panorâmica, provavelmente útil do ponto de vista informativo mesmo para um especialista do ramo que, sobre aquele particular, jamais tenha efetuado estudos aprofundados.”

Martins (1994, p. 28) apresenta dentre os diversos tipos de estudo, o bibliográfico, o qual pretende conhecer as contribuições científicas sobre determinado assunto, recolhendo, selecionando, analisando e interpretando as contribuições teóricas já existentes sobre o assunto.

\subsection{Limitações de Pesquisa}

Em função do método utilizado e do tema da pesquisa, o estudo apresenta algumas limitações, como: a abrangência dos achados é delimitada para as empresas estudadas, não podendo ser feita nenhuma generalização a todas as empresas de médio porte; não há objetivo de exaurir o assunto em análise, mas de apresentar os achados da pesquisa para contribuir com o conhecimento da área e diminuir a lacuna existente; Além disso, como menciona Bergamini (2006, p. 30), aqueles que se interessam em estudar o comportamento não devem ter expectativas de conseguir conceitos e definições inquestionáveis ou únicos, ela ainda comenta que: 
“como muitos fenômenos do comportamento humano não podem ser experimentalmente comprovados e estudados, porque fogem do princípio de experimentação, ou porque são constituídos de fatos que se espalham ao longo de um grande período de tempo, lança-se mão da observação de vários indivíduos a respeito de um mesmo fenômeno”. (BERGAMINI, 2006, p. 25)

Outra limitação existente refere-se à influência das opiniões pessoais dos entrevistados. Todavia, para tentar minimizar seus efeitos, é utilizado o protocolo de pesquisa, que é uma das táticas principais para aumentar a confiabilidade da pesquisa de estudo de caso (Yin, 2005, p. 92). Além deste, Yin (2005, p. 57) apresenta outras três táticas para aumentar a validade do construto, sendo: a utilização de várias fontes de evidência; o encadeamento de evidências; e a revisão por informantes-chave do rascunho do relatório.

\section{$2.5 \quad$ Protocolo}

Segundo Yin (2005, p.92), um protocolo de pesquisa deve conter os instrumentos do estudo de caso, assim como os procedimentos e regras para utilização desse instrumento. Além disso, deve apresentar os seguintes itens: visão geral do projeto; procedimentos de campo; questões do estudo de caso; e guia para o relatório do estudo. Ele serve para guiar o pesquisador durante o estudo de caso. Martins (2006, p. 3) comenta que o estudo deve ser orientado por um detalhado protocolo, que forneça "evidências de que as respostas dos entrevistados e respondentes seriam as mesmas se as questões fossem repetidas”.

O autor ainda comenta que um estudo de caso pode ser considerado importante se for desenvolvido "a partir do protocolo de um outro estudo, evidentemente com os mesmos propósitos, cujos resultados se aproximam, isto é, obtêm-se evidências que garantam generalizações analíticas dos achados das duas investigações”. Martins (2006, p. 9) comenta que o protocolo oferece segurança de um trabalho científico, uma vez que oferece uma condição prática de para se testar a confiabilidade do estudo. Conforme citado, Yin (2003, p. 94) considera quatro seções que deve haver em um protocolo, quais sejam:

a) Uma visão geral do projeto de estudo de caso;

b) Procedimentos de campo; 
c) Questões do estudo de caso;

d) Guia para o relatório do estudo de caso.

Na primeira seção, a da visão geral do projeto de estudo de caso, Yin (2005, p. 94) afirma que deve conter informações prévias sobre o projeto, as questões que estão sendo estudadas, e as leituras relevantes sobre essas questões. As informações prévias podem ser encontradas no início deste trabalho, onde são apresentados: a contextualização do tema, os objetivos e as questões de pesquisa. Sobre as leituras relevantes, estão contidas nos capítulos três e quatro, que tratam de sistemas de informação e das dificuldades de implementação respectivamente.

Para Yin (2005, p. 95), nesta seção pode constar uma declaração que possa ser apresentada a qualquer pessoa que queira saber sobre o projeto, e que esta pode ser acompanhada de uma carta de apresentação. Dentre os procedimentos contidos neste protocolo está o envio de uma carta de apresentação dirigida aos entrevistados (apêndice quatro). Ela apresenta uma visão geral do projeto, onde constam sucintamente: as questões de pesquisa, a relevância do assunto, as proposições e outras informações do cenário do projeto.

A próxima seção que deve constar de um protocolo para estudo de caso são os procedimentos de campo. As definições desses procedimentos são importantes para que orientem as ações do protocolo, principalmente porque os dados serão coletados de pessoas em suas situações cotidianas, diferentemente de um laboratório (YIN, 2005, p. 97). Neste último, há um controle do ambiente de coleta de dados, dependendo do método de pesquisa, como a experimentação. Dessa forma, a fim de orientar as ações do projeto, são apresentados a seguir alguns procedimentos e definições.

a) Deve ser realizado um contato inicial com as empresas pré-selecionada que atendam aos requisitos contidos no capítulo dois. No primeiro contato são apuradas informações sobre a possibilidade da empresa participar do estudo. Em caso afirmativo, coletam-se algumas informações sobre a empresa, para determinar se ela se enquadra nos parâmetros estipulados para o grupo em análise. Em caso afirmativo, agenda-se uma primeira visita para poder explicar maiores detalhes sobre o estudo;

b) No segundo contato, deve ser entregue a carta de apresentação e ser efetuado um detalhamento das informações nela contidas (contextualização, objetivo, etc.). 
Confirma-se a possibilidade da participação da empresa no estudo e, em caso positivo, verifica-se o nome das principais pessoas que farão parte da pesquisa (vide próximo item). A essas pessoas será entregue a carta de apresentação e o questionário que deverá ser preenchido e devolvido antes das entrevistas, em um prazo de 10 dias;

c) Inicialmente verifica-se quem foi o responsável principal do projeto de implementação. Com esta pessoa serão obtidos os nomes das pessoas que responderão os questionários. Os entrevistados devem ter poder de decisão e participação próxima no processo de implantação do sistema de custeio. É importante frisar que esses dois requisitos devem ser atendidos concomitantemente, não sendo suficiente sua incidência isolada. Os cargos esperados dessas pessoas são: presidente, diretor, controller; gerente financeiro; gerente de $\mathrm{TI}^{1}$ ou correspondentes;

d) O questionário entregue faz parte da primeira de três partes da pesquisa de campo. Nesta primeira fase, há o preenchimento do questionário antes das entrevistas. Na segunda fase, há uma tabulação dos dados obtidos e a seleção de questões que possam ser necessitar de maiores esclarecimentos, principalmente nos casos de desalinhamento com a literatura e nos itens de maiores coincidências. No primeiro caso, pretende-se o esclarecimento dos resultados, e no segundo um maior aprofundamento da questão. Na terceira fase, é possível que, ao realizar a análise das informações coletadas, seja identificada a necessidade de entrevistas adicionais para outros esclarecimentos;

e) Após a coleta dos questionários, as respostas serão tabuladas e comparadas em sua incidência e em escala de importância. Nessa fase, a principal preocupação está na identificação dos itens de maior incidência, que deverão ser analisados com maiores detalhes nas entrevistas, e os que estiverem contraditórios, tanto no próprio questionário como entre os demais;

f) Na terceira etapa é agendada a data para realização das entrevistas, que devem ser realizadas conforme o roteiro de entrevista adiante. Deve-se tentar agendar com o

\footnotetext{
${ }^{1}$ A inclusão da área de TI justifica-se pelo fato de, nas empresas de porte pequeno e médio, projetos de implementação de sistemas de informação serem também liderados por essa área. Mendes e Escrivão Filho (2008, p. 253) comentam que em seu estudo empírico envolvendo dez empresas que: "Ao estabelecer contato com as empresas [...] os dirigentes designavam a área de informática para disponibilizar as informações desejadas, em virtude da área ser responsável por todo o processo de adoção do sistema e suporte ao usuário".
} 
máximo de entrevistados possíveis na mesma data, para que não seja necessário um número excessivo de retornos à empresa. Também se deve informar que o tempo previsto para cada entrevista é de aproximadamente uma hora e meia;

g) Para a realização das entrevistas, estas devem ser, preferencialmente, em ambiente reservado, diferente de seu local de trabalho, para evitar interrupções por atividades profissionais cotidianas do entrevistado;

h) A forma de registro será através de anotações e, se autorizado pelo entrevistado, através de gravações que serão transcritas posteriormente. Deve-se informar ao entrevistado que esse procedimento visa evitar a perda ou distorção nas informações coletadas, e que após a transcrição das respostas a gravação será apagada;

Na terceira seção citada por Yin (2005, p. 94), estão as questões do estudo de caso, que para ele, “são, em essência, os lembretes que você deverá utilizar para lembrar das informações que precisam ser coletadas e o motivo para coletá-las”. No caso deste trabalho, essas informações que precisam ser coletadas, assim como os objetivos, constam do roteiro de entrevista e do questionário apresentados adiante.

O guia para o relatório do estudo de caso é a quarta seção que, segundo Yin (2005, p. 94), deve constar de um protocolo de estudo de caso. Apesar de comentar que esse elemento geralmente não está presente na maioria dos projetos de estudo de caso, Yin (2005, p. 171) apresenta diversas características e detalhes para essa este assunto, como: etapas que devem ser obedecidas e estruturas de composição. Esses fatores não serão aprofundados neste trabalho por não serem foco deste estudo.

\subsubsection{Questionário}

O questionário entregue no primeiro contato é dividido em três partes, sendo a primeira, relacionada a características e organização da empresa, com dois objetivos: a verificação de sua aderência com o grupo de empresas em análise e; possível estratificação de acordo com as características coletadas. Na segunda e terceira parte são abordados os materiais encontrados 
na literatura em relação às dificuldades de implementação e aos fatores críticos nas implementações de sistemas de custeio e de sistemas ERP.

Todos os fatores relacionados aos dois assuntos encontrados em empresas de médio porte foram inseridos no questionário, para posterior tabulação dos dados, servindo como base na comparação com a literatura. Dessa forma, foram incluídos no questionário os itens identificados relacionados às dificuldades e aos fatores críticos na implementação de sistemas de custos, sendo relacionados a fatores comportamentais, administrativos e de escassez de recursos. Essa classificação é esclarecida de forma mais detalhada no item 5.2 adiante.

Os itens relacionados às empresas de médio porte são apresentados de acordo com a mencionada classificação, para que o(s) entrevistado(s) possa(m) atribuir-lhes valores de acordo com o grau de importância. Para isso é apresentada uma escala de zero a cinco, onde o zero refere-se à inexistência do fator na empresa entrevistada, aumentando até o valor cinco que representa a máxima incidência ou importância do quesito.

\subsubsection{Roteiro de entrevista}

O roteiro de entrevista está dividido em quatro blocos, onde o primeiro trata de questões específicas do processo de implementação. No segundo bloco, abordam-se questões abertas relativas às dificuldades encontradas no processo de implementação do sistema de custeio, e no terceiro, sobre fatores importantes na implementação. No quarto bloco são apresentadas as perguntas relacionadas aos questionários anteriormente coletados. Não se pode ignorar a colocação de Martins (2006, p. 4) de que o estudo de caso deve revelar análises em profundidade, não em extensão.

\section{BLOCO I - CARACTERIZAÇÃO DA EMPRESA}

1) Qual o número médio de funcionários da empresa na época da implementação do sistema de custeio?

2) Qual o faturamento bruto anual em dólares americanos na época da implementação?

3) Qual o ramo de atividade da empresa?

4) Qual o ano de início das atividades da empresa? 
5) A composição societária é familiar? Se sim, quais os cargos ocupados por membros da família?

\section{BLOCO II - PROCESSO DE IMPLEMENTAÇÃO}

6) Quem é (foi) o principal responsável pelo projeto de implementação?

Objetivo: Determinar o respondente principal da pesquisa, pois pode haver outros respondentes além deste.

7) Houve mais alguma pessoa chave no processo, e com poder de decisão sobre a implementação, envolvida diretamente com o processo? Se sim, quem?

Objetivo: Saber se todas as pessoas envolvidas foram incluídas nas entrevistadas.

8) Em qual fase está a implementação? Início, meio, fim, ou já foi finalizada? Quais as datas de início e fim?

Objetivo: Para registro da etapa em que a empresa se encontra e para possível estratificação.

Obs: Caso o respondente não saiba a resposta, deve-se verificar o cronograma de implementação.

9) O que levou a empresa a decidir pela implementação do sistema de custeio?

Objetivo: Coletar informações sobre os motivos da implementação.

10) Já havia um sistema de informações integrado sendo utilizado (ERP)?

Objetivo: Determinar se a empresa já havia passado por um processo de implementação de sistemas integrados de gestão.

11) Se sim, o sistema de custos faz parte do sistema de informações integrado?

Objetivo 1: Diferenciar entre sistema integrante de ERP ou sistema exclusivo de custos. existente.

Objetivo 2: Diferenciar entre uma implementação nova ou uma adaptação a um sistema

12) A implantação do sistema de custos foi simultânea ao sistema ERP?

Objetivo: Diferenciar entre uma implementação onde já seja incluso o sistema de custos de uma implementação posterior do módulo de custos.

13) Houve um projeto para a implantação do sistema que tenha envolvido uma análise estruturada da escolha do fornecedor, dos custos e dos prazos, com contatos para coleta de referências?

Objetivo: Verificar a aderência com a literatura e identificar ocorrências nas empresas de médio porte objetos do estudo.

14) Houve a auxílio de consultoria externa?

Objetivo: Verificar a aderência com a literatura e identificar ocorrências nas empresas de médio porte objetos do estudo.

15) Se sim, em qual fase (pré-implementação / implementação / pós-implementação)?

Objetivo: Verificar a aderência com a literatura e identificar ocorrências nas empresas de médio porte objetos do estudo. 
16) Houve a interrupção do processo de implementação? Se sim, em qual fase e por qual motivo?

Objetivo: Verificar a aderência com a literatura e identificar ocorrências nas empresas de médio porte objetos do estudo.

17) Quanto tempo durou todo o processo de pré-implementação, desde a identificação da necessidade de um sistema de custos até a decisão pelo fornecedor?

Objetivo: Verificar a aderência com a literatura e identificar ocorrências nas empresas de médio porte objetos do estudo.

18) Quanto tempo durou o processo da implementação em si, desde a definição do projeto até o início do funcionamento do sistema?

Objetivo: Verificar a aderência com a literatura e identificar ocorrências nas empresas de médio porte objetos do estudo.

19) Quanto tempo durou o processo pós-implementação, desde o início do funcionamento do sistema até a aceitação e utilização rotineira do sistema.

Objetivo: Verificar a aderência com a literatura e identificar ocorrências nas empresas de médio porte objetos do estudo.

\section{BLOCO II - DIFICULDADES}

20) Quais foram as principais dificuldades encontradas na fase de pré-implementação do sistema de custos, desde a identificação da necessidade de um sistema de custos até a decisão de escolha do fornecedor?

Objetivo: Verificar a aderência com a literatura e identificar ocorrências nas empresas de médio porte objetos do estudo.

21) Quais foram as principais dificuldades encontradas na fase de implementação em si, desde a definição do projeto de implementação (caso tenha existido), até o início de funcionamento do sistema?

Objetivo: Verificar a aderência com a literatura e identificar ocorrências nas empresas de médio porte objetos do estudo.

22) Quais foram as principais dificuldades encontradas na fase pós-implementação do sistema de custos, desde o início de funcionamento do sistema até a aceitação e utilização rotineira do sistema?

Objetivo: Verificar a aderência com a literatura e identificar ocorrências nas empresas de médio porte objetos do estudo.

23) Classifique as dificuldades citadas nas três questões anteriores, de acordo com o seguinte critério:

\begin{tabular}{|l|l|}
\hline 0 & Não identificado \\
\hline 1 & Pequena dificuldade \\
\hline 2 & Considerável dificuldade \\
\hline 3 & Média Dificuldade \\
\hline 4 & Grande dificuldade \\
\hline 5 & Extrema dificuldade \\
\hline
\end{tabular}


Objetivo: Identificar o grau de relevância das dificuldades atribuído pelos entrevistados e fazer uma comparação com o que foi respondido no questionário previamente enviado.

24) Tente apontar as causas e soluções encontradas para as dificuldades apresentadas.

\section{BLOCO III - FATORES IMPORTANTES OU CRÍTICOS DE SUCESSO}

25) Cite fatores que considere como importantes e devam ser considerados na implementação de sistemas de custeio.

Objetivo 1: Verificar a aderência com a literatura e identificar ocorrências nas empresas de médio porte objetos do estudo.

Objetivo 2: Realizar uma triangulação com as respostas obtidas no questionário.

26) Classifique os fatores a seguir de acordo com o grau de importância que eles tiveram na implementação do sistema de custeio da sua empresa.

\begin{tabular}{|l|l|}
\hline 0 & Não identificado \\
\hline 1 & Pouco importante \\
\hline 2 & Considerável importância \\
\hline 3 & Importante \\
\hline 4 & Muito importante \\
\hline 5 & Extremamente importante \\
\hline
\end{tabular}

Objetivo 1: Identificar o grau de importância atribuído pelos entrevistados.

Objetivo 2: Realizar uma triangulação com as respostas obtidas no questionário.

BLOCO IV - DIFICULDADES E FATORES IMPORTANTES NA IMPLEMENTAÇÃO DE SISTEMAS DE CUSTEIO

(neste bloco são inseridas as perguntas decorrentes da análise dos questionários e das respostas do bloco anterior) 


\section{SISTEMAS DE INFORMAÇÃO}

Para que as dificuldades de implementação de sistemas de custos possam ser analisadas, fazse necessário que inicialmente se compreendam conceitos relacionados ao tema para a formulação de um construto teórico. Dessa forma, este capítulo tem como principal objetivo fornecer um referencial teórico sobre sistema de informação, das quais o sistema de custos faz parte, sendo um de seus subsistemas. Para isso, serão abordados conceitos de sistema, informação, sistema de informação, sistemas de custo e sistemas ERP, necessários para a compreensão do ambiente no qual o tema está inserido.

Borinelli (2006, p. 76) comenta sobre os três pilares que formam o conceito de teoria, quais sejam: "o que é teoria, como se constrói ou se constitui a teoria, ou seja, como se materializa, e para que ela serve.”. Utilizando-se desses três pilares, para a compreensão conceitual dos assuntos abordados neste trabalho, suas análises serão realizadas sob três aspectos: a) qual sua definição ou significado; b) quais suas características ou como funciona; e c) qual sua utilidade ou finalidade. Dessa forma, os conceitos apresentados serão, dentro de suas possibilidades, analisados sempre sob estes três aspectos.

\subsection{Sistemas}

Conforme mencionado, alguns conceitos serão abordados para a formulação do construto, sendo que o primeiro desses conceitos refere-se a Sistemas. Sobre este tema somente serão abordados apenas pontos fundamentais como sua definição e características principais, devido sua literatura já vir sendo abordada há muito tempo. Dessa forma, somente será revisado o que for, de fato, imprescindível à formulação do construto.

Um sistema pode ser definido como um complexo de elementos em interação, segundo Bertalanffy (1977, p. 84), autor conhecido como fundador da Teoria Geral dos Sistemas. Outra definição muito utilizada é de que um sistema pode ser entendido como um conjunto de elementos interdependentes que interagem na consecução de um objetivo comum (Glautier \& Underdown, 1995, p. 11; Catelli, 2001, p. 37; Guerreiro, 1989, p. 153). Os sistemas têm como características comuns: compõem-se de partes que unidas constituem um todo; possuem uma 
razão ou objetivo que justifiquem essa união; têm delimitações, apesar de que estas delimitações podem formar outros compostos ou ainda subdividir-se de acordo com suas interações com o ambiente. (Catelli, 2001, p. 38). Com isso, pode-se entender que o sistema é um conjunto de elementos que interagem para uma finalidade, sendo que esse sistema pode ser parte de outros sistemas.

Na Teoria Geral dos Sistemas, os sistemas podem ser classificados como sistemas abertos ou fechados, onde resumidamente, pode-se explicar o sistema aberto como um sistema que interage com o meio, enquanto o sistema fechado não interage e não realiza transações externas. No caso dos sistemas abertos, existe uma troca com o ambiente e uma contínua transformação em seu interior (Bertalanffy, p. 167), influenciando e sendo influenciado pelo meio. A teoria geral de sistemas baseou-se, originalmente, em conceitos relacionados com a biologia, passando também a ser relacionada com a área de ciências humanas, como na sociologia e a economia. No caso desta última, o conceito de sistemas é muito utilizado para comparar a empresa como um sistema aberto, que interage com o meio com entradas e saídas, as quais estão relacionadas com transformações internas. (CATELLI, 2001, p.38; GLAUTIER \& UNDERDOWN, 1995, p.11; KASSAI, 1996, p. 47; PEREIRA, 2002, p.48).

Dependendo da capacidade de um sistema modificar suas características, um sistema pode ser classificado como estático, dinâmico ou homeostáticos. Um sistema estático não apresenta uma evolução ou mudança de seu estado no decorrer do tempo; os sistemas dinâmicos, por sua vez, apresentam mudança ou evolução no decorrer do tempo; os sistemas homeostáticos são como um sistema aberto, que regulam seu ambiente interno para manter uma situação estável. As empresas podem ser classificadas como um sistema aberto e dinâmico, como um conjunto de elementos interdependentes que interagem entre si para a consecução de um fim comum, em constante inter-relação com seu ambiente (CATELLI, 2001, p.38), ou ainda um sistema aberto que tem uma interação dinâmica com seu meio ambiente do qual retira recursos e para quem entrega produtos e serviços (GLAUTIER \& UNDERDOWN, 1995, p.11).

Dentro do conceito de empresa como um sistema aberto, ela pode ser dividida em outros subsistemas: institucional, físico, social, formal, sistema de informação e sistema de gestão (CATELLI, 2001, p.55; GUERREIRO, 1989, p.154). Sinteticamente, o sistema institucional está relacionado a crenças, princípios e valores que influenciam os demais sistemas; o sistema 
físico refere-se basicamente aos equipamentos e outros recursos físicos necessários ao funcionamento da empresa; o sistema social está relacionado às pessoas, assim como a cultura, características e demais aspectos intangíveis relacionados com as pessoas; o sistema formal diz respeito à estrutura administrativa da empresa, de autoridades e responsabilidades; no sistema de gestão está o processo de gestão, com o planejamento, execução e controle; O sistema de informações, um dos subsistemas do sistema empresa, refere-se a todo conjunto de necessidades informacionais da empresa, e será tratado adiante com maiores detalhes.

A finalidade do sistema, de acordo com as definições analisadas, encontra-se na obtenção da finalidade a que ele se propõe, utilizando-se da organização de seus componentes. Pode-se considerar que a utilização de um sistema facilita a realização de um objetivo, ou seja, mesmo que um fim possa ser atingido sem a utilização de um sistema, ele existe para facilitar essa tarefa. Como exemplo, pode-se citar o resultado de sistemas mecânicos, que têm como produto final um produto alterado ou manufaturado. Em alguns casos, a finalidade só é alcançada através da existência do sistema, como no caso de seres vivos, que também é considerado como um sistema. Assim, a finalidade de um sistema confunde-se com a sua definição mais básica, de que um sistema é um conjunto de elementos que operam juntos organizadamente para atingir um objetivo (GLAUTIER \& UNDERDOWN, 1995, p.11).

\subsection{Informação}

Sendo o sistema de custos um sistema de informação, é preciso que se compreenda o conceito de informação, como funciona e para que serve. Assim como no caso de sistemas, este é um assunto já muito abordado pela literatura, e por isso somente serão apresentados os pontos importantes para a formulação do construto. Laudon \& Laudon (1999, p. 9) comentam que as definições de informação, dado e conhecimento são estudados há séculos. Eles ainda comentam que a origem latina da palavra informação (informare) significa “dar forma”, e que a maioria dos filósofos acredita que a mente humana dá forma aos dados para criar uma informação. Eles definem informação como sendo um "Conjunto de dados aos quais seres humanos deram forma para torná-los significativos e úteis” (LAUDON \& LAUDON, 1999, p.10). Além disso, a informação vem crescendo em abrangência e importância, devido 
impacto das transformações sociais, políticas, econômicas e tecnológicas nas organizações. (Albuquerque, 2004, p. 24).

A informação é um dado trabalhado, e que auxilia no processo decisório, através do conhecimento que ela propicia ao tomador de decisões (SUSSMANN, 2005, p.8). Também relacionando a informação à decisão, Bio (1987, p.112) comenta que a informação é um elemento, um ingrediente de suporte aos processos decisórios, e complementa dizendo que “é eficaz na medida que está de acordo com as necessidades e é efetivamente utilizada pelos tomadores de decisão, afetando suas decisões”. Além de ser indispensável para uma correta tomada de decisão, Albuquerque (2004, p. 24) comenta que os administradores precisam das informações para auxiliar as empresas a minimizar o risco e garantir a sobrevivência e o bom desempenho do futuro.

Analisado o conceito da informação, é preciso analisar a sua utilidade, e para que ela é necessária. Pela afirmação anterior de Bio (1987, p.112) percebe-se a finalidade da informação, que é fornecer subsídio para que o seu receptor possa utilizá-la para uma tomada de decisão. A utilidade da informação está vinculada diretamente ao processo de gestão, sendo a relação entre informação e decisão estreita (CATELLI, 2001, p.315). Guerreiro (1989, p.105) fala da importância da informação como um recurso da organização, e que ela tem se tornado um dos principais elementos das atividades de negócios. Caso a informação não seja útil ao tomador de decisão, não pode ser classificada como tal, pois não passa de um dado e não atinge a sua finalidade. A informação, segundo Rocha (1999, p.87), é um objeto ou evento mensurado que: provoca surpresa no receptor; é útil ao receptor; é resultante do processamento de um dado ou de um conjunto de dados.

Para que a informação seja útil seu receptor, ela precisa auxiliar o tomador de decisão de alguma forma, como minimizando as incertezas. "A informação configura-se como um conhecimento disponível, para uso imediato, que permite orientar a ação, antes cercada de incerteza, possibilitando sua condução a um nível de risco adequado” (CATELLI, 2001, p.315). Uma vez que o tomador de decisões processa informações (GUERREIRO, 1989, p.38), e que no processo de tomada de decisão são coletadas as informações relevantes e avaliadas as alternativas (GUERREIRO, 1989, p.54), para que a informação seja útil ao tomador de decisão, os dados devem ser organizados num formato compreensível e que possa por ele ser processado. 
Hendriksen \& Van Breda (1999, p. 95) apresentam características qualitativas necessárias para que a informação seja útil, quais sejam: relevância, confiabilidade, valor preditivo, oportunidade, verificabilidade, fidelidade, valor como feedback, comparabilidade e neutralidade. Semelhantemente, Stair \& Reynolds (1999) apresentam como características necessárias: precisa; completa; econômica; flexível; confiável; relevante; simples; em tempo; verificável, acessível e segura. Padovezze (1998, p. 41) complementa com características como: conteúdo; freqüência; adequação à decisão; valor econômico; uniformidade de critério. Dentre as diversas qualidades, Hendriksen \& Van Breda (1999, p. 96) consideram a relevância e a confiabilidade como as mais importantes.

DeLone \& McLean (1992, p.61) apresentam para a informação, que é um “output” do sistema de informação, diferentes níveis para ser analisada. Segundo os autores, os níveis de Shannon \& Weaver são: nível técnico, nível semântico e nível de eficácia. O nível técnico refere-se à qualidade da informação, e depende da precisão e eficácia do sistema que produz a informação. O nível semântico está relacionado com sucesso da informação em transmitir o significado da mensagem. O nível de eficácia refere-se ao efeito provocado no receptor da informação. Para que os dados coletados possam ser devidamente processados e transformados em informações com as características citadas por Stair, e dentro dos níveis de Shannon \& Weaver, utiliza-se dos sistemas de informação.

\subsection{Sistemas de informação}

Continuando com a abordagem dos conceitos sob a forma de definição, finalidade e utilização, o próximo tópico refere-se a sistemas de informação, sobre o qual também serão revisados somente os pontos necessários ao construto. Assim como no caso de informação, há diversas definições para sistemas de informação na literatura, das quais são apresentadas as seguintes:

Um sistema de informação (SI) pode ser definido como um conjunto de componentes interrelacionados trabalhando juntos para coletar, recuperar, processar, armazenar e distribuir informação com a finalidade de facilitar o planejamento, o controle, a coordenação, a análise e o processo decisório em empresas e outras organizações. (LAUDON \& LAUDON, 1999, p.4) 
Sistema de Informações é o conjunto de elementos que objetiva fundamentalmente gerar informações para apoio à execução das atividades operacionais, bem como às fases de planejamento e controle do subsistema gestão. (GUERREIRO, 1995)

Sistema de Informação é um conjunto de subsistemas que atuam coordenadamente para, com o seu produto, permitirem às organizações o cumprimento de seus objetivos principais. (RICCIO, 1989)

Conjunto de atividades, tecnologia, equipamentos, processos, procedimentos, métodos destinados a obter, processar e produzir informações. (BIO, 1987, p.116).

Dessa forma, entende-se que o sistema de informações é um conjunto de elementos ou componentes agrupados de forma ordenada, que coletam e armazenam dados, que são processados, gerando relatórios que são utilizados para tomadas de decisão. Sussmann (2005, p.11) comenta que um sistema de informação pode ser manual, mas que os computadores a substituíram no processamento de grandes volumes de dados. Vários elementos compõem um sistema de informação, desde a captação de dados até a divulgação das informações em relatórios ou outros formatos. Laudon \& Laudon (1999, p.5) afirmam que o sistema de informações é um produto de três componentes: tecnologia, organizações e pessoas, e que o conhecimento dessas três dimensões é necessário para a utilização do sistema de forma eficiente.

Em relação à finalidade de um sistema de informação, seu principal objetivo é a transformação dos dados coletados em informações úteis aos tomadores de decisão. Esse conceito é apresentado por alguns autores da seguinte maneira: “O objetivo do sistema (de informação) é de fornecer informação que satisfaça a necessidade dos usuários” (GLAUTIER \& UNDERDOWN, 1995, p. 13); “[...] com a finalidade de facilitar o planejamento, o controle, a coordenação, a análise e o processo decisório [...]; [...] ajudando empregados ou gerentes a tomar decisões, analisar e visualizar assuntos complexos e resolver outros tipos de problemas.” Laudon \& Laudon (1999, p.4); Guerreiro (1989, p.14) afirma que razão da existência do subsistema de informação é dar o devido suporte informativo ao subsistema de gestão. Bio (1987, p.132) comenta que no projeto do sistema deve haver a preocupação no que se refere às informações necessárias aos processos gerenciais e operacionais. O sistema de informação também serve para “[...] estabelecer um conjunto de procedimentos que possibilitem captar ocorrências internas e externas, nos assuntos relacionados a sua gestão, de maneira estruturada e subsidiando os gestores nas decisões requeridas no processo de gestão” (CATELLI, 2001, p.316). Ainda sobre a finalidade dos sistemas de informação, Laudon \& Laudon (1999, p.26) fazem a seguinte afirmação: 
"As empresas constroem sistemas para reagir a concorrentes, clientes, fornecedores e mudanças sociais e tecnológicas em um ambiente dinâmico e fluido. [...] criados para reagir a novas oportunidades no ambiente externo, incluindo o aparecimento de novas tecnologias. As empresas também constroem sistemas para monitorar materiais, pessoas e atividades dentro da firma e para administrar seus problemas internos [...]” (LAUDON \& LAUDON, 1999, p. 26)

Para que o sistema atinja seu objetivo de fornecer informações, é necessário que ele as produza em tempo hábil, que sejam confiáveis e num grau de detalhe adequado (BIO, 1987, p.138). Também é necessário que os sistemas de informações armazenem dados de forma organizada, para que sejam facilmente acessíveis para processamento ou saída (LAUDON \& LAUDON, 1999, p.4). Outra característica do sistema de informações é apresentada por Guerreiro (1989, p.24): “devem ser configurados de forma a atender as necessidades informativas de seus usuários, bem como incorporar conceitos, políticas e procedimentos que motivem e estimulem o gestor a tomar as melhores decisões para a empresa”.

Para que o sistema consiga fornecer as informações, é necessário que haja uma preocupação com as três atividades básicas de um sistema, a entrada, o processamento e a saída. Laudon \& Laudon (1999, p.4) detalham cada um desses processos: a entrada, que se refere à captação de dados da organização ou de seu ambiente, através de atividades como registro, codificação, classificação e edição, os quais se preocupam em assegurar que os dados necessários são corretos e completos. No processamento, que se refere à conversão dessa entrada bruta para uma forma mais útil e apropriada, "os dados são organizados, analisados e manipulados através de cálculos, comparações, resumos e classificações, objetivando uma forma de disposição mais significativa e útil”. A saída refere-se à transferência da informação processada, transmitem os resultados do processamento a locais onde serão usados para a tomada de decisão, coordenação ou controle.

DeLone \& McLean (1992, p.62) apresentam uma combinação dos níveis da informação de Shannon \& Weaver com um conjunto de características ou aspectos dos sistemas de informação (figura 1). São eles: qualidade do sistema; qualidade da informação; uso; satisfação do usuário; impacto individual e impacto organizacional. Os autores mostram que estudos de pesquisadores de sistemas de informação podem ser classificados nesses grupos. Além disso, nessa taxionomia os sistemas de informação e as informações estão a ela relacionadas. Segundo o modelo, “qualidade do sistema” mensura o sucesso técnico; “qualidade da informação” mensura o sucesso semântico; e “uso; satisfação do usuário; 
impacto individual e impacto organizacional” mensuram o sucesso da eficácia. (DeLone \& McLean, 2003, p. 9).

\begin{tabular}{|c|c|c|c|c|c|}
\hline Technical & Semantic & & Effe & iveness or In & fluence \\
\hline Level & Level & & & Level & \\
\hline $\begin{array}{l}\text { System } \\
\text { Quality }\end{array}$ & $\begin{array}{l}\text { Information } \\
\text { Quality }\end{array}$ & Use & $\begin{array}{c}\text { User } \\
\text { satisfaction }\end{array}$ & $\begin{array}{c}\text { Individual } \\
\text { Impact }\end{array}$ & $\begin{array}{l}\text { Organizational } \\
\text { Impact }\end{array}$ \\
\hline
\end{tabular}

Figura 1 - Categoria de sucesso de sistemas de informação

FONTE: Adaptado de DeLEONE e McLEAN, 1992, p. 62.

Além do modelo apresentado por DeLone \& McLean (1992, p. 62), eles citam mais dois modelos utilizados na literatura para avaliar o sucesso de sistemas de informações gerenciais, o de Ives e Olson e o modelo de Zmud. No primeiro, são consideradas duas variáveis: qualidade do sistema e aceitação do sistema; no segundo modelo, as categorias são: desempenho do usuário; utilização do sistema e satisfação do usuário. Ginzberg (1980, p. 374) corrobora com a afirmação, quando comenta que esses são os três principais conceitos de sucesso de implementação. Ao final do estudo de DeLone \& McLean (1992, p. 88), eles concluem que apesar das diversas formas de mensuração do sucesso de um sistema, todas acabam se enquadrando em uma das seis taxionomias do modelo por eles apresentados. Além disso, o modelo é formado com a inter-relação e interdependência das categorias. Nesse estudo, ao se analisar as dificuldades de implantação, estas estão contidas nas categorias uso, satisfação do usuário, impacto individual e impacto organizacional.

\subsubsection{Sistemas de Custos}

Antes de iniciar a definição conceitual do tema referente a sistemas de custos, é necessário que se faça uma breve discussão em relação à terminologia utilizada neste trabalho para definir o tema, pois se encontra na literatura nacional tanto "Sistemas de Custos" como “Sistemas de Custeio". Esperava-se que o critério utilizado por esse estudo baseasse na adoção do termo mais encontrado na literatura, e que quando se referisse a alguma citação, seria apresentado o termo utilizado pelo autor, a fim de manter a fidelidade ao texto original. 
Porém, percebeu-se que não há uma predominância unânime na terminologia utilizada. Para a identificação do termo mais utilizado na literatura, foi feito um levantamento do material nacional utilizado neste estudo, referente a esse tipo de sistema. Os dados são apresentados no quadro 1 a seguir, onde constam os nomes dos autores, o ano de publicação, o tipo de material e o termo mais utilizado pelo autor. Apesar de alguns autores utilizarem ambos os termos, há a predominância entre um dos dois em seus estudos, sendo este o que foi inserido no quadro comparativo. Dessa forma, por definição, o termo utilizado neste estudo, é de sistemas de custeio, mas nos casos de citações e paráfrases dos autores, será apresentada a expressão utilizada pelos autores no contexto.

Quadro 1 - Utilização dos termos: "Sistema de Custos" e "Sistemas de Custeio"

\begin{tabular}{|l|l|l|l|}
\hline AUTOR & ANO & MATERIAL & TERMO \\
\hline AFONSO & 2002 & Dissertação & Sistemas de Custeio \\
\hline DURAN \& RADAELLI & 2000 & Artigo & Sistemas de Custeio \\
\hline FAMÁ et al. & 2000 & Artigo & Sistemas de Custeio \\
\hline KASSAI \& KASSAI & 1998 & Artigo & Sistemas de Custos \\
\hline KRUGLIANSKAS & 1977 & Dissertação & Sistemas de Custos \\
\hline MARTINS & 2003 & Livro & Sistemas de Custos \\
\hline MASSUDA & 2003 & Dissertação & Sistemas de Custeio \\
\hline MEDEIROS & 1999 & Dissertação & Sistemas de Custeio \\
\hline MORAES & 2002 & Dissertação & Sistemas de Custos \\
\hline NAKAGAWA & 1991 & Livro & Sistemas de Custeio \\
\hline NASCIMENTO & 2002 & Dissertação & Sistemas de Custos \\
\hline PINOTTI & 2003 & Dissertação & Sistemas de Custos \\
\hline POMPERMAYER & 2004 & Tese & Sistemas de Custos \\
\hline SANTOS & 2002 & Dissertação & Sistemas de Custeio \\
\hline SCRAMIM et al. & 2002 & Artigo & Sistemas de Custeio \\
\hline
\end{tabular}

O sistema de custos é um subsistema do sistema de informações (BIO, 1987, p.133; PADOVEZE, 1998, p. 188; VIEIRA, 2004, p.23; SUSSMANN, 2005, p. 45). Nakagawa (1993, p.15) comenta que os sistemas de custeio tradicionais foram inicialmente desenvolvidos para apuração de inventários, para demonstrações fiscais e contábeis, e que têm sido aperfeiçoados através dos tempos. Ele ainda comenta que, a melhora de produtividade e a redução de custos exigem "a geração de dados e informações precisas e atualizadas, que auxiliem os gestores a tomarem decisões corretas [...]” (NAKAGAWA, 1993, p. 35). Pompermayer (2004, p. 69) apresenta o sistema de custos como um centro processador, onde ele acumula, organiza, analisa e interpreta dados, concebido para "produzir informações adequadas às necessidades gerenciais da organização no tocante à determinação de resultado, à avaliação de patrimônio, ao controle das operações, ao planejamento de produção, à tomada de decisões e à gestão de recursos”. 
Famá et al. (2000, p. 24) afirmam que o desenvolvimento de sistemas de apuração de custos se justifica pela controlabilidade, variabilidade, responsabilidade e aplicabilidade dos custos. O autor ainda comenta da sua importância para o desenvolvimento dos negócios, principalmente em um mercado sem fronteiras e de concorrência internacional, e que uma administração eficaz dos custos pode melhorar o desempenho da empresa. Nakagawa (1991, p. 36) comenta sobre os objetivos iniciais dos sistemas de custeio de gerar informações para melhora de desempenho das empresas, além da demanda por informações sobre a eficiência das atividades operacionais. Outra finalidade dos sistemas é apresentada pelo autor, quando menciona que "pretende fornecer as informações de custos necessárias para apoiar adequadamente as decisões estratégicas e operacionais, para aquisição e utilização eficiente e eficaz de recursos produtivos".

Drury \& Tayles (1998, p. 40) afirmam que a determinação dos custos dos produtos através de um sistema de custos serve a diversos propósitos como: determinação de preços; decisão de quais produtos fabricar; quais descontinuar; redesenho; terceirização; e alocação de custos. Eles ainda comentam que, se a coleta das informações do consumo de recursos não tiver exatidão, diversas decisões relacionadas aos fatores citados podem ser tomadas incorretamente, como a continuidade de produtos com margens negativas ou a determinação incorreta de preços, que podem gerar prejuízos ou diminuição de vendas. Além desses motivos, Duran \& Radaelli (2000, p. 120) mencionam: as decisões entre comprar ou produzir, composição do mix de produtos e o risco de afastar clientes lucrativos. Pompermayer (2004, p. 71) lista algumas necessidades gerenciais que podem ser atendidas pelas informações geradas pelos sistemas de custos:

- $\quad$ planejamento de lucros;

- redução de custos totais nos estágios de planejamento e desenho dos produtos e serviços;

- $\quad$ avaliação de resultados;

- redução de custos nas etapas de manufatura;

- $\quad$ redução de custos de cada modelo de produto;

- redução de custos por departamento a cada período;

- $\quad$ apuração dos custos de cada produto/serviço;

- $\quad$ identificação das linhas e produtos que mais influenciam os lucros;

- identificação de padrões de comportamento de custos;

- $\quad$ avaliação de desperdícios e sua representação nos custos dos processos;

- $\quad$ custeamento das atividades desenvolvidas (custeio dos produtos/serviços por atividades);

- acompanhamento do comportamento dos custos indiretos;

- $\quad$ comparação entre a estrutura atual de custos e a capacidade instalada;

- $\quad$ avaliação de desempenho e melhoria contínua;

- $\quad$ decisões sobre mix de produtos; 
- melhoria de negociações com clientes e fornecedores;

- geração de produtos e serviços que atendam às expectativas dos clientes com baixo custo;

- $\quad$ apoio à formação de preços de venda;

- $\quad$ análise de atividades que agregam e de atividades que não agregam valor;

- análise da margem de contribuição e lucratividade;

- análise da variação entre custo indireto real e a taxa do custo indireto aplicado;

- obtenção de um valor monetário como medida para o custeamento dos produtos.

(POMPERMAYER, 2004, p. 71).

Apesar das necessidades listadas por Pompermayer, Nakagawa (1993, p. 35) afirma que "a Controladoria não tem sido capaz de colocar a sua disposição um sistema de gestão e mensuração de custos igualmente eficiente e eficaz” (às tecnologias avançadas de produção). Essa situação tem-se modificado, com as evoluções apresentadas pelos métodos e técnicas utilizados pelos sistemas de custos, situação sobre a qual Pompermayer (2004, p. 75) diz:

A adoção desses critérios, métodos, técnicas, tipos de controle e instrumentos de gestão pelas empresas pode ocorrer numa trajetória evolutiva e compatível com as necessidades gerenciais determinadas pelas estratégias e diretrizes da empresa, inovações tecnológicas de produção, pressões de mercado fornecedor e consumidor. Pode-se, portanto, considerar que quanto mais híbrido o sistema de gestão, maior torna-se a possibilidade para a empresa de obter informações confiáveis para a sua gestão empresarial. (POMPERMAYER, 2004:75).

Em relação ao seu funcionamento, conceitualmente o sistema de custos opera da mesma maneira que um sistema de informações, onde se coletam dados, há o processamento desses dados, gerando assim informações (Pompermayer, 2004, p. 70). Martins (2003, p. 305) fala do sistema de custos como uma forma de controle. Ao utilizar como exemplo a situação financeira das pessoas, mostra a importância do controle de custos, que pode ser aplicada por analogia às empresas. Com esse exemplo de conceito simples, faz com que fique claro como o sistema pode auxiliar no controle dos custos e o que isso significa, apresentando questões como: conhecer o valor e destino de cada despesa; se estas estão nos limites que deveriam; qual a velocidade para saber quando elas se desviam do esperado; qual a razão do desvio; e qual atitude deve ser tomada para corrigir o desvio.

Em relação à utilização dos sistemas de custeio por atividades, Gosselin (2007, p.656) afirma que "muitos estudos e levantamentos têm demonstrado que a adoção do ABC costuma ser mais freqüente dentro de grandes organizações”. Apesar disso, Needy et al. (2003, p.3) afirmam que as empresas de menor porte também passaram a utilizar esse tipo de sistema. Devido à maior complexidade desse tipo de sistema em relação aos sistemas tradicionais, a quantidade de estudos relacionados a ele são maiores que nos demais. Conseqüentemente, a literatura que trata das dificuldades de implantação de sistemas de custos, assim como dos 
seus fatores críticos de sucesso, está mais relacionada a sistemas de custeio de atividades, independente do porte da empresa.

Alguns pontos importantes apresentados por Martins (2003, p. 358) referente à implantação de sistemas de custos são: o planejamento deve considerar que a implantação seja feita de uma maneira progressiva, tanto em abrangência como em sofisticação; “deve-se iniciar pela motivação junto ao pessoal”, explicando-lhes a importância de suas atividades para o todo; as pessoas antes devem ser conscientizadas da necessidade e utilidade da informação, para depois serem treinadas a obter e transmitir os dados; não se devem exigir todos os dados de início, iniciando-se com uma das informações, e partindo para a próxima depois da certeza da primeira; e o treinamento, onde o pessoal poderá esclarecer totalmente "todos os tipos de dificuldades que venha a encontrar”.

\subsubsection{Sistemas ERP}

Riccio (2001, p.32-53) comenta que os sistemas de informação tiveram início na década de 1960, passando pelos sistemas MRP na década seguinte, até chegar aos sistemas ERP no início da década de 1990. Uma definição de sistema ERP é apresentada por Souza \& Saccol (2008, p. 64): “Sistemas ERP são sistemas de informação integrados adquiridos na forma de pacotes comerciais de software com finalidade de dar suporte à maioria das operações de uma empresa industrial [...]”. Sobre a utilização por empresas industriais, os autores comentam que, embora tenham sido originados para esse tipo de empresas, atualmente diversos ramos também os tem utilizado. Dentre as definições apresentadas em seu trabalho, eles comentam que o aspecto-chave é a integração apresentada por elas.

\footnotetext{
"Em vez de utilizar diversos sistemas de informação, de diferentes fornecedores, com diferentes linguagens de programação e estrutura de bancos de dados, passa-se a utilizar um sistema único, em que todos os módulos referentes às diferentes funções organizacionais são escritos na mesma linguagem e compartilham um banco de dados único.” (SOUZA; SACCOL, 2008, p. 213).
}

Davenport (1998, p. 121) comenta que um sistema ERP permite que uma companhia integre os dados utilizados através de toda a organização, resolvendo o problema que eles foram designados a resolver, de fragmentação de informação. Ele ainda afirma que um sistema ERP racionaliza o fluxo de dados de uma empresa e permite gerenciamento com acesso direto a vastas informações operacionais em tempo real. Themistocleous et al. (2001, p. 195) 
comentam que esse tipo de sistema permite o compartilhamento de dados e práticas através da empresa, além de produzir e disponibilizar informação em tempo real. Os autores ainda afirmam que esses sistemas são desenhados para resolver a fragmentação de informações, integrando o fluxo de informações dentro da companhia. Souza e Saccol (2008, p. 244) apresentam definições de sistema ERP de diversos autores, as quais constam do quadro 2 a seguir.

\section{Quadro 2 - Definições de sistemas ERP}

\begin{tabular}{|l|l|}
\hline Lima et al. (2000) & $\begin{array}{l}\text { Controlam toda a empresa, registrando e processando cada fato novo, } \\
\text { distribuindo informação em tempo real }\end{array}$ \\
\hline $\begin{array}{l}\text { Souza \& Zwicker } \\
(2000)\end{array}$ & $\begin{array}{l}\text { Sistemas de informação integrados, adquiridos na forma de pacotes, para } \\
\text { suportar a maioria das operações da empresa. A integração é possível pelo } \\
\text { compartilhamento de informações entre os diversos módulos, em um único } \\
\text { banco de dados. }\end{array}$ \\
\hline $\begin{array}{l}\text { Buckout et al. } \\
(1999)\end{array}$ & $\begin{array}{l}\text { Sistema ERP é um software de planejamento dos recursos empresariais. } \\
\text { Integra os dados-chave e a comunicação entre as áreas da empresa, } \\
\text { fornecendo informações sobre suas operações. }\end{array}$ \\
\hline $\begin{array}{l}\text { Centoula e Zabeu } \\
(1999)\end{array}$ & $\begin{array}{l}\text { O ERP fornece informações geradas a partir de um processo operacional, para } \\
\text { otimizar o dia-a-dia da empresa e permitir um planejamento estratégico mais } \\
\text { seguro. }\end{array}$ \\
\hline $\begin{array}{l}\text { Corrêa } \\
\text { (1997) et }\end{array}$ al. & $\begin{array}{l}\text { Um ERP é constituído por módulos para informações à tomada de decisão de } \\
\text { todos os setores da empresa, com uma base de dados integrada. }\end{array}$ \\
\hline Hehn (1999) & $\begin{array}{l}\text { Representam uma coleção integrada de sistemas para as necessidades do } \\
\text { negócio, que são integrados e partilham os mesmos dados. Trazem em si } \\
\text { processos padronizados, procurando representar as melhores práticas } \\
\text { mundiais de cada função. }\end{array}$ \\
\hline Cunha (1998) & $\begin{array}{l}\text { O ERP é um modelo de gestão baseado em sistemas corporativos de } \\
\text { informação que visam integrar os processos de negócio da empresa e apoiar } \\
\text { decisões estratégicas. }\end{array}$ \\
\hline Stamford (2000) & $\begin{array}{l}\text { O ERP possibilita um fluxo de informações único, contínuo e consistente por } \\
\text { toda a empresa e com um único banco de dados. É um instrumento para } \\
\text { melhoria dos processos. }\end{array}$ \\
\hline Wood Jr. (1999) & $\begin{array}{l}\text { Esses sistemas são capazes de integrar a gestão da empresa, agilizando a } \\
\text { tomada de decisão. Fatores para seu surgimento: integração de empresas com } \\
\text { tratamento único e em tempo real; substituição de estruturas funcionais por } \\
\text { processos; vários sistemas em um único. }\end{array}$ \\
\hline
\end{tabular}

Apesar de não haver uma definição única adotada pelos diversos autores, há algumas características que são constantes nas definições, como:

a) Banco de dados unificado;

b) Sistema único, ao invés de vários sistemas específicos;

c) Procedimentos voltados a processos, representando as chamadas melhores práticas de mercado; 
d) Integração das diversas áreas da empresa, baseando-se nos processos;

e) Informação em tempo real;

f) Fornecer informações para um planejamento estratégico mais adequado.

Uma vez analisada a definição de sistemas ERP, é preciso compreender sua finalidade. A afirmação de Riccio (2001, p.52) sobre a origem dos sistemas integrados auxilia na compreensão da finalidade de um sistema ERP: “Os sistemas empresariais integrados têm sua origem na necessidade das empresas em gerir suas estruturas organizacionais - cada vez mais complexas e dinâmicas.”. Com a utilização de um sistema integrado, os dados e as práticas passam a ser comum para toda empresa. Com isso, as informações podem ser fornecidas de maneira mais ágil e confiável. Outros benefícios decorrentes de um sistema ERP são expostos por Davenport (1998): uma base de dados única, pois em grandes empresas, existem dados armazenados em vários locais distintos, que servem para atividades específicas. Com a união desses dados, pode haver um aumento de produtividade e performance nos negócios; A substituição de diversos sistemas de informação por um único. Essa mudança traz diversos benefícios, como a economia em menos equipamentos para armazenar e processar dados, na economia em não precisar transformar dados para integração entre um sistema e outro, ou na atualização de diversos sistemas; as atividades são uniformizadas por toda organização, ou seja, independente do país ou localização, os procedimentos são iguais; a automatização dos processos seqüenciais, como por exemplo, as atividades financeiras, logísticas e de produção decorrentes de um pedido de venda.

Dessa forma, assim como as características constantes das definições encontradas, pode-se citar como benefícios gerados por esse tipo de sistema:

a) Eliminação de retrabalho, uma vez que as informações são inseridas uma única vez no sistema;

b) Possibilidade de obtenção de informações em tempo real, de forma mais ágil e confiável, uma vez que o processamento de dados é realizado automaticamente;

c) Redução de custos com equipamentos para: armazenamento de dados, processamento de vários softwares; infra-estrutura para redes maiores; manutenção dos equipamentos e atualização dos softwares;

d) Possibilidade de aplicação das consideradas melhores práticas de mercado nas empresas, somente com a aplicação dos processos constantes no sistema padrão; 
e) Auxílio na condução das empresas, devido alta quantidade de dados que precisam ser processados, que aumenta proporcionalmente ao tamanho da empresa;

f) Facilidade de obter informações necessárias à decisões estratégicas das empresas, de forma ágil e confiável;

g) Integração de procedimentos e dados entre as empresas e suas filiais ou unidades, nacional ou internacionalmente.

Para compreender como os sistemas ERP podem atingir as finalidades a que se propõem, é necessário analisar as características desses sistemas. Algumas dessas características confundem-se com suas definições ou finalidades. Souza \& Saccol (2008, p. 65) cita como características desses sistemas:

a) Serem pacotes comerciais de softwares;

b) Incorporam modelos de processos de negócios;

c) São sistemas de informação integrados e utilizam um banco de dados corporativo;

d) Possuem grande abrangência funcional;

e) Requerem procedimentos de ajuste para que possam ser utilizados em determinada empresa.

Em relação à unificação de processos, os autores comentam que esses sistemas procuram atender a requisitos do maior número de empresas possível, para obter maior ganho de escala no desenvolvimento. Devido essa unificação, os processos utilizados são modelos de processos aplicados pelas empresas, conhecidas como melhores práticas, originadas pela experiência acumulada obtida pelas empresas fornecedoras na implantação desses sistemas nas empresas (SOUZA; SACCOL, 2008, p. 66). Em relação à integração, os sistemas ERP são baseados em um banco de dados único, que são compartilhados por diversos módulos interligados entre si. Riccio (2001, p. 47) comenta que a integração pode ser obtida em diferentes softwares através de "interfaces", interligações ou dispositivos que permitam seu intercâmbio, mesmo com diferentes arquiteturas, linguagens ou plataformas. Porém, uma característica que diferencia os sistemas ERP é o fato de que não ser preciso utilizar diversos softwares separadamente. Para Pereira (2003, p. 129), integração “ocorre quando os módulos ou sistemas de um conjunto ou um pacote são concebidos segundo um mesmo módulo conceitual e tecnológico”. 
Outra característica desses sistemas é a sua composição por módulos, os quais geralmente correspondem a um departamento. Souza \& Saccol (2008, p. 66) ilustram os principais módulos através da figura 2. Riccio (2001, p. 50) cita como exemplo de módulos de um sistema ERP os módulos de contabilidade, recursos humanos, manufatura e logística. Davenport (1989) também cita alguns módulos como: financeiro (contemplando o contábil), recursos humanos, vendas e marketing. O autor comenta que quando uma nova informação é inserida em um local, informações relacionadas são automaticamente atualizadas. Como exemplo, ele cita exemplos de como informações de vendas em um país desencadeiam procedimentos automaticamente em outros locais, em departamentos distintos como a produção, até a contabilização do resultado da venda. Essa é a característica principal de seu funcionamento, a inserção num banco de dados unificado que atualiza e processa automaticamente os módulos relacionados.

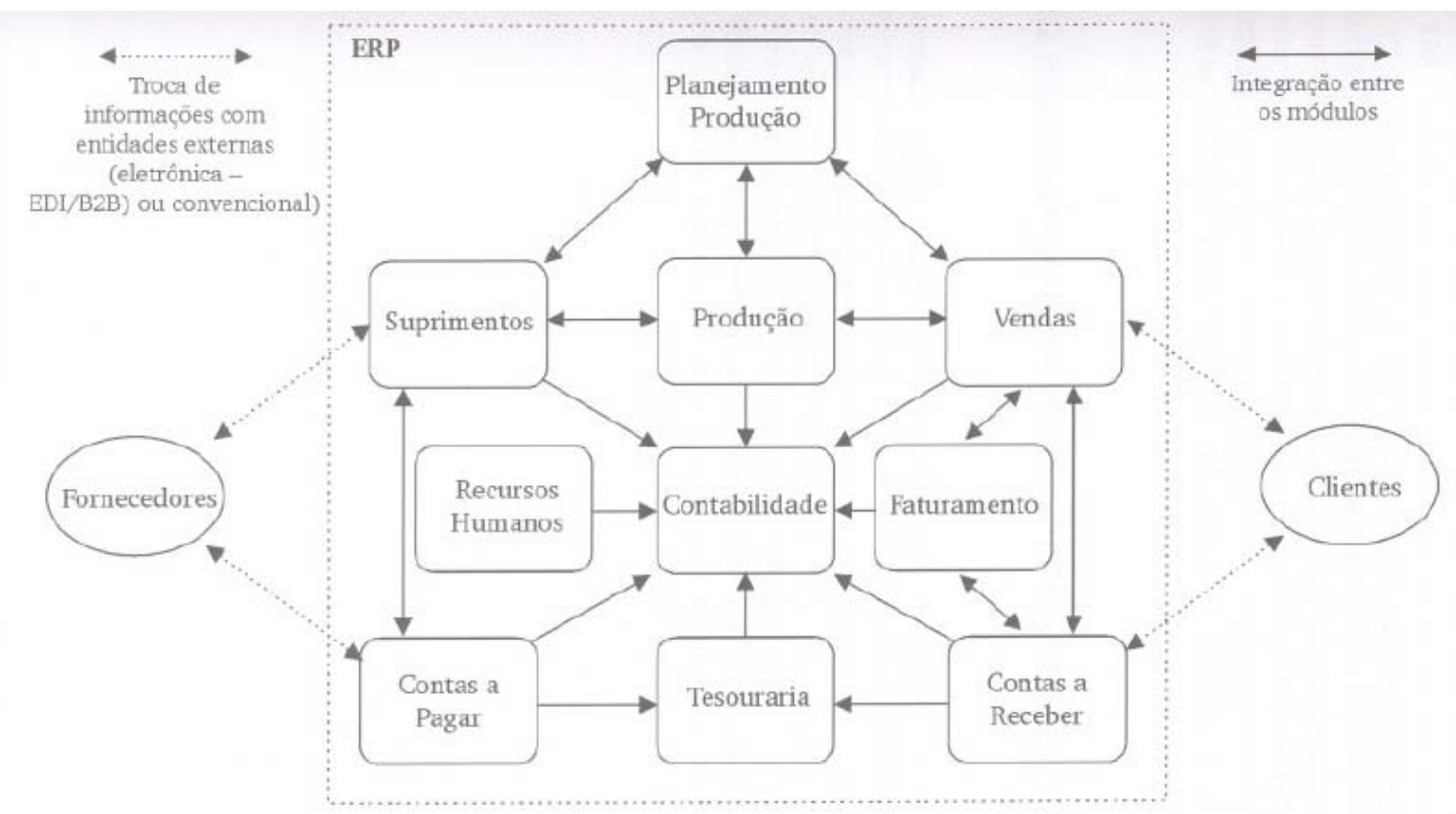

Figura 1 Principais módulos de um sistema ERP em uma empresa industrial e suas principais interligações.

Figura 2- principais módulos de um sistema ERP FONTE: SOUZA e SACCOL $(2008,66)$. 


\section{DIFICULDADES NA IMPLANTAÇÃO DE SISTEMAS DE CUSTOS E DE SISTEMAS ERP}

Este capítulo tem como finalidade principal discorrer sobre as dificuldades, empecilhos ou fatores inibidores da implantação de sistemas de custos e de sistemas ERP, tal como encontradas na literatura pesquisada. A inclusão dos sistemas ERP nessa análise justifica-se basicamente por dois motivos: (a) pelo fato de ambos serem sistemas de informações gerenciais; e (b) pelo fato de o sistema de custos ser, muitas vezes, parte do sistema ERP. Dessa forma, espera-se que, devido à suas semelhanças ou complementaridade, possa, por analogia, utilizar-se do conteúdo desses materiais para auxiliar nas conclusões desse estudo.

Antes de iniciar a apresentação dos dados encontrados na revisão dos estudos, serão apresentados alguns conceitos e definições necessários para uma maior compreensão do assunto, quais sejam: implantação de sistemas; dificuldades; e classificação do porte de empresas. Na seqüência, serão apresentados os materiais encontrados sobre: dificuldades na implantação de sistemas ERP e dificuldades de implantação de sistemas de custos. As dificuldades encontradas em cada um desses tipos de sistemas estão subdivididas pelo porte das empresas, de acordo com o material que foi encontrado. No primeiro caso, de sistemas ERP, este está dividido em empresas de pequeno, médio e grande porte; No caso das dificuldades de implementação de sistemas de custos, este será dividido em empresas de pequeno e grande porte, pois não foram encontrados estudos sobre isso para as de médio porte ${ }^{2}$.

Além da classificação apresentada por tipo de sistema (de custos e ERP), e do porte das empresas (pequeno, médio e grande), existe mais um critério que deve ser considerado ao analisar os estudos encontrados, no que se refere à abordagem do estudo. Esta pode tratar somente do processo de implementação em si (etapas a serem seguidas, etc.) ou incluir em seu estudo as dificuldades encontradas neste processo. Apesar de todos os trabalhos selecionados terem relação com a implementação de sistemas, não são todos que abordam as suas dificuldades. Dessa forma, as características que devem ser consideradas para poder analisar esses e outros estudos, devem considerar o que eles abordam, e podem ser classificadas em:

\footnotetext{
${ }^{2}$ Como foi explicado no Capítulo 1, essa é a lacuna que este trabalho pretende preencher.
} 
a) Sistemas de ERP; sistemas de custos;

b) Pequeno porte; médio porte; grande porte;

c) Casos de implementação que não abordam dificuldades; implementações que abordam dificuldades.

Tal classificação se faz necessária devido à variedade de trabalhos que podem ser encontrados na matriz formada por esses elementos. Quanto ao primeiro item, os sistemas ERP são mais estudados, conforme mencionado anteriormente, e encontram-se diversos trabalhos abordando tanto casos de implantação como suas dificuldades. Também são encontrados esses dois tipos de trabalhos, os que tratam de implementação e os que tratam das dificuldades, em todos os portes de empresas. Como exemplos de apresentação de modelos de implantação de ERP, podem ser citados: o trabalho de Vieira (2004), que trata de processos de implantação de ERP em PME; em empresas de médio porte, há estudos como o de Susmann (2005) que tratam da implantação e os casos apresentados por Souza \& Saccol (2008) que abordam dificuldades de implantação; para casos de sistemas ERP para empresas maiores, têm-se como exemplos os estudos de Bancroft (2001), Tsay et al. (2007) e Riccio (2001), que tratam da implantação como um todo.

Em relação a sistemas de custos, há vários estudos que tratam do seu processo de implantação, em todos os portes de empresa. No caso específico das pequenas e médias, a maioria dos estudos relacionados a sistemas de custos apresenta um modelo para ser implementado, ou que foi implementado em algumas empresas, como Santos (2002), Nascimento (2002) e Moraes (2002). Alguns estudos tratam das dificuldades, as quais, geralmente, são contingenciais, como em Roztocki (1999), Afonso (2002) e Massuda (2003). No caso das grandes empresas, por outro lado, é possível encontrar as duas situações em relação aos estudos de sistemas de custos, tanto aqueles que tratam de casos de implantação como de dificuldades, como é o caso do estudo de Medeiros (1999). Porém, no caso das médias, encontram-se casos de implantação, como em Kruglianskas (1977) e Scramim (2002), mas quase não se encontram estudos sobre as dificuldades de implantação.

Dessa forma, a revisão bibliográfica deste capítulo contribuirá para a construção da plataforma teórica deste trabalho, em conjunto com os conceitos teóricos apresentados no capítulo anterior, analisando estudos que tratam de dificuldades de implantação de sistemas de custeio para empresas de pequeno e grande porte (pois não foram encontrados estudos que 
tratem especificamente de empresas de médio porte) e analisando estudos que tratam de dificuldades de implantação de sistemas ERP em empresas de todos os portes. Com isso, espera-se que possam ser identificadas as prováveis dificuldades relacionadas à implantação de sistemas de custos nas empresas de porte médio. Além disso, ao estudar as dificuldades encontradas nas empresas de pequeno e grande porte, espera-se que esses achados possam servir de referência para as dificuldades nas empresas de médio porte.

O capítulo, que se iniciou com esses esclarecimentos, na seqüência apresentará os conceitos e definições dos assuntos: implantação de sistemas; dificuldades; e classificação de porte das empresas. Depois de apresentados esses conceitos, o material encontrado através da revisão será apresentado da seguinte forma:

a) Dificuldades de implantação de sistemas de custos:

- $\quad$ Em empresas de pequeno porte;

- $\quad$ Em empresas de grande porte;

b) Dificuldades de implementação de sistemas ERP

- $\quad$ Em empresas de pequeno porte;

- $\quad$ Em empresas de médio porte;

- $\quad$ Em empresas de grande porte.

\subsection{Implementação de Sistemas}

De forma semelhante ao caso da terminologia entre "sistemas de custos" ou "sistemas de custeio", é preciso definir qual termo utilizar neste estudo em relação à “implantação" ou “implementação" de sistemas. Assim como no primeiro par, verificou-se a incidência de utilização de ambos os termos nos principais estudos utilizados neste trabalho, conforme quadro 3. Além disso, analisando-se as definições em Ferreira (2004) constantes do quadro 4, não é possível obter uma conclusão definitiva utilizando-se desses conceitos. Sendo assim, para este estudo fica entendido que, por definição, o termo utilizado é “implementação”, de tal 
forma que a expressão utilizada é tratada como: “implementação de sistemas de custeio". Assim como na situação "custo e custeio", para manter a fidelidade aos textos originais, quando se referir a uma citação ou paráfrase, será mantido o termo utilizado pelo autor.

Quadro 3 - Incidência dos termos "implantação" e "implementação"

\begin{tabular}{|l|l|}
\hline \multicolumn{1}{|c|}{ TERMO } & \multicolumn{1}{c|}{ AUTORES } \\
\hline IMPLANTAÇÃO & $\begin{array}{l}\text { Duran (2000); Famá et al. (2000); Kassai \& Kassai (1998); Mendes \& Escrivão Filho } \\
\text { (2008); Moraes (2002); Nascimento (2002); Padoveze (1998); Pinotti (2003); Santos } \\
\text { (2002); Sussmann (2005); Vieira (2004) }\end{array}$ \\
\hline IMPLEMENTAÇÃO & $\begin{array}{l}\text { Afonso (2002); Medeiros (1999); Nakagawa (1991); Ozaki \& Vidal (2008); Pereira } \\
\text { (2002); Pereira (2003); Pereira \& Riccio (2008); Pompermayer (2004); Riccio (2001); } \\
\text { Soutes (2006); Souza \& Zwicker (2008); Valente (2004) }\end{array}$ \\
\hline
\end{tabular}

Quadro 4 - significados dos termos implantação, implantar, implementação e implementar

\begin{tabular}{|l|}
\hline Implantação. 1. Ato de implantar(-se); implante. 2. Inserção de medicamento sólido sob a pele; implante. 3. \\
Lus. Locação. \\
\hline Implantar. 1. introduzir; inaugurar; estabelecer. 2. Inserir (uma coisa) em outra; plantar, arraigar, fixar. 3. \\
Hastear, desfraldar, içar. 4. Med. Fazer implante de. 5. Planta-se, arraigar-se. 6. Fixar-se, estabelecer-se. \\
\hline Implementação. Ato ou efeito de implementar. \\
\hline $\begin{array}{l}\text { Implementar. 1. Dar execução a (um plano, programa ou projeto). 2. Levar à prática por meio de } \\
\text { providências concretas. 3. Prover de implementos. }\end{array}$
\end{tabular}
FONTE: FERREIRA, 2004.

Em relação ao desenvolvimento de sistemas de informação, Laudon \& Laudon (1999, p. 244) apresentam cinco diferentes formas, dentre eles: o ciclo de vida de sistemas tradicional, a prototipagem, o desenvolvimento de quarta geração, a terceirização e o uso de pacotes de software. Souza \& Zwicker (2000, p. 49), por sua vez, apresentam quatro formas de ciclo de vida de sistemas, sendo: o ciclo de vida de sistema tradicional, o waterfall, a prototipação, e o ciclo de vida de pacotes comerciais. Pereira (2002, p. 98) explica que, considerando o alto custo e os sérios riscos de fracasso, a utilização desses modelos visa à redução de riscos de insucesso e o efetivo desenvolvimento ou implantação de um sistema que melhore a eficiência organizacional. Ele ainda detalha o ciclo de vida como um plano detalhado, onde se identificam: as tarefas relevantes; quem e quando as executarão; e as categorias nas quais elas se enquadram, representando as fases do projeto.

Laudon \& Laudon (1999, p. 249) comentam que o ciclo de vida de pacotes comerciais está sendo cada vez mais utilizado pelas empresas, pois alguns problemas em comum encontrados por muitas organizações podem ser solucionados pelos mesmos sistemas ou sistemas semelhantes. Além disso, os sistemas de custos, na sua maioria, fazem parte ou são decorrentes de sistemas integrados de gestão, e como as empresas foco deste trabalho 
utilizam-se principalmente de pacotes de software, a abordagem de desenvolvimento de sistemas utilizada no decorrer deste estudo será a de aplicação de pacotes de software. É necessário comentar, porém, sobre uma precaução que deve ser tomada para esses tipos de sistemas:

\footnotetext{
“A utilização de sistemas de contabilidade de custos pré-fabricados, já testados e em funcionamento em outras empresas locais ou estrangeiras, só pode dar bons resultados quando as estruturas de custos são semelhantes, a qualidade do pessoal é de nível bastante igual, o processo de produção é semelhante e também as necessidades de informações por parte da administração são as mesmas.” (MARTINS, 2003:362).
}

Os sistemas de informação sob a forma de pacotes de software são "programas pré-escritos, pré-codificados e comercialmente disponíveis que eliminam a necessidade de se escreverem programas quando se desenvolve um sistema de informação”. (LAUDON \& LAUDON, 1999, p. 249). Para a aplicação desses sistemas, os autores apresentam o projeto de solução dividido nas seguintes etapas: definição do problema; estudo do sistema; avaliação do pacote; instalação do pacote; adequação do pacote à organização e pós-implementação. Valente (2004, p. 34) utiliza-se em seu estudo de três fases para o processo de implementação de um sistema: pré-implementação (que envolve a decisão e escolha), a implementação (colocação dos módulos em prática) e a utilização do sistema. Esse conceito utilizado pela autora é o mesmo que será considerado para este trabalho, ou seja, a implantação envolvendo desde a seleção do software até a utilização por parte dos usuários finais. Segundo Souza, (2000, p. 26) tal abordagem também é adotada pelos autores, considerando "implementação o processo que vai desde o reconhecimento de que existe um problema [...], passa pelas etapas de projeto, desenvolvimento [...] e vai até o ponto em que [...] obtêm-se ganhos de eficiência e eficácia organizacional”.

Considerando o ciclo de vida de pacotes comerciais, pode-se dividi-lo em três etapas principais, presentes em praticamente todos os modelos (Laudon \& Laudon, 1999:249; Souza, 2000:27; Valente, 2004:34; Zwicker \& Souza, 2008:70; Pereira \& Riccio, 2008:155), sendo eles: pré-implantação (que envolve a decisão pelo uso do sistema e escolha do software); a fase de implantação (processo de funcionamento dos módulos) e a utilização (sistema passa a fazer parte do dia-a-dia, institucionalizando-se). Cada uma das fases tem características específicas, que devido suas relações diretas com as dificuldades de implantação, serão analisadas a seguir. 
Na fase de pré-implantação é feita a decisão pela utilização do sistema e a seleção dentre as diversas opções de pacotes. Souza (2000, p. 27) comenta que essa fase, a de decisão e escolha, ao contrário das outras duas, ocorre uma única vez. As outras duas fases, a de implantação e a de utilização, entram num ciclo de retroalimentação, onde com a utilização identificam-se novas necessidades que exigem uma nova implementação. Escouto \& Schilling (2008, p. 281) afirmam que a escolha de um software representa, "mais do que escolher uma ferramenta tecnológica para implementar serviços pela organização a seus clientes, representa introduzir uma nova filosofia de trabalho, novos comportamentos e valores”. Valente (2004, p. 36) apresenta alguns fatores apresentados por Bancroft et al. que devem ser considerados na etapa de decisão e seleção:

a) Comprometimento, desde o início, da alta direção com o processo;

b) Conhecimento e comunicação dos possíveis benefícios e potenciais dificuldades dos sistemas ERP para todos os níveis;

c) Entendimento de que será provavelmente necessário mudar a organização;

d) Envolvimento dos usuários desde o princípio e obtenção de seu comprometimento com a alternativa selecionada;

e) Escolha de um líder de projeto que possua habilidades de negociação e gerenciamento de projetos e experiência em realização de mudanças organizacionais.

(Bancroft et al. apud VALENTE, 2004, p.36)

Souza (2000, p. 28) comenta que, na medida do possível, a empresa deve considerar “os fatores envolvidos na utilização [...], analisando vantagens e desvantagens [...] de cada um dos fornecedores”. O autor também explica que devem ser consideradas as características, as funcionalidades e possibilidades de cada um dos produtos disponíveis para fazer a seleção. Ainda quanto à decisão de implantar ou não o sistema, ele comenta que, devido ao alto grau de integração, várias partes da organização são envolvidas e é preciso analisar a adequação entre sistema e empresa. Uma vez decidido pela utilização do sistema integrado, Souza (2000, p. 31) comenta que a seleção de qual sistema utilizar deve ser feita comparando-se as alternativas mediante critérios e pesos. Uma vez determinados os critérios utilizados, atribuem-se notas para cada um deles, a fim de determinar qual a opção mais adequada. Alguns exemplos de critério citados são: base instalada no país, custo, qualidade, funções básicas, comunicação com bancos, disponibilidade de customizações e atendimento a requisitos dos usuários.

Escouto e Schilling (2008, p. 266) apresentam uma metodologia para a seleção de sistemas ERP. Apesar de ser direcionada a sistemas ERP, a metodologia, que está dividida em etapas, e pode ser utilizada para outros tipos de sistemas. As etapas analisadas são: Levantar as 
necessidades da organização; formar um comitê de decisões; especificar requisitos da organização; identificar os possíveis fornecedores; solicitar proposta comercial; selecionar o fornecedor. Na etapa de especificar requisitos da organização, são apresentados alguns critérios que devem ser considerados, como: requisitos concorrentes. Requisitos futuros; implementabilidade do projeto; suportabilidade do produto; custo de investimento e operação. Cada etapa também é analisada com maior profundidade em seu estudo, mas a metodologia de seleção por ela apresentada não será detalhada neste trabalho.

Para Zwicker \& Souza (2008, p. 71) “A implementação constitui a segunda etapa do ciclo de vida de sistemas [...] e pode ser definida como processo pelo qual os módulos do sistema são colocados em funcionamento em uma empresa.”. Para os autores, esta fase também pode ser considerada uma etapa de eliminação de discrepâncias, que são as diferenças entre as funcionalidades do pacote e os requisitos da empresa. Além disso, eles afirmam que a etapa da implementação é uma das mais críticas, devido ao fato dela envolver mudanças organizacionais, de relação entre departamentos e alterações de tarefas e responsabilidades. Sobre a importância da implantação de sistemas de informação, Guerreiro, (1989, p. 14), faz a seguinte colocação:

\footnotetext{
"Acreditamos que a implantação de sistemas de informação contábeis eficazes possui uma importância que transcende as próprias fronteiras do campo contábil, pois constitui-se em um processo de mudança, que impacta profundamente os diversos espectros da organização, desde a postura dos administradores, até o modelo de gestão adotado pela empresa.” (GUERREIRO, 1989, p.14)
}

Outro ponto importante apresentado por Zwicker \& Souza (2008, p. 72) é que, devido essas mudanças, há a necessidade de grande participação e comprometimento da alta direção nessa etapa. Os autores também mencionam que é nessa fase que se decide como será feito o início da operação: o big-bang, onde todos os módulos iniciam em todas as unidades da empresa; o small-bang, onde também se iniciam todos os módulos, mas sucessivamente em cada divisão ou planta; ou em fases, onde cada módulo vai sendo implantado em fases, em todas ou em cada unidade.

Laudon \& Laudon (1999, p. 245) afirmam que o estágio chamado de pós-implementação refere-se à etapa de usar e avaliar um sistema depois de sua instalação e que, uma vez que o sistema esteja em uso, especialistas empresariais e técnicos avaliam se os objetivos anteriormente definidos estão sendo satisfeitos, e podem determinar modificações necessárias. 
Souza (2000, p. 48) comenta que nessa etapa é aplicado grande esforço para combinar o pacote com a organização, pois geralmente não se conhecem todas as possibilidades de uso no momento da implementação. O autor cita que, uma vez que o sistema esteja adequado às atividades da empresa, pode-se pensar em novas alternativas e usos para o sistema. Zwicker \& Souza (2008, p. 72) comentam que nessa etapa, a qual chamam de etapa de utilização, o sistema passa a fazer parte do dia a dia, e ela "realimenta a etapa de implementação com novas possibilidades e necessidades”. Sobre essas modificações, Laudon \& Laudon (1999, p. 245) afirmam que, "com o passar do tempo, os sistemas podem ter de ser modificados para satisfazer novos requisitos de informações ou aumentar a eficiência do processamento. [...] são chamadas de manutenção”.

Mendes \& Escrivão Filho (2008, p. 246), para quem a etapa de implantação envolve desde a seleção, aquisição, até a implantação e testes, apresentam características consideradas importantes para o sucesso dessas implantações, conforme quadro 5, obtidas de um levantamento realizado por eles.

Quadro 5 - Aspectos relevantes ao sucesso na implantação de ERP

\begin{tabular}{|c|c|}
\hline al. (2000) & $\begin{array}{l}\text { ticulação entre objetivos do projeto e expectativas de mudança da } \\
\text { ganização; boa gerência; comprometimento da alta administração; usuários } \\
\text { vem compreender a mudança; conhecimento dos processos de negócio da } \\
\text { ppresa. }\end{array}$ \\
\hline $\begin{array}{l}\text { Souza } \quad \& \quad \text { Zwicker } \\
(2000)\end{array}$ & $\begin{array}{l}\text { efinição de líder e equipe de implantação; conhecimento prévio da } \\
\text { screpância entre sistema e empresa; comprometimento da alta direção; } \\
\text { einamento de usuários finais. }\end{array}$ \\
\hline$(2000)$ & danças na estrutura, operação, estratégia e cultura da \\
\hline et al. (1999) & ta direção deve estar comprometida e envolvida. \\
\hline $\begin{array}{lll}\text { Centola } & \& & \text { Zabeu } \\
\text { (1999) } & & \end{array}$ & $\begin{array}{l}\text { Envolvimento dos usuários e treinamento conceitual e operacional; exploração } \\
\text { do sistema; parametrização; redesenho de processos e assimilação de nova } \\
\text { cultura. }\end{array}$ \\
\hline l. (1999) & empresas de consultoria. \\
\hline Taurion (1999) & $\begin{array}{l}\text { npresa de consultoria para implantação; ger } \\
\text { mprometimento da empresa e da alta direção; form }\end{array}$ \\
\hline Corr & nciada por $\mathrm{F}$ \\
\hline
\end{tabular}

FONTE: Adaptado de MENDES E ESCRIVÃO FILHO (2008, p. 246)

\subsection{Dificuldades}

Continuando com a definição de termos utilizados neste estudo, em relação ao termo “dificuldades” que se encontra no decorrer do trabalho, este pode ser entendido como sendo 
qualquer fator limitante ou inibidor ao sucesso na implementação de sistemas. Também podem ser entendidas como quaisquer obstáculos, limitações, problemas, empecilhos, estorvos, complicação ou impedimento relacionados à implementação de sistemas. Tais fatores podem ser de caráter físico (como a limitação de recursos), comportamental (atitudes), ou ambiental (contingenciais).

Nos estudos encontrados que tratam das dificuldades de implementação de sistemas, há situações em que algumas delas são representadas pela ausência de algum fator, como a falta de apoio da gerência. Todavia, quando listadas, são apresentadas somente com a sua citação, como por exemplo, “apoio gerencial” na situação citada. Nesses casos, quando explícito que se trata de uma dificuldade, esses fatores serão precedidos dos termos "ausência de" ou "falta de”. Situação semelhante ocorre nos casos em que se tratar de fatores críticos de sucesso (vide item 4.6), mas estes serão mantidos como no original, pois podem não se referir especificamente à sua ausência.

\subsection{Classificação do porte das empresas}

A classificação das empresas em relação ao porte apresenta diversos critérios no Brasil. As diferenças entre as empresas podem ser analisadas através de fatores qualitativos ou quantitativos. No quadro 6 a seguir, é feita uma comparação entre as características das empresas de pequeno e grande porte. Kassai (1997, p. 61) comenta que, apesar de ser possível a utilização de dados qualitativos para determinar as chamadas pequenas empresas, os dados quantitativos prevalecem como critério, pois: “permitem determinar o porte das empresas; são mais fáceis de serem coletados; permitem o emprego de medidas de tendência no tempo; possibilitam análises comparativas; são de uso corrente nos setores institucionais e públicos e privados".

Quadro 6 - Características qualitativas das PMEs

\begin{tabular}{|l|l|l|}
\hline \multicolumn{1}{|c|}{ CARACTERÍSTICAS } & \multicolumn{1}{|c|}{ GRANDES EMPRESAS } & \multicolumn{1}{c|}{ PEQUENAS EMPRESAS } \\
\hline Adaptabilidade & Pequena & Grande \\
\hline Administração & Profissional & Pessoal ou familiar \\
\hline $\begin{array}{l}\text { Capacidade de interpretar e utilizar } \\
\text { políticas e dispositivos legais }\end{array}$ & Grande & Pequena \\
\hline Capacidade de utilizar especialista & Grande & Pequena \\
\hline Capacitação profissional & Especializada & Não especializada \\
\hline
\end{tabular}




\begin{tabular}{|l|l|l|}
\hline Capital & Dissolvido & Concentrado \\
\hline Concentração de recursos & Capital & Trabalho \\
\hline Decisão & Descentralizada & Centralizada \\
\hline Estrutura & Organizada & Informal \\
\hline Flexibilidade & Pequena & Grande \\
\hline Forma jurídica & Sociedade anônima & Limitada \\
\hline Ganhos de escala & Grandes & Pequenos \\
\hline Idade média & Alta & Pequena \\
\hline Níveis hierárquicos & Muitos & Poucos \\
\hline Número de funcionários & Grande & Pequeno \\
\hline Número de produtos & Grande & Pequeno (único) \\
\hline Recursos financeiros & Abundantes formalizados e e & $\begin{array}{l}\text { Simples, informais e manuais } \\
\text { (mecanizados) }\end{array}$ \\
\hline Sistemas de informação & $\begin{array}{l}\text { Complexos, fortesanal) } \\
\text { informatizados }\end{array}$ & Baixa (artesana \\
\hline Utilizaço da tecnologia & Alta & \\
\hline
\end{tabular}

FONTE: KASSAI, 1996, p. 84.

Os critérios utilizados pelos países para determinar o porte das empresas geralmente são baseados em número de funcionários, valor do faturamento anual ou outros, como valor do patrimônio ou do balanço. Além da variação dos critérios em si, variam também os valores de cada faixa, de país para país. Para as instituições brasileiras, como: SEBRAE - Serviço Brasileiro de apoio às micro e pequenas empresas; MTE - Ministério de Trabalho e Emprego; BNDES - Banco Nacional de Desenvolvimento Econômico e Social; e a Secretaria da Receita Federal, vários critérios são utilizados, conforme são apresentados na tabela 01 a seguir:

Tabela 1: Classificação por porte de empresa

\begin{tabular}{|l|c|c|c|}
\hline \multicolumn{1}{|c|}{ ENTIDADE } & MICRO & PEQUENA & MÉDIA \\
\hline \multicolumn{1}{|c|}{ POR N $^{\text {. }}$. DE EMPREGADOS } & & & \\
\hline SEBRAE (comércio e serviços) & $0-9$ & $10-49$ & $50-99$ \\
\hline SEBRAE (indústria) & $0-19$ & $20-99$ & $100-499$ \\
\hline Ministério do Trabalho e Emprego & $0-19$ & $20-99$ & $100-499$ \\
\hline & & & \\
\hline \multicolumn{1}{|c|}{ POR FATURAMENTO ANUAL } & $\mathrm{R} \$ 240.000$ & $\mathrm{R} \$ 2.400 .000$ & \\
\hline Secretaria da Receita Federal & $\mathrm{R} \$ 1.200 .000$ & $\mathrm{R} \$ 10.500 .000$ & $\mathrm{R} \$ 60.000 .000$ \\
\hline BNDES $\$ 3.000 .000$ & \\
\hline Ministério do Trabalho e Emprego & \multicolumn{2}{|c|}{} \\
\hline $\begin{array}{l}\text { Fornecedores de ERP (Mendes \& } \\
\text { Escrivão) }\end{array}$ & & \\
\hline
\end{tabular}

FONTE: Elaborado a partir de dados de: SEBRAE; MTE; SRF; BNDES; Mendes \& Escrivão Filho, 2008, p. 254.

De acordo com dados obtidos no endereço eletrônico do MDIC - Ministério do Desenvolvimento, Indústria e Comércio Exterior (2007), a classificação das PME por porte da empresa de alguns países é realizada por diversos critérios. Na tabela 2 a seguir é apresentada a classificação utilizando-se o número de empregados como critério: 
Tabela 2: Classificação por número de empregados

\begin{tabular}{|c|c|c|c|}
\hline REGIÃO & MICRO & PEQUENA & MÉDIA \\
\hline Mercosul (indústria) & $1-10$ & $11-40$ & $41-200$ \\
\hline Mercosul (comércio/serviços) & $1-5$ & $6-30$ & $31-80$ \\
\hline Argentina & $1-5$ & $5-50$ & $51-300$ \\
\hline Equador & $1-9$ & $10-49$ & $50-100$ \\
\hline Peru & $1-10$ & $11-40$ & \\
\hline Uruguai & $1-4$ & $5-19$ & $20-99$ \\
\hline Venezuela & $1-10$ & $11-50$ & $51-100$ \\
\hline Canadá & \multicolumn{3}{|c|}{$1-250$} \\
\hline Indústria e mineração (regra geral) & \multicolumn{2}{|c|}{$1-500$} & \\
\hline México (indústria) & $0-30$ & $31-100$ & $101-500$ \\
\hline México (comércio) & $0-5$ & $6-20$ & $21-100$ \\
\hline México (serviço) & $0-20$ & $21-50$ & $51-100$ \\
\hline União Européia (1998) & $0-9$ & $10-49$ & $50-249$ \\
\hline Alemanha & \multicolumn{2}{|c|}{$1-20$} & $21-500$ \\
\hline Dinamarca & $1-10$ & $11-50$ & $51-250$ \\
\hline Espanha & & 49 & 249 \\
\hline Grécia & $1-9$ & $10-99$ & $100-$ \\
\hline Irlanda & $1-10$ & $11-50$ & $51-250$ \\
\hline Itália (Indústria) & & 50 & 250 \\
\hline Itália (Comércio e serviços) & & 250 & 95 \\
\hline Portugal & \multicolumn{3}{|c|}{$1-500$} \\
\hline Reino Unido (companies act) & & $0-50$ & $51-250$ \\
\hline Reino Unido (depto. com. ind.) & $0-9$ & $10-49$ & $50-249$ \\
\hline Suíça & 9 & $10-49$ & $50-249$ \\
\hline Irã & 9 & $10-49$ & $50-99$ \\
\hline Israel & & 50 & 100 \\
\hline Turquia & & $1-50$ & $51-150$ \\
\hline Austrália & & 20 & 200 \\
\hline Coréia do sul (manufaturas) & & 50 & 300 \\
\hline Hong Kong (manufaturas) & \multicolumn{3}{|c|}{100} \\
\hline Japão (indústria) & \multicolumn{3}{|c|}{300} \\
\hline Malásia & & 50 & 150 \\
\hline Rússia (indústria) & & 100 & \\
\hline Singapura & \multicolumn{3}{|c|}{200} \\
\hline Tailândia (produção e serviços) & & 50 & $51-200$ \\
\hline Taiwan (indústria) & \multicolumn{3}{|c|}{200} \\
\hline Banco Mundial - IFC & $0-10$ & $11-50$ & $51-300$ \\
\hline
\end{tabular}

FONTE: Elaborado a partir dos dados do MDIC, 2007.

Outro critério comumente adotado é o faturamento bruto anual das empresas. Na tabela 3 a seguir, pode-se observar a classificação em alguns países de acordo com este critério (valores em dólares convertidos pelas taxas de 30/11/07). Além desses dois critérios mais utilizados, que são o número de empregados, e o faturamento bruto anual, outros critérios são também utilizados, como: total do balanço, do capital, do ativo ou do patrimônio, como pode ser observado na tabela 4. 
Tabela 3: Classificação por faturamento anual

\begin{tabular}{|c|c|c|c|}
\hline REGIÃO & MICRO & PEQUENA & MÉDIA \\
\hline Mercosul (indústria) & US\$ $400 \mathrm{mil}$ & US\$ 3,5 milhões & US\$ 20 milhões \\
\hline Mercosul (comércio/serviços) & US\$ $200 \mathrm{mil}$ & US\$ 1,5 milhões & US\$ 7 milhões \\
\hline Argentina (agropecuária) & US\$ 85,8 mil & US\$ $572 \mathrm{mil}$ & US\$ 3,4 milhões \\
\hline Argentina (indústria e mineração) & US\$ 286 mil & US\$ 1,7 milhões & US\$ 13,7 milhões \\
\hline Argentina (comércio) & US\$ $572 \mathrm{mil}$ & US\$ 3,4 milhões & US\$ 27,4 milhões \\
\hline Argentina (serviços) & US\$ $143 \mathrm{mil}$ & US\$ 1 milhão & US\$ 6,9 milhões \\
\hline Chile & US\$ $59 \mathrm{mil}$ & US\$ 615 mil & US\$ 2,4 milhões \\
\hline Peru & US\$ $90 \mathrm{mil}$ & US\$ 180mil & \\
\hline Uruguai & US\$ 60 mil & US\$ $180 \mathrm{mil}$ & US\$ 5 milhões \\
\hline Estados Unidos (regra geral) & \multicolumn{2}{|c|}{ US\$ 6 milhões } & \\
\hline União Européia (1998) & US\$ 1,5 milhões & US\$ 13,5 milhões & US\$ 75 milhões \\
\hline Espanha & & US\$ 27,1 milhões & US\$ 271 milhões \\
\hline Grécia & & US\$ 10,5 milhões & US\$ 60 milhões \\
\hline Itália (Indústria) & & US\$ 7,5 milhões & US\$ 30 milhões \\
\hline Itália (Comércio e serviços) & & US\$ 2,8 milhões & US\$ 15 milhões \\
\hline Portugal & \multicolumn{3}{|c|}{ US\$ 32,1 mil } \\
\hline Reino Unido & & US\$ 5,8 milhões & US\$ 23 milhões \\
\hline Israel & & US\$ 5 milhões & US\$ 20 milhões \\
\hline Malásia & & US\$ 2,6 milhões & US\$ 6,5 milhões \\
\hline Tailândia (produção e serviços) & & US\$ 1,1 milhão & US\$ 4,6 milhões \\
\hline Banco mundial - IFC & US\$ $100 \mathrm{mil}$ & US\$ 3 milhões & US\$ 15 milhões \\
\hline
\end{tabular}

FONTE: Elaborado a partir dos dados do MDIC, 2007.

Tabela 4: Classificação por outros critérios diversos

\begin{tabular}{|c|c|c|c|}
\hline REGIÃO & MICRO & PEQUENA & MÉDIA \\
\hline Equador (volume de capital) & US\$ $10 \mathrm{mil}$ & US\$ $250 \mathrm{mil}$ & US\$ $250 \mathrm{mil} \mathrm{>}$ \\
\hline Uruguai (total do ativo) & US\$ $20 \mathrm{mil}$ & US\$ $50 \mathrm{mil}$ & US\$ $350 \mathrm{mil}$ \\
\hline União Européia (balanço) & US\$ 2,1 milhões & US\$ 15,5 milhões & US\$ 64,7 milhões \\
\hline Espanha (ativo total) & & US\$ 19,5 milhões & US\$ 195 milhões \\
\hline Itália - Indústria (patrimônio) & & US\$ 3 milhões & US\$ 15 milhões \\
\hline Itália - com. e serv. (patrimônio) & & US\$ 1,1 milhões & US\$ 5,6 milhões \\
\hline Reino Unido (balanço) & & US\$ 2,9 milhões & US\$ 11,5 milhões \\
\hline Japão - indústria (capital) & \multicolumn{3}{|c|}{ US\$ $900 \mathrm{mil}$} \\
\hline Taiwan - indústria (capital) & \multicolumn{3}{|c|}{ US\$ 1,8 milhão } \\
\hline
\end{tabular}

FONTE: Elaborado a partir dos dados do MDIC, 2007.

A análise dos critérios utilizados em cada país para definir o porte das empresas é necessária para que, ao estudar os materiais existentes em diversos países, que tratam de empresas de pequeno e médio porte, haja a clara compreensão do grupo que está sendo analisado. Dessa forma, é possível evitar que estudos que tratem de empresas de portes distintos, sejam considerados como sendo do mesmo grupo. Adicionalmente à atenção exigida aos critérios apresentados nas tabelas anteriores, houve a precaução de que todo material estrangeiro fosse interpretado e dividido em grupos de acordo com o porte de empresa o qual se referia, antes de ser analisado em conjunto com os demais. 
Assim como os critérios utilizados pelos diversos países para classificar as empresas são distintos, poder-se-ia considerar que as dificuldades de implementação também o são. Quanto a isso, Hopper et al. (1999, p. 86) mostram que, mesmo considerando as diferenças entre os diversos países, como os Estados Unidos e Japão, eles podem ter sinais de convergência em seus sistemas de custos. Dessa forma, neste estudo, os achados apresentados em publicações internacionais referentes a dificuldades de implementações de sistemas foram considerados com o mesmo grau de importância.

Conforme será discutido adiante, talvez a pequena quantidade de estudos específicos para empresas de médio porte seja decorrência dessa dificuldade de determinação de seu porte. Porém, como foi demonstrado anteriormente, essas empresas fazem parte de um nicho específico relevante para a economia, representando 4,63 vezes o número das empresas de grande porte e empregando mais da metade do que as grandes empresas empregam (BRASIL, 2007).

\subsection{Dificuldades na implantação de sistemas de custos}

Em relação aos sistemas de custos, a maioria dos estudos que envolvem as dificuldades de implantação aborda o sistema ABC, fato compreensível devido à sua maior complexidade em relação aos sistemas de custeio ditos tradicionais. Na análise dos trabalhos não será feita uma classificação de acordo com o método, considerando-os apenas como sistemas de custeio, mas, quando se fizer necessária alguma menção sobre o modelo do sistema de custeio utilizado, esta será colocada.

Gosselin (2007, p. 641-648) afirma que muitos artigos na literatura descrevem as dificuldades no processo de implementação do ABC e tentam fornecer soluções para eles e que, desde 1995, acadêmicos começaram a examinar quais eram os fatores contextuais que influenciam a implementação do ABC em vários estágios. Ele também afirma que muitas organizações que tinham adotado e implementado o ABC abandonaram-no devido a diversas dificuldades, e cita que Kaplan \& Anderson (2004) sugerem como causas do abandono os altos custos e a irritação dos empregados (como dificuldade e complexidade da implementação). 
Considerando a primeira etapa de implantação de sistemas, que envolve a seleção e decisão, Martins (2003, p. 360) comenta sobre duas decisões que precisam ser tomadas: sobre qual método é o mais adequado e será utilizado (absorção, variável, ABC, etc.), e qual o nível de detalhamento que será necessário. Em relação a qual modelo utilizar, ele comenta que "a decisão de qual modelo será utilizado depende de quem vai receber as informações na ponta da linha e o que fará com elas”. Para isso, deve-se verificar para que se quer o sistema, se é para controle, se é para simples avaliação de estoques, se é para fornecimento rápido de informações necessárias a decisões rotineiras ou se é para decisões que não demandam tanta rapidez nos dados. Quanto à decisão sobre qual o nível de detalhamento necessário, é preciso que se verifique, junto ao usuário final, o que ele necessita, para que com isso possa ser determinada a sofisticação necessária do sistema.

Conforme mencionado, quando se trata de implementação de sistemas de custos para empresas de pequeno e médio porte, é comum encontrar-se estudos que somente relatam o processo de implementação em si, sem abordar as dificuldades ou problemas encontrados, como nos estudos de: Kassai \& Kassai (1998), Nascimento (2002), Santos (2002), Pinotti (2003) e Scramim (2002). Destes, apenas o último refere-se à empresa de porte médio, um laticínio com 65 funcionários. Quando se trata de empresas de grande porte, os estudos geralmente envolvem sistemas que utilizam o método $\mathrm{ABC}$ e tratam, mesmo que superficialmente, como em Pompermayer (2004), das dificuldades de implantação. Outros, como Gosselin (2007) e Medeiros (1999), têm uma abordagem maior sobre essas dificuldades.

\subsubsection{Em empresas de pequeno porte}

No estudo de Needy et al. (2003, p. 3), no qual analisaram três empresas de pequeno porte, com menos de 100 funcionários, eles comentam que, diferentemente das grandes empresas, existem poucos estudos sobre a implementação e uso do $\mathrm{ABC}$ nas pequenas empresas industriais. Conforme os autores, a implementação prática também é pequena, e afirmam que estudos mostram que as pequenas empresas não são familiarizadas com mecanismos de $\mathrm{ABC}$ e não implementam esse sistema devido alto custo e desenvolvimento e de implementação. Ao final do estudo, após demonstrarem três implementações de sistemas de custos ABC com 
sucesso em empresas de pequeno porte, recomendam um sistema relativamente simples que inclua apenas algumas poucas atividades e direcionadores de custos.

Semelhantemente aos trabalhos anteriormente mencionados, nos quais foram apenas apresentados modelos de implantação, Moraes (2002, p.90) também propõe um sistema para pequenas empresas industriais, mas diferentemente daqueles, apresenta algumas dificuldades encontradas para sua implantação, tais como: a falta de controles básicos, como controles de estoques e financeiros; falta de credibilidade nas informações de consumo de materiais, despesas e custos indiretos de fabricação e resistência dos funcionários para anotarem as informações da produção necessárias para o sistema. Por outro lado, comentou da importância que teve o apoio dos sócios na implantação. O estudo de Duran \& Radaelli (2000, p. 130) também se refere à apresentação de uma implantação de sistemas de custeio ABC em uma microempresa, onde comenta que as maiores dificuldades foram relacionadas com a acuracidade dos direcionadores, ou seja, na mensuração dos dados dos direcionadores.

Afonso (2002, p.16) comenta que, segundo Heitger et al., alguns fatores influenciam na concepção de um sistema de custos, sendo eles:

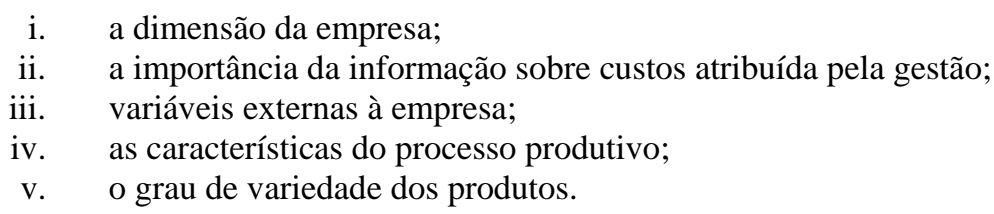

Considerando-se que o porte da empresa possa afetar a concepção do sistema de custos, as diferenças entre as características dessas empresas com as demais devem ser consideradas, para que se tenha uma maior compreensão dos sistemas de custeio que elas utilizam.

Alguns autores, concomitantemente à abordagem das dificuldades, tratam de fatores considerados importantes na implantação de sistemas de custos. Gosselin (2007, p. 666) é um exemplo, quando cita que tamanho, estratégia, incerteza ambiental, e diversidade de produto afetam a decisão de implementá-lo. De mesma forma, na implantação de sistemas de custeio ABC, Afonso (2002, p.169-172) destaca alguns pontos importantes como:

a) constatar as vantagens e as desvantagens da implantação;

b) haver um sistema anterior de informação implementado; 
c) preparar e envolver os empregados;

d) ter o apoio e crença no valor do projeto por parte dos administradores;

e) definir os objetivos do sistema e quais as informações necessárias para atingir esses objetivos;

f) ter uma equipe multidisciplinar (engenharia, produção e contabilidade);

g) haver alguém com experiência em implantação de ABC ou obter auxílio externo.

Afonso (2002, p.176) também faz um levantamento de trabalhos envolvendo sistemas de custeio $\mathrm{ABC}$, onde são citados autores que realizaram estudos referentes à concepção e implementação de ABC: Zhuang \& Burns (1992); Lyne \& Friedman (1996); Coskins (1997); Schneeweis (1998) e Sohal Chung (1998). Para estudos referentes à implementação de sistemas ABC em PME: Bharara e Lee (1996); Benjamin et al. (1994); Hicks (1992); Need et al. (2000); Roztocki \& Needy (1999).

Para Needy et al. (apud Afonso, 2002, p.177), o sistema ABC para pequenas empresas deve ter cálculos simples, ser flexível e dinâmico e necessitar de poucos recursos. Para Roztocki et al. (2004, p. 19), são vários os fatores que impedem as pequenas indústrias de implementar um sistema de custos ABC: falta de dados, recursos técnicos, recursos financeiros e adequados recursos de TI. Eles apresentam como principais problemas: a coleta e o processamento de dados necessários e na forma correta, e a um custo razoável. Além disso, ao sugerir que para uma mais fácil transição de um sistema de custeio tradicional para um sistema de custeio ABC, Roztocki et al. (2004, p.25) mencionam um modelo que não necessita de alto investimento na coleta de dados e de uma séria reestruturação organizacional.

Semelhantemente a Pinotti (2003), Massuda (2003) também aborda a implantação de um sistema de custos em uma indústria do ramo de confecções e, apesar de não ser o foco de seu trabalho, listou algumas dificuldades encontradas:

a) a resistência implícita de parte do pessoal com relação à metodologia aplicada, por considerá-la como instrumento de controle ou punição, talvez pela própria cultura já existente na empresa de uma estrutura vertical e tradicional, embora tenha havido a colaboração dos envolvidos no processo; 
b) a resistência dos sócios, pois cada setor é de responsabilidade do seu gerente de área, fazendo se sentirem rotulados como a própria ineficiência, uma vez que seu setor é passível de melhorias não identificadas pela estrutura em uso.

c) Outra dificuldade detectada foi o próprio investimento das propostas de melhorias, há a necessidade de um gasto inicial e isto dependerá de um planejamento e do mercado não ser outro gargalo.

As dificuldades consideradas pelos autores, além das que foram por eles apresentadas, encontradas na literatura sobre implementação de sistemas de custos nas empresas de pequeno porte, são apresentadas no quadro abaixo:

Quadro 7 - Dificuldades encontradas na implementação de sistemas de custos em pequenas empresas

\begin{tabular}{|c|c|}
\hline AUTORES & DIFICULDADES ENCONTRADAS \\
\hline \multirow[t]{2}{*}{$\begin{array}{l}\text { Roztocki et al. (2004) - } \\
\text { ABC }\end{array}$} & $\begin{array}{l}\text { Não conseguir coletar e processar os dados necessários de forma correta e a } \\
\text { um custo razoável. }\end{array}$ \\
\hline & $\begin{array}{l}\text { Falta de: dados, recursos técnicos, recursos financeiros, e adequados recursos } \\
\text { de informática. }\end{array}$ \\
\hline Duran \& Radaelli (2000) & Falta de acuracidade dos direcionadores \\
\hline
\end{tabular}

FONTE: ROZTOCKI ET AL. (2004); DURAN; RADAELLY (2000).

\subsubsection{Em empresas de grande porte.}

Apesar de não estar focado em pequenas e médias empresas, o estudo de Medeiros (1999) faz um levantamento de trabalhos que analisaram os sistemas ABC que tivessem relação com a área de logística. Nessa comparação entre alguns estudos, foram apresentados os estudos de: Pohlen e Londe de 1993; outro trabalho dos mesmos autores em 1998; e um estudo de Cobb et al. realizado em 1992. No primeiro trabalho de Pohlen e Londe, eles analisam 22 empresas logísticas, das quais $76 \%$ eram de manufatura, 14\% de atacadistas e $10 \%$ de varejistas. Os principais problemas citados relacionados à implementação de um sistema ABC foram:

a) Tempo consumido;

b) Elevado custo de consultoria;

c) Dificuldade para identificar direcionadores de custo em linha de produto diversa (variada);

d) Falta de medidas anteriores de performance;

e) A necessidade de mudança de perspectiva (mentalidade ou ponto de vista); 
f) Resistência à mudança dentro da estrutura organizacional de custo.

Ainda segundo Medeiros (1999, p. 47), em 1998, os mesmos autores fizeram uma nova pesquisa, na qual os seguintes problemas durante a implementação foram apontados:

a) Sistema de contabilidade inadequado;

b) Conhecimento técnico;

c) Identificação de direcionadores de custo;

d) Apoio de trabalhadores/funcionários;

e) Apoio gerencial.

Outro trabalho analisado por Medeiros (1999, p.56) foi o estudo de Cobb, Innes e Mitchel, de 1993, no qual analisaram diversas empresas e concluem que os problemas com ABC enquadram-se em duas categorias:

a) Resistência à mudança pelos usuários (gerentes), assim como pelos produtores de informação (contadores);

b) Uma série de problemas técnicos associados à metodologia $\mathrm{ABC}$, mas que são pouco significantes quando comparados à resistência à mudança.

Outros problemas apresentados pelos autores foram:

a) Volume de trabalho envolvido na instalação;

b) Prioridades mais elevadas para os recursos;

c) Falta de adequado recurso da equipe de contadores;

d) Escassez de recursos computacionais;

e) Dificuldades em selecionar direcionadores de custos.

Ainda Medeiros (1999, p.83) expõe as quatro categorias de Gary Cokins para as causas de fracasso de um sistema ABC: interruptoras; rejeição do usuário; obstáculos da organização e nocivas. Cada categoria engloba várias causas conforme segue:

I) Interruptoras: 
a. Quando o projeto é lançado pelas áreas de finanças ou contabilidade (ou se a equipe de projeto é excessivamente composta por contadores), o projeto pode ser considerado outro projeto inexpressivo ou exercício gerencial.

b. A contabilidade de custo está fora das zonas de conforto.

c. Compete com o sistema oficial de contabilidade.

d. Sub-avaliação da resistência dos empregados.

e. Projeto for considerado um delírio.

f. Projeto for muito detalhado.

II) Rejeição do usuário:

a. Pessoal de vendas e marketing não sabem como reagir aos novos ganhadores e perdedores de lucro.

b. Sistema $A B C$ não provê todas as informações necessárias às decisões em relação aos produtos e clientes.

c. Sistema ABC compete com outro sistema.

d. Tomar decisões gerenciais envolve desgastes pessoais

III) Obstáculos da organização:

a. Perda do envolvimento das gerências, especialmente a alta.

b. Não responsabilidade real quanto a perdas e ganhos.

c. Pouca diversidade de produtos.

d. Escritório central comanda/define atividades.

e. Falta de pessoal competente em gestão de custo

f. Reputação de que o ABC é dispendioso de manter ou é uma ferramenta errada.

IV) Nocivas:

a. Fraca liderança no projeto do sistema.

b. Treinamento inadequado.

c. Atividades incongruentes com os direcionadores de custo.

d. Dados relevantes estão indisponíveis.

e. Escopo do sistema restringe-se aos custos operacionais, e não a cadeia de valores.

Os levantamentos realizados por Medeiros (1999) são sintetizados no quadro 8 a seguir:

Quadro 8 - Dificuldades encontradas na implantação de sistemas ABC em empresas de grande porte.

\begin{tabular}{|c|c|}
\hline Autores (ano) & Dificuldades \\
\hline \multirow{6}{*}{$\begin{array}{l}\text { Pohlen \& Londe } \\
(1994)\end{array}$} & Tempo consumido; \\
\hline & Elevado custo de consultoria; \\
\hline & $\begin{array}{l}\text { Dificuldade para identificar direcionadores de custo em linha de produto diversa } \\
\text { (variada); }\end{array}$ \\
\hline & Falta de medidas anteriores de performance; \\
\hline & A necessidade de mudança de perspectiva (mentalidade ou ponto de vista); \\
\hline & Resistência à mudança dentro da estrutura organizacional de custo. \\
\hline \multirow{5}{*}{$\begin{array}{l}\text { Pohlen \& } \quad \text { Londe } \\
(1998)\end{array}$} & Sistema de contabilidade inadequado; \\
\hline & Conhecimento técnico; \\
\hline & Identificação de direcionadores de custo; \\
\hline & Apoio de trabalhadores/funcionários; \\
\hline & Apoio gerencial. \\
\hline \multirow[t]{5}{*}{ Cobb et al. (1992) } & $\begin{array}{l}\text { Resistência à mudança pelos usuários (gerentes), assim como pelos produtores de } \\
\text { informação (contadores); }\end{array}$ \\
\hline & Volume de trabalho envolvido na instalação; \\
\hline & Prioridades mais elevadas para os recursos; \\
\hline & Falta de adequado recurso da equipe de contadores; \\
\hline & Escassez de recursos computacionais; \\
\hline
\end{tabular}


Dificuldades em selecionar direcionadores de custos

Em trabalho semelhante ao de Medeiros (1999), Gosselin (2007, p. 641), ao realizar uma revisão histórica dos sistemas $\mathrm{ABC}$, fez um comparativo de estudos que trataram de dificuldades e fatores críticos de sucesso de sistemas ABC, dos quais seus resultados são apresentados no quadro 9. Dentre os estudos apresentados por Gosselin (2007), está o trabalho de Anderson (1995), no qual são identificados dezenove fatores que influenciam positiva ou negativamente a implementação do $\mathrm{ABC}$ em indústrias automotivas. Uma constatação do estudo de Anderson (1995, p. 666) é de que os impactos dos fatores que influenciam a adoção e implementação dos sistemas ABC variam de acordo com os estágios de implementação, fato observado também pelos autores que ele analisou. Ele também afirma que fatores como tamanho, estratégia, incertezas ambientais e diversidades de produtos afetam a decisão de implementar o ABC. Tal situação enquadra-se na fase pré-implantação abordada neste trabalho.

Quadro 9 - Dificuldades encontradas na implantação de sistemas ABC em empresas de grande porte.

\begin{tabular}{|c|c|}
\hline Autores (ano) & Dificuldades \\
\hline \multirow[t]{5}{*}{ Nicholls (1992) } & Falta de disponibilidade de dados \\
\hline & Escassez de recursos \\
\hline & Resistência à mudança \\
\hline & Falta de treinamento onde houve maiores problemas \\
\hline & Fatores críticos \\
\hline \multirow{5}{*}{$\begin{array}{l}\text { Anderson (1995) } \\
\text { Fatores que afetam } \\
\text { negativamente }\end{array}$} & Centralização \\
\hline & Responsabilidade do trabalhador \\
\hline & Comunicação interna \\
\hline & Incerteza e falta de clareza de objetivos \\
\hline & Autonomia de trabalho \\
\hline \multirow{15}{*}{$\begin{array}{l}\text { Anderson (1995) } \\
\text { Fatores que afetam } \\
\text { positivamente } \\
\text { implementação }\end{array}$} & Competição \\
\hline & Heterogeneidade de demandas \\
\hline & Incertezas ambientais \\
\hline & Disposição para mudanças \\
\hline & Especialização funcional \\
\hline & Treinamento \\
\hline & Complexidade para usuários \\
\hline & Compatibilidade com sistemas existentes \\
\hline & Melhora sobre sistema existente \\
\hline & Conhecimento do processo \\
\hline & Total envolvimento \\
\hline & Importância para decisões dos gerentes \\
\hline & Compatibilidade com a estratégia da empresa \\
\hline & Centralização \\
\hline & Comunicações internas \\
\hline \multirow[t]{2}{*}{ Shields (1995) } & Apoio da alta gerência \\
\hline & Ligação com avaliação e recompensa de performance \\
\hline
\end{tabular}




\begin{tabular}{|l|l|}
\hline \multirow{2}{*}{$\begin{array}{l}\text { McGowan } \\
\text { Klammer (1997) }\end{array}$} & Treinamento \\
\cline { 2 - 3 } & Custos para contabilização \\
\cline { 2 - 2 } $\begin{array}{l}\text { Anderson \& Young } \\
(1999)\end{array}$ & Satisfação dos empregados \\
\cline { 2 - 2 } & Apoio da alta gerência \\
\cline { 2 - 2 } & Adequação dos recursos destinados ao projeto \\
\cline { 2 - 2 } & Comprometimento do respondente com a organização \\
\cline { 2 - 2 } & Se ospondente percebe a necessidade de mudança \\
\hline
\end{tabular}

FONTE: GOSSELIN (2007).

No trabalho de Pompermayer (2004, p. 170), ao analisar a influência de fatores organizacionais em sistemas de gestão de custos em quatro empresas, ela identificou dificuldades e fatores facilitadores à prática dos sistemas de gestão de custos, extraídas da observação das empresas em conjunto:

Facilitadores:

- $\quad$ interação entre os setores das empresas;

- $\quad$ alto nível de especialização;

- $\quad$ rápida comunicação interna;

- $\quad$ existência de comunicação multidirecional.

Dificuldades:

- $\quad$ alta centralização;

- lentidão na comunicação interna;

- $\quad$ comunicação vertical lenta.

Adiante, quando são citadas as dificuldades de implantação de sistemas ERP em empresas de grande porte, também é apresentada outra categorização, na qual Krasner (2000, p.23), apresenta os grupos de problemas gerenciais, de usuários e técnicos.

\subsection{Dificuldades de implantação de sistemas ERP}


Uma vez apresentadas as dificuldades existentes nos estudos que tratam da implantação de sistemas de custos, em empresas de pequeno e grande porte, são agora analisados materiais encontrados que tratam da implantação de sistemas ERP em empresas de pequeno, médio e grande porte. Tal análise é efetuada para que, conforme mencionado anteriormente, encontrem-se pontos que possam ser analogamente relevantes na implantação de sistemas de custos em empresas de médio porte.

Riccio (2001, p.12) comenta que, em relação aos sistemas ERP, houve um aumento de implementações a partir de 1995. Com a propagação da utilização desses sistemas ERP, vários estudos sobre o tema têm sido desenvolvidos, e o número de trabalhos vem aumentando em continuidade aos estudos anteriores sobre sistemas de informações. Nesse contexto, acompanhando o desenvolvimento dos sistemas de informação, vários estudos têm sido realizados sobre a implantação desses sistemas ERP. Existem trabalhos que descrevem um ou mais casos de implantação, como o de Scramim et al. (2002); outros tratam de analisar uma ou mais partes específicas dos ciclos de vida dos sistemas, como fez Susmann e Souza \& Zwicker, que analisam como ocorre a escolha e a implantação de sistemas ERPs em empresas de médio porte. Há ainda aqueles que tratam de fatores críticos para a implantação de sistemas ERP, como Tsay et al. e Chien (2007).

\subsubsection{Em empresas de pequeno porte}

Chien et al. (2007, p.381) expõe problemas e desafios apresentados por Martin e Liu \& Zhou relacionados à implantação de sistemas integrados em pequenas e médias empresas na China, que são respectivamente: implementações de ERP na China não conseguem cumprir com o prazo estipulado por estimativas incorretas e incertezas de prazos e planejamento; e os maiores desafios são falta de infra-estrutura de TI e falta de recursos humanos. O autor ainda compara as dificuldades da China com as de Taiwan, que na opinião de Tsai, os maiores obstáculos são: dificuldade de transição para novos sistemas; falta de pessoas especializadas e alta rotatividade de pessoas chaves dos projetos.

Assim como Afonso (2002) cita em seu trabalho a necessidade de pessoa especializada para a implantação do sistema de custos, Chien et al. (2007, p. 391) também vê essa necessidade nos sistemas ERP para as pequenas e médias empresas. Em seu trabalho, Chien et al. (2007) 
analisou 139 empresas de pequeno e médio porte em Taiwan e 105 empresas de mesmos portes na China. Apesar do objetivo de seu trabalho não ser a identificação de dificuldades, ele utiliza como variáveis fatores que considera importantes para o sucesso de uma implementação quais sejam: tamanho da equipe do projeto; tamanho da firma; experiência do líder de projeto; características da estrutura de incentivos; localização (ambiente econômico e social).

Valente (2004, p.49), que assim como Vieira (2004), fez uma revisão de literatura das dificuldades encontradas na implantação de sistemas ERP para empresas de grande porte, comparando com estudo de casos em empresas de menor porte. A autora cita como barreiras e dificuldades mais relevantes, de acordo com os autores pesquisados: o planejamento inadequado da implantação, a análise dos processos e a mudança organizacional. Em seu estudo, Valente (2004), além de analisar as dificuldades, analisa os fatores críticos de sucesso na implementação dos sistemas ERP. Serão apresentados dois quadros referentes seus estudos, sendo um (quadro 10) que apresenta as principais dificuldades de implantação, e outro (quadro 11) no qual são contemplados os fatores críticos de sucesso apresentados pela autora.

Quadro 10 - principais dificuldades de implementação de sistemas ERP em pequeno porte - Valente

\begin{tabular}{|c|c|}
\hline Autores (ano) & Dificuldades \\
\hline \multirow[t]{9}{*}{ Krasner (2000) } & Falta de plano integrado de implementação para as equipes \\
\hline & Falha na comunicação entre os diversos níveis de usuários e entre equipes \\
\hline & Processo de tomada de decisão mal estruturada ou inexistente \\
\hline & Ausência de um plano e administração de testes integrados \\
\hline & Não aplicação de conhecimentos adquiridos em implementações passadas \\
\hline & Pacotes incompletos ou pouco robustos \\
\hline & Problemas de integração \\
\hline & Problemas de parametrização \\
\hline & Problemas de baixa performance do sistema \\
\hline \multirow{4}{*}{$\begin{array}{l}\text { Mendes \& } \text { Escrivão } \\
\text { Filho (2002) }\end{array}$} & Análise de processos \\
\hline & Mudança organizacional \\
\hline & Planejamento de implantação inadequado \\
\hline & Equipe experiente para conduzir a implantação \\
\hline \multirow[t]{6}{*}{ Ozaki \& Vidal (2003) } & $\begin{array}{l}\text { Práticas administrativas impostas pela controladora geraram muitas } \\
\text { customizações e desenvolvimentos específicos no sistema ERP }\end{array}$ \\
\hline & Alta rotatividade das pessoas demandou consultoria externa para treinamento \\
\hline & Sobrecarga de funções \\
\hline & $\begin{array}{l}\text { Falta de capacitação dos funcionários dificultou enquadramento da nova } \\
\text { realidade com o sistema }\end{array}$ \\
\hline & $\begin{array}{l}\text { Vínculo com empresa fornecedora do ERP criou forte dependência - alto custo } \\
\text { das atualizações das versões e das adaptações das customizações realizadas }\end{array}$ \\
\hline & $\begin{array}{l}\text { Necessidade constante de manutenção e aprimoramento demanda novos } \\
\text { desenvolvimentos no sistema ERP que exigem profissionais caros }\end{array}$ \\
\hline
\end{tabular}

FONTE: VALENTE, 2004. 
Quadro 11 - principais fatores críticos de sucesso em sistemas ERP de pequeno porte - Valente

\begin{tabular}{|c|c|}
\hline Autores (ano) & Fatores críticos de sucesso \\
\hline \multirow[t]{5}{*}{ Bancroft et al. (1998) } & Comprometimento da alta direção com o processo desde o início \\
\hline & $\begin{array}{l}\text { Conhecimento e comunicação dos benefícios e dificuldades dos sistemas para } \\
\text { todos os níveis }\end{array}$ \\
\hline & Entendimento de que será provavelmente necessário mudar a organização \\
\hline & Envolvimento dos usuários e obtenção de seu comprometimento \\
\hline & $\begin{array}{l}\text { Escolha de um líder de projeto que possua habilidades de negociação e } \\
\text { gerenciamento de projetos e experiência em realização de mudanças } \\
\text { organizacionais }\end{array}$ \\
\hline \multirow{7}{*}{$\begin{array}{l}\text { Mendes \& Escrivão } \\
\text { Filho (2002) }\end{array}$} & Mudança organizacional \\
\hline & Comprometimento dos usuários \\
\hline & Adequação e funcionalidades \\
\hline & Análise de processos \\
\hline & Profissionais com conhecimento técnico e de negócio \\
\hline & Comprometimento da alta direção \\
\hline & Treinamento \\
\hline
\end{tabular}

FONTE: VALENTE, 2004.

Quadro 12 - dificuldades de implementação de sistemas ERP em empresas de pequeno porte

\begin{tabular}{|l|l|}
\hline \multicolumn{1}{|c|}{ AUTORES } & \multicolumn{1}{c|}{ DIFICULDADES ENCONTRADAS } \\
\hline Valente (2004) & $\begin{array}{l}\text { Falta da qualidade profissional (conhecimento técnico) e comprometimento das } \\
\text { pessoas-chave nas implementações }\end{array}$ \\
\cline { 2 - 2 } & Falta de conhecimento prévio de contabilidade pelos usuários \\
\hline Chien et al. (2007) & Estimativas incorretas e incertezas de prazos e planejamento \\
\cline { 2 - 2 } & Falta de infra-estrutura de TI e falta de recursos humanos \\
\hline & \\
\hline & \\
\hline
\end{tabular}

\subsubsection{Em empresas de médio porte}

Semelhantes ao caso dos sistemas de custeio, também em relação aos sistemas ERP não há abundância de estudos específicos que tratem de dificuldades de implementação para empresas de médio porte. Apesar da utilização de termos que façam menção a esse porte de empresa, como: pequena e média empresa; médios e grandes portes, PME, small and medium sized, small and medium enterprise; SME, existem dois principais problemas encontrados. $\mathrm{O}$ primeiro é a utilização do termo "médio" quando estes não são efetivamente incluídos no estudo. Por exemplo, em situações como quando se utiliza o termo PME quando se quer referir a pequenas empresas, ou quando se exclui exatamente esse grupo, e utiliza-se a expressão: "médias e grandes empresas”, quando na realidade o grupo refere-se às grande empresas. O segundo problema é a delimitação do porte das empresas para o termo utilizado, 
quando ele destoa dos padrões normalmente utilizados, como estudos onde empresas com quase mil empregados são considerados como empresa média.

Mesmo assim, dentre os estudos analisados, há estudos que tratam especificamente de sistemas ERP em empresas de médio porte, como o de Sussmann (2005) e os estudos contidos no trabalho organizado por Souza \& Saccol (2008) de Escouto e Schilling (2008) e Ozaki e Vidal (2008). O trabalho de Mendes \& Escrivão Filho (2008), apesar de tratar de empresas de pequeno e médio porte, será incluído nesse tópico devido seu critério utilizado, de empresas com faturamento entre R \$ 8 milhões e R \$ 100 milhões, estar mais próximo dos critérios de médio porte da maioria das classificações. Iniciando por esses autores, eles fazem um levantamento das dificuldades apresentadas em alguns estudos, as quais constam do quadro a seguir:

Quadro 13 - dificuldades de implementação de sistemas ERP em empresas de médio porte

\begin{tabular}{|c|c|}
\hline AUTORES & DIFICULDADES ENCONTRADAS \\
\hline Lima et al. (2000) & Cálculo incorreto dos custos de implantação \\
\hline \multirow{3}{*}{$\begin{array}{lll}\begin{array}{l}\text { Souza } \\
(2000)\end{array} & \& & \text { Zwicker } \\
\end{array}$} & Atualização constante do sistema e gerenciamento de versões \\
\hline & $\begin{array}{l}\text { Adoção do ERP é um processo de mudança organizacional, com alterações de } \\
\text { tarefas e responsabilidades }\end{array}$ \\
\hline & Alteração de relação entre departamentos \\
\hline \multirow[t]{9}{*}{ Stamford (2000) } & Escala de reengenharia de processos \\
\hline & Tarefas de customização durante a implantação \\
\hline & Inexperiência da equipe de suporte \\
\hline & Implantação longa \\
\hline & Alto custo da consultoria e treinamento \\
\hline & Complexidade da customização \\
\hline & Benefícios não concretizados \\
\hline & Implantação e serviços associados custam até sete vez o valor do software \\
\hline & $\begin{array}{l}\text { Desencontro entre as práticas dos sistemas e das práticas específicas de um } \\
\text { segmento }\end{array}$ \\
\hline \multirow[t]{2}{*}{ Dempsey (1999) } & $\begin{array}{l}\text { Projeto amplo, que faz com que as empresas percam de vista as motivações } \\
\text { originais }\end{array}$ \\
\hline & Interface ruim com o usuário, que dificulta sua utilização \\
\hline \multirow[t]{4}{*}{ Wood Jr. (1999) } & Falta de envolvimento da alta direção \\
\hline & Planejamento inadequado \\
\hline & Baixa adequação entre o sistema e o contexto empresarial do país \\
\hline & Falta de suporte adequado \\
\hline \multirow[t]{3}{*}{ Taurion (1999) } & Interfaces para adaptação dos sistemas existentes \\
\hline & Planejamento de um projeto para essa adaptação \\
\hline & Projeto longo e caro \\
\hline
\end{tabular}

FONTE: MENDES; ESCRIVÃO FILHO, 2008

Junto com as dificuldades apresentadas pelos autores, Mendes \& Escrivão Filho (2008, p. 252) fazem algumas colocações, além das de outros autores como Taurion e Wood Jr., que apesar de serem apresentadas junto com as dificuldades, podem ser classificadas como fatores 
críticos de sucesso ou de importância para o sucesso das implementações. Dentre esses fatores, pode-se citar:

- $\quad$ o redesenho dos processos; as mudanças organizacionais;

- $\quad$ mudança de estrutura organizacional para estrutura baseada em processos;

- $\quad$ ajustes após implantação;

- $\quad$ interface com outros sistemas;

- $\quad$ perceber a amplitude e profundidade decorrente da implantação do ERP;

- $\quad$ analisar a estratégia da empresa e as necessidades de informação;

- $\quad$ equipe experiente e com bom conhecimento do negócio;

- $\quad$ realização da análise dos processos, que nem sempre é realizada;

- $\quad$ envolvimento de profissionais com conhecimento do negócio e objetivos da empresa;

- $\quad$ Previsão do tempo e custo da implantação;

- discussão de variáveis numéricas que afetam o custo como: preços dos sistemas, quantidade de módulos, números de licenças, quantidade de horas de consultoria, modificações, investimento em hardware e em treinamento.

Mendes \& Escrivão Filho (2008, p. 252) também mencionam algumas desvantagens apresentadas na pesquisa de Wood Jr., como: não atendimento das necessidades específicas dos negócios; perda de algumas funções essenciais dos negócios; visão superficial dos processos; dependência de um único fornecedor; excesso de controles; falta de envolvimento da alta direção; planejamento inadequado; perda de histórico durante a conversão; baixa adequação entre o sistema e o contexto empresarial do país; falta de suporte adequado. Dentre as desvantagens apresentadas, algumas parecem representar situações específicas para algumas empresas ou softwares, e a maioria pode ser classificada como dificuldades. Dessa forma, os itens relacionados à implementação de sistema também são apresentados no quadro de dificuldades. As dificuldades apontadas pela pesquisa de Mendes \& Escrivão Filho (2008, p. 258) são apresentadas no quadro de resumo das dificuldades (quadro xx). É importante citar a afirmação dos autores que, diferente do que eles encontraram na revisão de literatura, algumas dificuldades não foram citadas pelos entrevistados nos estudos práticos, como: documentação dos processos; regras de negócios definidas pelo sistema; empresa orientada a processos; criação de base tecnológica. Por outro lado, a maior dificuldade apresentada pelos entrevistados, que foi a resistência dos usuários, não foi encontrada na revisão realizada pelos autores. 
O estudo de Escouto \& Schilling (2008, p. 266), apesar de focar uma empresa de médio porte, não trata de dificuldades de implementação, mas apresenta uma metodologia para seleção de um sistema ERP, com suas etapas. As etapas, já mencionadas neste trabalho, são, segundo os autores, essenciais para o processo de escolha de um pacote de ERP. Apesar de não tratarem de dificuldades, eles apresentam, ao analisar cada etapa, alguns pontos importantes que podem ser úteis na seleção dos pacotes de sistemas ERP. No estudo de Sussmann (2004, p. 80), onde ele analisa 24 indústrias que têm entre 100 e 500 funcionários, consideradas por ele como de médio porte, a hipótese de resistência de funcionários ao uso do novo sistema é aceita. O motivo principal para essa resistência é a dificuldade de aprendizado, seguido de medo de perda de poder ou do emprego.

O estudo de Ozaki \& Vidal (2008, p. 285), por sua vez, analisa de forma um pouco mais ampla que os dois estudos anteriores, as dificuldades de implementação de sistemas ERP, utilizando estudo de caso em uma empresa de médio porte, com faturamento anual em torno de US\$ 40 milhões e com 70 funcionários. Eles apresentam em seu estudo pontos de preocupação segundo Laughlin, que são:

a) Não aderência do sistema aos processos da empresa;

b) Resistência organizacional pela não aceitação do sistema pelos membros da organização;

c) Tecnologia necessária para o processamento do sistema;

d) Integração com outros sistemas;

e) Migração de dados de sistemas anteriores.

Se considerar o critério de dificuldades e fatores críticos de sucesso, os dois primeiros itens podem ser considerados como dificuldades e os três seguintes podem ser considerados como fatores críticos de sucesso. Em seu estudo, os autores ainda citam algumas dificuldades adicionais decorrentes de porte da empresa, como "orçamento limitado e menos sujeito a revisões, ambiente familiar e não profissional, carência de pessoas qualificadas e experientes, entre muitas outras”. No caso estudado por Ozaki \& Vidal (2008, p. 298), as dificuldades encontradas foram: 
a) Excesso de customizações devido exigência da controladora multinacional para manter a uniformidade de gestão;

b) Alta rotatividade de funcionários, que ocasionou reciclagem completa dos usuários e contratação de consultores externos para treinamento;

c) Sobrecarga de função devido corte de pessoal e utilização temporária do sistema novo e do antigo concomitantemente;

d) Falta de capacitação dos funcionários;

e) Vínculo com a empresa fornecedora, especificamente em relação à necessidade de atualização da versão descontinuada;

f) Necessidade constante de manutenção e aprimoramento.

Quadro 14 - dificuldades encontradas na implementação de sistemas ERP em empresas de médio porte

\begin{tabular}{|c|c|}
\hline AUTORES & DIFICULDADES ENCONTRADAS \\
\hline \multirow[t]{16}{*}{$\begin{array}{l}\text { Mendes \& escrivão } \\
\text { Filho (2008) }\end{array}$} & $\begin{array}{l}\text { Custo alto na contratação de profissionais com experiência e com bons conhecimentos } \\
\text { sobre negócios }\end{array}$ \\
\hline & Dificuldade de adaptação ao novo sistema e processos \\
\hline & Planejamento de projeto inadequado \\
\hline & Insegurança dos funcionários em relação ao manuseio e utilização do sistema; \\
\hline & Falta de participação do fornecedor na seleção do hardware necessário \\
\hline & Alto custo para customizar e desenvolver relatórios \\
\hline & Perda do foco com aumento de custo e prazo \\
\hline & Dificuldade no atendimento pelo fornecedor (lento e inadequado) \\
\hline & Consultoria para acompanhamento do projeto cara \\
\hline & Resistência por parte dos funcionários \\
\hline & Adaptação às mudanças na rotina de trabalho \\
\hline & $\begin{array}{l}\text { Resistência da alta direção e dos funcionários mais antigos que não tem conhecimentos } \\
\text { básicos de informática }\end{array}$ \\
\hline & Funcionários sem qualificação técnica para dar suporte \\
\hline & Funcionários sem qualificação técnica para utilizar o sistema \\
\hline & Falta de confiabilidade nas informações extraídas do sistema \\
\hline & Encarar a implantação como projeto de mudança organizacional \\
\hline $\begin{array}{|lll|}\begin{array}{l}\text { Ozaki } \\
(2008)\end{array} & \& & \text { Vidal } \\
\end{array}$ & $\begin{array}{l}\text { Excesso de customizações devido exigência da controladora multinacional para manter } \\
\text { a uniformidade de gestão; } \\
\text { Alta rotatividade de funcionários, que ocasionou reciclagem completa dos usuários e } \\
\text { contratação de consultores externos para treinamento; } \\
\text { Sobrecarga de função devido corte de pessoal e utilização temporária do sistema novo } \\
\text { e do antigo concomitantemente; } \\
\text { Falta de capacitação dos funcionários; } \\
\text { Vínculo com a empresa fornecedora, especificamente em relação à necessidade de } \\
\text { atualização da versão descontinuada; } \\
\text { Necessidade constante de manutenção e aprimoramento. }\end{array}$ \\
\hline \multirow[t]{2}{*}{ Sussmann (2004) } & Resistência ao sistema devido dificuldade de aprendizado \\
\hline & Resistência ao sistema devido medo de perda de poder ou do emprego \\
\hline
\end{tabular}

\subsubsection{Em empresas de grande porte}


No seu estudo, Pereira (2002, p. 103), ao abordar a fase de implementação, cita alguns problemas e fatores importantes como: resistência interna ao sistema; necessidade de um plano de implementação; treinamento de usuários; conhecimento técnico dos funcionários; motivação dos funcionários. Ele também considera como premissa e cita os fatores críticos de sucesso de Bancroft, constantes no quadro 15.

Quadro 15 - fatores críticos de sucesso em implementações de sistemas ERP em empresas de grande porte

\begin{tabular}{|c|c|}
\hline Autores (ano) & Fatores críticos de sucesso \\
\hline \multirow[t]{4}{*}{ Pereira (2002) } & Necessidade de um plano de implementação \\
\hline & Treinamento de usuários \\
\hline & Conhecimento técnico dos funcionários \\
\hline & Motivação dos funcionários \\
\hline \multirow{9}{*}{$\begin{array}{ll}\text { Bancroft } & \text { Apud } \\
\text { Pereira (2002) }\end{array}$} & Entender a cultura da empresa em termos de sua capacidade para mudança e presteza \\
\hline & Iniciar as mudanças nos processos prioritários para a implementação \\
\hline & $\begin{array}{l}\text { Manter a comunicação contínua com todos os níveis hierárquicos de usuários, de } \\
\text { maneira compreensiva e não técnica, sobre o andamento e realizações do projeto }\end{array}$ \\
\hline & Ter apoio irrestrito dos altos executivos da instituição para o projeto \\
\hline & $\begin{array}{l}\text { Garantir que o gerente do projeto seja capaz de negociar igualmente em exigências } \\
\text { técnicas operacionais }\end{array}$ \\
\hline & $\begin{array}{l}\text { Escolher uma equipe equilibrada entre membros da tecnologia e das áreas de } \\
\text { negócios, além de dar-lhes papéis claramente definidos }\end{array}$ \\
\hline & $\begin{array}{l}\text { Selecionar uma boa metodologia para implementação do projeto, com medidas de } \\
\text { desempenho adequadas }\end{array}$ \\
\hline & $\begin{array}{l}\text { Treinar os usuários e dar-lhes o suporte necessário para as mudanças nos seus } \\
\text { trabalhos. Além disso, treinar a equipe de implementação é igualmente importante }\end{array}$ \\
\hline & $\begin{array}{l}\text { Estar pronto para o surgimento de problemas. Deve-se estar comprometido com a } \\
\text { mudança }\end{array}$ \\
\hline
\end{tabular}

Quadro 16 - dificuldades de implementação de sistemas ERP em empresas de grande porte

\begin{tabular}{|c|c|}
\hline AUTORES & DIFICULDADES ENCONTRADAS \\
\hline \multirow[t]{5}{*}{ Pereira (2002) } & Resistência interna ao sistema \\
\hline & Pacotes de ERP incompletos ou pouco robustos \\
\hline & Problemas de integração \\
\hline & Problemas de parametrização \\
\hline & Problemas de baixa performance do sistema \\
\hline \multirow{5}{*}{$\begin{array}{ll}\text { Krasner } & \text { apud } \\
\text { Pereira (2002) } & \end{array}$} & Falta de um plano integrado de desenvolvimento/implementação para as equipes \\
\hline & $\begin{array}{l}\text { Falha na comunicação entre os diversos níveis de usuários e entre as próprias equipes } \\
\text { de implementação }\end{array}$ \\
\hline & Processo de tomada de decisões mal estruturado ou inexistente \\
\hline & Ausência de um plano e administração de testes integrados \\
\hline & Não aplicação de conhecimentos adquiridos em implementações passadas \\
\hline
\end{tabular}

Souza \& Zwicker (2008, p. 95) listam algumas dificuldades na implantação de sistemas ERP observadas em estudo de casos de oito empresas de ramos diversos, por eles consideradas como de médio e grande porte, mas que neste estudo são classificadas como de grande porte, devido valores de seus faturamentos: 
a) resistência devido aumento de trabalho das áreas responsáveis pela entrada de dados;

b) resistência devido ao aumento da cobrança sobre as áreas responsáveis pela entrada de dados;

c) não-obtenção de redução de mão-de-obra nas áreas responsáveis pela entrada de dados;

d) dificuldades para suporte, principalmente nos momentos iniciais da operação em bigbang;

e) dificuldades na troca de conhecimento com consultores;

f) perda de funcionalidades existentes em sistemas anteriores;

g) excesso de telas e campos a serem digitados;

h) ausência de relatórios gerenciais e operacionais adequados;

i) necessidade de grande cuidado com cadastros que possam ser compartilhados entre as áreas;

j) excesso de dados no banco de dados, gerando problemas de performance.

No estudo de Vieira (2004), que comparou as dificuldades nas implantações de sistemas integrados de gestão (ERP) nas empresas de grande porte, com as dificuldades encontradas em quatro estudos de caso em empresas de pequeno e médio porte, os pontos coincidentes entre elas foram: "a resistência a mudanças; falta de treinamentos; dificuldade de assimilação das novas rotinas de trabalho cooperativas e integradas e dificuldades na obtenção de alterações e melhorias no sistema, além da complexidade de parametrização”. Ainda em seu estudo, ao verificar o quadro comparativo entre as dificuldades encontradas nos quatro estudos de caso, percebe-se uma grande incidência de fatores relativos à resistência à mudanças, como: resistência em descreverem suas rotinas, resistência quanto à utilização do novo sistema; falta de comprometimento de líderes, resistência em descontinuar o antigo sistema; entre outros aspectos comportamentais (Vieira, 2004, p.148).

Em todos os grupos analisados, sejam relacionados a sistemas de custos, ou a sistemas ERP, verifica-se a incidência constante de fatores relacionados aos indivíduos das organizações, seja em treinamentos ou em aspectos comportamentais, mas principalmente referente a resistências em adotar ou abandonar hábitos. Problemas como estes, relacionados aos usuários, são abordados no trabalho de Krasner (2000, p.23), no qual o autor apresenta os problemas de dificuldades de implantações de sistemas ERP em três grupos: problemas gerenciais, problemas de usuários e problemas técnicos. Tal categorização será novamente abordada adiante. 


\section{CATEGORIZAÇÃO}

\subsection{Dificuldades e Fatores Críticos}

Efetuado o levantamento das dificuldades de implementação de sistemas de custeio e de sistemas ERP, em empresas de pequeno, médio e grande porte, percebeu-se que, no decorrer da revisão, alguns autores não fazem distinção entre: dificuldades e pontos considerados relevantes para a implementação de sistemas, tratando-os muitas vezes com o mesmo sentido. Este tópico tem como principal objetivo consolidar os dados apurados para a realização de sua interpretação e análise, para uma adequada organização das informações. Sendo assim, quando os autores apresentam consolidadas num mesmo grupo, as dificuldades e os fatores críticos, estes serão considerados como distintos.

Apesar do foco principal deste trabalho referir-se às dificuldades de implementação, os fatores apresentados na literatura como importantes para a implementação também serão analisados. Este fato se justifica, pois, se os fatores são considerados como importantes, ou críticos para o sucesso da implementação, qualquer alteração que estes venham a sofrer podem causar dificuldades para a implementação. Além disso, em muitos casos, pela descrição do fator, pode-se supor que a dificuldade seja seu excesso ou insuficiência, como no caso de "treinamentos de usuários”, no qual se supõe que a dificuldades esteja relacionada com a sua insuficiência. Por outro lado, alguns itens não permitem essas suposições, como no caso do “tamanho da equipe do projeto”, com a qual a dificuldade pode estar relacionada tanto com uma equipe insuficiente como uma demasiadamente numerosa. Dessa forma, os itens que não puderam ter esses pontos esclarecidos pela literatura analisada, foram classificados como fatores críticos.

Sendo assim, as informações serão compiladas em grupos, iniciando-se com a divisão entre dificuldades e fatores críticos. O objetivo principal deste capítulo é de segregar as informações colhidas na revisão bibliográfica nesses dois grupos, para que o grupo de dificuldades, que é o foco deste trabalho, possa ter o devido tratamento para a construção do protocolo de pesquisa deste estudo. Na seqüência, dentro de cada grupo serão listados todos 
os fatores encontrados por porte de empresa, tanto para sistemas de custos como para sistemas ERP (figura 3).

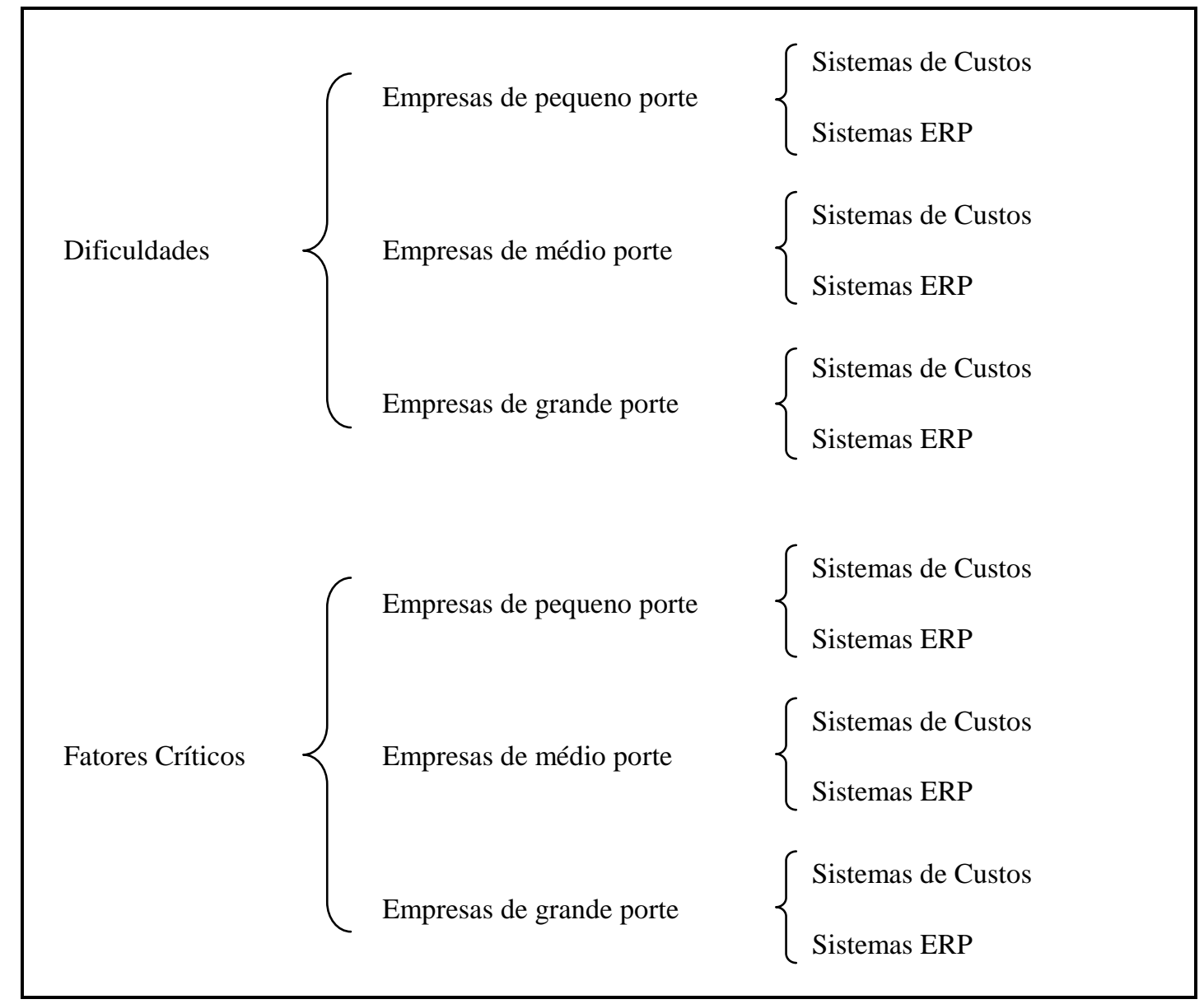

Figura 3 - Dificuldades e Fatores Críticos

Considerando que o objetivo básico deste capítulo é a classificação dos fatores encontrados nos grupos citados, e com o objetivo de tornar a leitura mais clara e compreensível, a listagem completa com a classificação de cada item é anexada à parte (apêndice 2), sendo apresentada somente a estrutura desta classificação.

\subsection{Comportamentais, Administrativas e Escassez de Recursos}

Analisando-se as dificuldades e os fatores críticos encontrados na literatura, listados no tópico anterior, percebe-se que muitos são semelhantes e que têm características similares. Dessa forma, decidiu-se realizar uma categorização dos itens, considerando-se essas características. 
Conforme visto anteriormente, estudos anteriores também apresentaram categorizações das dificuldades, como as de Gary Cokins, apresentada por Medeiros (1999, p.83), onde o autor classifica as causas do fracasso entre: interruptoras; rejeição do usuário; obstáculos da organização; e nocivas. Outra categorização é utilizada por Pompermayer (2007), onde ela apresenta um grupo de dificuldades e outro de facilitadores em relação a sistemas de custos. Encontra-se ainda a categorização apresentada por Krasner (2000, p.23), onde o autor classifica as dificuldades em gerenciais, de usuários e técnicos. As categorias desses estudos foram analisadas, mas não consideradas ou utilizadas da mesma forma neste estudo por não serem as categorias completamente excludentes e nem complementares.

Para definir a taxonomia utilizada, foram consideradas as naturezas das dificuldades apresentadas, sendo que essas origens foram divididas em três grupos: comportamentais, administrativas e de escassez de recursos. Para a determinação dos grupos também foi considerado que eles deveriam ser complementares e mutuamente excludentes. Por não ser a área de humanidades tão específica como as ciências exatas, os grupos não são completamente excludentes, podendo haver intersecções entre eles. Exemplo disso é a influência do comportamento na administração, assim como da responsabilidade da administração na escassez de recursos. As especificações de cada grupo serão apresentadas a seguir, para que haja uma melhor compreensão dos critérios que fazem parte de cada um deles. Dessa forma, as categorias que classificam as dificuldades são apresentadas da seguinte maneira:

- $\quad$ Comportamentais

- $\quad$ Administrativas

- $\quad$ Escassez de recursos

O primeiro grupo, das dificuldades que têm origens comportamentais, está relacionado a todo tipo de reações das pessoas dentro da empresa. O tema comportamento é muito amplo, e por não ser foco deste estudo, não será aprofundado. Para este trabalho considera-se que comportamento refere-se à interação entre o indivíduo e seu meio, sua forma de pensar e de agir. Dessa forma, nesse grupo estão inclusas as dificuldades que tem origem em fatores que se relacionam com esses aspectos. 
O segundo grupo considera as dificuldades de natureza administrativa. Neste grupo estão os fatores administrativos relacionados ao processo de gestão dos administradores das empresas. Como processo de gestão, considera-se o processo que envolve as atividades de planejamento, execução e controle dos gestores da organização. Dessa forma, os tópicos inseridos nesse grupo estão relacionados a decisões ligadas a uma dessas três fases, sejam ações no planejamento, na execução ou no controle. Em relação à influência do comportamento nessas fases da administração, esta não pode ser ignorada. Todavia, os itens classificados no grupo de fatores administrativos referem-se a ações e decisões que supostamente são realizadas de forma mais racional possível, com o mínimo de influência emocional e comportamental, como exemplo a estimativa de prazo para conclusão do projeto.

O terceiro grupo, que trata da escassez de recursos, aborda situações onde se identifica sua insuficiência, sejam eles recursos humanos, físicos, tecnológicos (do sistema) ou de conhecimentos específicos. Sendo assim, este grupo subdivide-se nessas quatro categorias. Quando se trata da escassez de recursos humanos, a insuficiência está referindo-se principalmente à quantidade de pessoas considerada necessária para o processo de implementação; em relação aos recursos físicos, este engloba toda e qualquer falta de equipamentos, infra-estrutura e outros bens materiais necessários ao processo; os recursos tecnológicos referem-se à incompatibilidade do sistema com os processos da empresa, ou à ausência de necessidades específicas da empresa que o sistema não apresenta; em relação à insuficiência de conhecimentos específicos, esta se refere a conhecimentos técnicos necessários para o processo de implementação. Sendo assim, o grupo de escassez de recursos fica dividido conforme a insuficiência de:
a) Recursos humanos (quantidade)
b) Recursos físicos
c) Recursos tecnológicos (ou do sistema) e de
d) Conhecimentos específicos

Não foi criado um grupo específico para recursos financeiros, visto que a sua falta ou insuficiência reflete nos demais grupos relacionados. Dessa forma, os itens encontrados que tratam de insuficiência financeira foram analisados para que pudessem ser relacionados aos seus respectivos grupos de escassez de recursos (humanos, físicos, de sistema ou de conhecimentos). Em casos onde os autores dos materiais pesquisados não fazem menção 
sobre qual o efeito da insuficiência financeira, sendo simplesmente afirmado: "falta de recursos financeiros”, o item não é classificado em nenhum grupo, sendo eliminado na lista.

Dessa forma, todas as dificuldades para implementação de sistemas de custeio encontradas foram classificadas de acordo com a taxionomia apresentada (comportamentais, administrativas e insuficiência de recursos). No caso das administrativas, esta foi novamente classificada em atividades de planejamento, execução e controle, e o terceiro grupo, o de escassez de recursos, novamente classificada de acordo com o tipo de insuficiência. (apêndice 3). Na divisão a seguir estão classificadas as dificuldades identificadas e apresentadas anteriormente de acordo com suas características e, quando necessário, acrescida dos respectivos comentários.

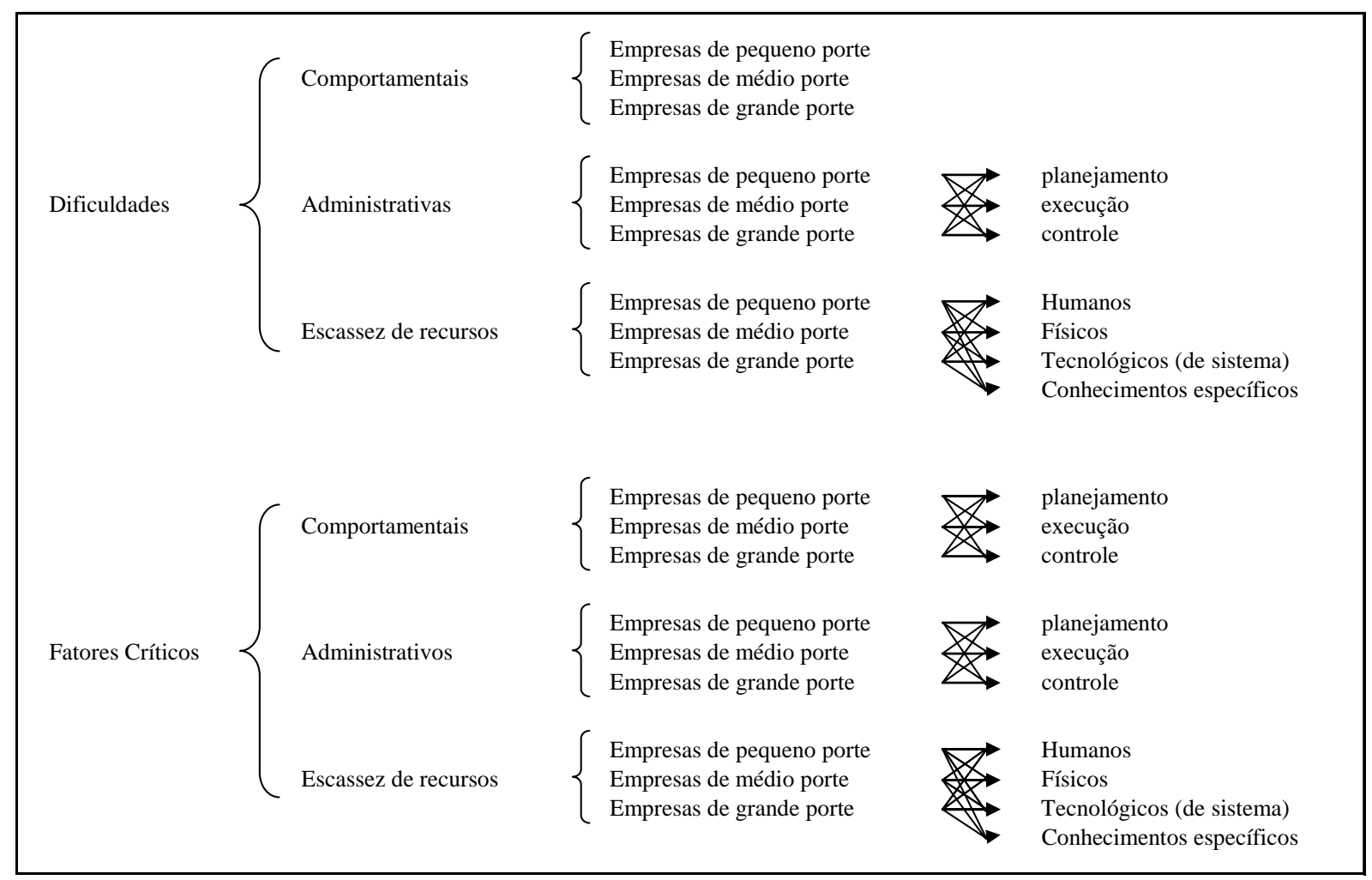

Figura 4 - Categorização das dificuldades e dos fatores críticos

\subsubsection{Dificuldades}




\subsubsection{Comportamentais}

Os fatores identificados na literatura que fazem parte desse grupo serão apresentados em grupos distintos de acordo com o porte da empresa. Nessa categorização não será feita distinção entre os fatores encontrados nas implementações de sistemas de custos e nos sistemas ERP.

\subsection{Nas empresas de pequeno porte}

a) Resistência dos funcionários para registrarem os dados de produção necessários para o funcionamento do sistema;

b) Resistência com relação à metodologia aplicada, que podem ser considerados instrumentos de controle e punição;

c) Resistência em descreverem suas rotinas;

d) Resistência dos sócios em expor a ineficiência da área sobre a qual é responsável;

Os três primeiros itens, os quais representam os receios das pessoas, são decorrentes da percepção de que as mudanças decorrentes da nova metodologia são formas de controlar suas atividades e conseqüentemente permitir uma punição pelas falhas evidenciadas. De forma semelhante, no item “d” foi identificada a resistência também por parte dos gestores, na figura dos sócios, por também haver a possibilidade de evidenciar a ineficiência das áreas sobre as quais eles têm responsabilidade. Para que resistências dessa natureza possam ser minimizadas, sugere-se a necessidade de que todos sejam bem informados sobre: os objetivos da implementação da nova metodologia; a possibilidade de que ineficiências sejam evidenciadas, mas que estas não terão fins punitivos, mas sim de melhorias.

e) Mudança organizacional decorrente do sistema;

Ao tratar de mudanças organizacionais, os autores referem-se a alterações nas tarefas e responsabilidades de indivíduos, departamentos e relações entre departamentos. Por se tratar de alterações que envolvem a interação do indivíduo com o meio e as suas ações, esse item está classificado no grupo dos fatores comportamentais. Assim como no item anterior, sugerese o esclarecimento das mudanças e alterações que devem ocorrer, assim como deixar explícito os objetivos de melhoria decorrentes das mudanças. 
f) Falta de comprometimento das pessoas-chave nas implementações;

g) Falta de comprometimento dos líderes;

Os dois itens anteriores são considerados no grupo de dificuldades comportamentais por refletirem ações em relação ao comprometimento das pessoas. Para estes itens também é sugerida a interação dos envolvidos no processo.

h) Resistência a mudanças;

i) Resistência quanto à utilização do novo sistema;

j) Resistência em descontinuar o antigo sistema;

Os três itens anteriores estão enquadrados no grupo de dificuldades comportamentais por ser a resistência relacionada ao comportamento das pessoas, assim como os primeiros tópicos apresentados nesta lista. A diferença entre eles é de que os primeiros têm origem no receio de controle, enquanto estes se referem à resistência a mudanças, principalmente em relação às atividades às quais já estão habituadas.

\subsection{Nas empresas de médio porte}

Como nas empresas de pequeno porte, várias dificuldades comportamentais encontradas em ambos os grupos são semelhantes, como a resistência dos funcionários ao uso do novo sistema, ou a falta de comprometimento dos líderes. Para poder minimizar os efeitos das dificuldades, seria necessário compreender os motivos e origens das dificuldades para que pudessem ser analisados e posteriormente sugerir soluções para estas dificuldades. Alguns itens permitem soluções simples, como no caso das dificuldades de aprendizado, que poderia ser resolvido com o fornecimento de treinamentos adequados.

Outros itens são mais complicados de se analisar, como a não aceitação do sistema pelos membros da organização, que podem ter diversas origens e que, para cada situação, exigiria 
uma respectiva solução. Este estudo não tem a intenção de aprofundar-se no estudo psicológico das origens, causas e soluções para os problemas comportamentais, sendo que as sugestões apresentadas são apenas possíveis soluções para os mesmos. Mesmo assim, o conhecimento das possíveis dificuldades por si só já é de grande valor, pois podem ser tomadas ações que minimizem suas incidências. Como no grupo anterior, cada item será analisado acompanhado dos respectivos comentários. Os itens pertencentes ao grupo de dificuldades comportamentais encontradas nas empresas de médio porte são:

a) Falta de envolvimento da alta direção;

O envolvimento da alta direção, que de forma semelhante também foi encontrado nas empresas de pequeno porte, no item de envolvimento dos líderes, é importante para que as pessoas envolvidas também se sintam comprometidas com o projeto, principalmente por envolver grandes mudanças organizacionais.

b) Não aceitação do sistema pelos membros da organização;

c) Resistência do usuário ao uso do novo sistema;

d) Resistência da alta direção e dos funcionários mais antigos que não tem conhecimentos básicos de informática;

Esses três itens referem-se à resistência dos usuários, também presente nas empresas de pequeno porte, sendo que os dois primeiros, conforme citado, podem ter diversos motivos e origens. Uma forma de minimizar essa resistência é a compreensão do que gerou a necessidade de utilização do sistema e quais os benefícios que podem dele advir, fazendo com que aumente o comprometimento desses usuários. Em relação ao terceiro item, o fornecimento de treinamento adequado pode minimizar a resistência. A mesma solução pode ser utilizada para os próximos quatro tópicos.

e) Dificuldades de aprendizado;

f) Insegurança dos funcionários em relação ao manuseio e utilização do sistema;

g) Dificuldade de adaptação ao novo sistema e processos;

h) Adaptação às mudanças na rotina de trabalho; 
Em relação aos dois últimos, além do treinamento, é necessário que as atividades sejam executadas durante determinado período, até que se tornem hábitos para as pessoas envolvidas.

i) Medo de perda de poder;

j) Medo de perder o emprego.

Os dois tópicos anteriores são exemplos dos itens que são mais complexos para identificar as origens e soluções. Os medos citados podem ter diversas causas, e estas devem ser analisadas para que se encontrem as medidas mais adequadas a cada situação, para que essas dificuldades também possam ser minimizadas. Podem também ser infundadas, ou não ter justificativas reais, situação a qual exige novamente um esclarecimento dos motivos e expectativas do projeto.

\subsection{Nas empresas de grande porte}

As dificuldades comportamentais encontradas nas empresas de grande porte são as seguintes:

a) Resistência interna ao uso do sistema;

b) Resistência devido ao aumento de trabalho das áreas responsáveis pela entrada de dados;

c) Resistência devido ao aumento da cobrança sobre as áreas responsáveis pela entrada de dados;

d) Resistência à mudança dentro da estrutura organizacional de custos;

e) Resistência à mudança pelos usuários (gerentes), assim como pelos produtores de informação (contadores);

Assim como no caso de pequenas e médias empresas, a resistência é um fator apresentado diversas vezes. Todos os itens mencionados estão relacionados à resistência, sejam elas ao uso do novo sistema ou às mudanças que podem ocorrer. No caso da resistência ao uso do sistema, duas causas identificadas foram o aumento de trabalho e o aumento de cobrança. Em relação à resistência à mudança, percebe-se que ambos os casos referem-se às alterações em 
situações já conhecidas por situações novas. É preciso compreender as causas de tais resistências para que possam ser analisadas soluções para cada uma delas.

f) Falta de apoio de funcionários;

g) Falta de apoio gerencial;

h) Perda do envolvimento das gerências, especialmente da alta;

Os três itens mencionados estão relacionados com o envolvimento das pessoas. Nesses casos, é necessário saber como se obtém o apoio e envolvimento das pessoas em projetos, para então aplicar nas empresas.

i) Alta centralização das decisões;

j) Fraca liderança no projeto do sistema;

k) Dificuldades na troca de conhecimento com consultores;

l) Irritação dos empregados com a complexidade da implementação;

m) Necessidade de mudança de perspectiva ou ponto de vista.

Os comportamentos mencionados estão relacionados diretamente com a personalidade das pessoas, dificultando a identificação de possíveis causas e respectivas ações. Os dois últimos itens, inclusive, apesar de serem apresentados como dificuldades, podem ser considerados como conseqüências e soluções (itens l e m). Como o objetivo deste estudo é apresentar as dificuldades encontradas na literatura, as causas, conseqüências e soluções para os itens citados não serão analisadas.

Dois itens mencionados que estão relacionados a este grupo são: a) projeto considerado um delírio e b) reputação de que o sistema é dispendioso de manter ou é uma ferramenta errada. Esses dois itens não foram apresentados como dificuldades diretamente, pois representam uma opinião dos usuários. Por outro lado, a existência dessas opiniões pode gerar a falta de apoio, que é uma característica comportamental.

\subsubsection{Administrativas}


A segunda categoria utilizada para classificar as dificuldades refere-se a decisões e problemas administrativos. Conforme citado anteriormente, os itens pertencentes a este grupo referem-se ao processo de planejamento, execução e controle de atividades das empresas. É importante salientar que, apesar do grupo anterior, que trata de problemas comportamentais, ter relação com a execução de atividades, há uma diferença entre os dois grupos. O primeiro basicamente se refere a executar atividades cumprindo ordens, ou seja, atividades de cunho operacional. Quando se trata de execução neste segundo grupo, de natureza administrativa, trata-se de colocar em prática o planejamento existente, ou realizar atividades de cunho gerencial, como por exemplo, a comunicação inadequada dos objetivos esperados com a implementação do sistema.

Como poderá ser verificado adiante, um fato que chama atenção é que grande parte dos problemas e dificuldades relacionados a este grupo está diretamente ligada à etapa de planejamento. Tal fato é compreensível por entender que um planejamento inadequado ou inexistente traz como conseqüências problemas na execução de atividades e respectivos controles. Assim como nas dificuldades comportamentais, os tópicos relacionados à administração foram separados em grupos de acordo com o porte da empresa, iniciando-se com as empresas de pequeno porte.

\subsection{Nas empresas de pequeno porte}

Como no grupo de fatores administrativos estão inclusas aqueles relacionados às fases de planejamento, execução e controle, inicialmente nas dificuldades encontradas nas empresas de pequeno porte será feito um agrupamento das dificuldades relacionadas à fase de planejamento administrativo, como por exemplo:
a) Estimativas de prazos incorretos;
b) Planejamento inadequado da implantação;
c) Ausência de um plano e administração de testes integrados;
d) Falta de plano integrado de implementação para as equipes;
e) Processo de tomada de decisão mal estruturado ou inexistente;
f) Sobrecarga de funções; 
Percebe-se que os itens mencionados estão ligados diretamente ao processo de planejamento dentro de uma administração, podendo considerar que, para enfrentar essas dificuldades é necessário que haja um planejamento adequado.

Os tópicos a seguir estão relacionados com a execução das atividades e cumprimento do planejamento administrativo.

g) Falta de credibilidade das informações de consumo de materiais, despesas e custos indiretos de fabricação;

h) Falta de confiabilidade dos direcionadores;

Nesses dois itens apresentados a administração deve garantir que as informações coletadas sejam confiáveis e condizentes com a realidade, assim como certificar-se de que os direcionadores são os mais adequados possíveis.

i) Falha na comunicação entre os diversos níveis de usuários e entre equipes;

j) Não aplicação de conhecimentos adquiridos em implementações passadas;

k) Práticas administrativas impostas pela controladora geraram muitas customizações e desenvolvimentos específicos no sistema ERP;

l) Falta de treinamentos;

m) Alta rotatividade de pessoas chaves dos projetos;

n) Dificuldade de assimilação de novas rotinas de trabalho cooperativas e integradas;

Nos itens citados a administração deve garantir e dar condições para que as dificuldades encontradas sejam minimizadas ou eliminadas.

Em relação à fase de controle da administração, foi citada a dificuldade a seguir, que na situação analisada pelos autores, apresentou-se como barreira na implementação do sistema de custos.

o) Falta de controles internos básicos, como de estoques e financeiros.

\subsection{Nas empresas de médio porte}


Da mesma forma que no item anterior, as dificuldades relacionadas a problemas administrativos serão apresentadas inicialmente os tópicos relacionados com a etapa de planejamento. Todas essas dificuldades apresentadas pelos autores podem ser minimizadas com um adequado planejamento da implementação, que pudesse prever ou considerar diversos problemas enfrentados.

a) Planejamento de projeto inadequado;

b) Planejamento de um projeto para adaptação com sistemas existentes;

c) Projeto amplo, que faz com que as empresas percam de vista as motivações originais;

d) Cálculo incorreto dos custos de implantação;

e) Implantação e serviços associados custam até sete vezes o valor do software;

f) Orçamento limitado e menos sujeito a revisões;

g) Visão superficial dos processos;

h) Não aderência do sistema aos processos da empresa;

i) Falta de participação do fornecedor na seleção do hardware necessário;

j) Utilização temporária do sistema novo e do antigo concomitantemente;

Todos os itens acima deveriam ser muito bem analisados antes da implantação, para que os problemas pudessem ser evitados minimizados. São de responsabilidade dos gestores o correto planejamento e a identificação das necessidades para o sucesso do projeto. A seguir, são apresentadas as dificuldades relacionadas à fase de execução das atividades, que deveriam ser realizadas de acordo com o planejamento dos gestores, ou ações que não deveriam ser tomadas por eles.

k) Alteração nas tarefas e responsabilidades dos indivíduos;

l) Alteração de relação entre departamentos;

m) Perda de histórico durante a conversão;

n) Sobrecarga de função devido corte de pessoal;

o) Perda do foco com aumento de custo e prazo;

p) Excesso de controles;

q) Implantação longa;

r) Falta de confiabilidade nas informações extraídas do sistema; 
Apesar do último item, poder ser confundido como uma deficiência ou falha do sistema, e portando de recursos tecnológicos, o motivo da falta de confiabilidade está relacionado à inserção dos dados e da forma como são organizados. Dessa forma, o item está classificado no grupo de problemas relacionados à administração, especificamente na fase de execução.

s) Ambiente familiar e não profissional;

A situação anterior está enquadrada no grupo de dificuldades administrativas por estar relacionado à administração da empresa, da qual se espera uma especialização adequada e profissional.

t) Alta rotatividade de funcionários.

Este item, também encontrado na relação das empresas de outros portes, refere-se a problemas administrativos por estar relacionado à gestão de recursos humanos inadequado.

\subsection{Nas empresas de grande porte}

Assim como nos grupos anteriores, as dificuldades de cunho administrativo encontradas nas grandes empresas foram divididas entre problemas relacionados às fases de planejamento, execução e controle.

Planejamento:

a) Sub-avaliação da resistência dos empregados;

b) Sistema compete com outros sistemas já existentes;

c) Falta de um plano integrado de desenvolvimento/implementação para as equipes;

d) Processo de tomada de decisões mal estruturado ou inexistente;

Em relação aos problemas de cunho administrativo relacionados à fase de execução, podemse citar:

e) Atividades incongruentes com os direcionadores de custos; 
f) Necessidade de grande cuidado com cadastros que possam ser compartilhados entre as áreas;

g) Tempo consumido;

h) Dificuldade para identificar direcionadores de custos;

i) Treinamento inadequado;

j) Não aplicação de conhecimentos adquiridos em implementações passadas;

k) Falha na comunicação entre os diversos níveis de usuários;

l) Falta de disponibilidade de dados;

m) Lentidão na comunicação interna;

n) Falta de medidas anteriores de performance.

\subsubsection{Escassez de Recursos}

Conforme comentado, o grupo apresentado para classificar as dificuldades relacionadas com a escassez de recursos é subdividido em outras quatro categorias, que também pretendem ser excludentes e exaustivas, sendo elas:

- $\quad$ Recursos humanos (quantidade)

- $\quad$ Recursos físicos

- $\quad$ Recursos tecnológicos (ou do sistema) e de

- $\quad$ Conhecimentos específicos

Dessa forma, os itens pertencentes a este grupo são apresentados de acordo com o porte da empresa e também segundo a classificação do tipo de escassez.

\subsection{Em empresas de pequeno porte}

- $\quad$ Recursos humanos (quantidade)

a) Falta de recursos humanos;

b) Custo alto para coleta e processamento de dados necessários e na forma correta. 
Os dois itens referentes à escassez de recursos humanos encontrados nas empresas de pequeno porte são dificuldades que basicamente podem ser solucionados com a obtenção de mais pessoas na organização. Conforme definido, como nos casos onde há referência a recursos financeiros, estes são classificados de acordo com a conseqüência desta insuficiência. No caso do item “b”, isso resulta na insuficiência de recursos humanos para a adequada coleta de informações.

- $\quad$ Recursos físicos

a) Falta de recursos técnicos;

b) Falta de adequados recursos de TI;

c) Falta de infra-estrutura de TI.

No grupo de recursos físicos, percebe-se que as dificuldades estão basicamente relacionadas à infra-estrutura adequada de TI - Tecnologia de Informação. Dessa forma, faz-se necessário que, antes da implementação dos sistemas, seja feito um estudo que identifique todas as exigências de recursos físicos, principalmente em relação à infra-estrutura.

- $\quad$ Recursos tecnológicos (ou do sistema)

a) Pacotes incompletos ou pouco robustos;

b) Problemas de integração;

c) Problemas de baixa performance do sistema;

d) Dificuldades na obtenção de alterações e melhorias no sistema;

e) Investimento alto para melhorias do sistema (customizações);

f) Alto custo das atualizações das versões e das adaptações das customizações realizadas.

A maioria das dificuldades encontradas neste grupo são relacionados à adequações necessárias no sistema para que este atenda às exigências e expectativas das empresas. Como serão apresentados adiante, esses problemas são os mesmos encontrados nos demais portes de empresas.

Como sugestões para as dificuldades encontradas podem-se citar: I) na fase de escolha do sistema, é preciso que se analise, inclusive utilizando-se de consultoria se necessário, as 
opções disponíveis de sistemas, em todos os aspectos e no máximo detalhamento possível. Dessa forma, será possível verificar: qual nível de dificuldade para a integração com sistemas anteriores; quais modificações serão necessárias para adequação à empresa; se o sistema atende às necessidades da empresa. II) Escolher um sistema que consiga atender aos quesitos anteriores com o mínimo de customizações possível.

Os dois últimos itens fazem parte do grupo de itens que, ao invés de serem classificados em um novo grupo de escassez de recursos financeiros, foi classificado de acordo com sua conseqüência, que no caso é a deficiência nos recursos tecnológicos ou do sistema.

- $\quad$ Conhecimentos específicos

a) Dificuldade de transição para novos sistemas;

b) Falta de pessoas especializadas;

c) Problemas de parametrização;

d) Complexidade de parametrização;

e) Equipe experiente para conduzir a implantação;

f) Necessidade de consultoria externa para treinamento;

g) Falta de capacitação dos funcionários;

h) Falta de conhecimento prévio de contabilidade pelos usuários.

Em relação ao grupo de conhecimentos específicos, as dificuldades encontradas não estão relacionadas a uma área específica, pois podem referir-se a conhecimentos para utilização do sistema, conhecimentos técnicos para a implementação, experiências anteriores em projetos semelhantes, entre outros. Ao analisar os itens encontrados deste grupo nas empresas de pequeno porte, verifica-se que basicamente os problemas estão relacionados à conhecimentos técnicos necessários à implantação, assim como conhecimentos necessários aos usuários. No primeiro item, podem ser apresentadas três soluções para suprir essa carência: escolha de empresa fornecedora que tenha equipe capacitada; desenvolvimento ou contratação de pessoas internas da organização; contratação de consultoria externa com os conhecimentos necessários. No segundo item, que trata dos conhecimentos dos usuários, uma das possíveis soluções é um treinamento que os habilite à adequada utilização do sistema. 
Considerando dois grupos das dificuldades, quais sejam: o relacionado a fatores administrativos, especificamente na fase de execução; e o grupo de escassez de recursos, relacionados a conhecimentos específicos; pode-se dizer que há uma grande proximidade entre eles. Isso se deve ao fato de que, para que os gestores possam executar o planejado de forma apropriada, às vezes é necessário que haja conhecimentos específicos para sua execução.

Dessa forma, pode-se considerar que, caso não haja o conhecimento e não a ação não possa ser executada, este seria um problema do grupo de escassez de recursos de conhecimentos específicos. Por outro lado, caso o gestor tenha o conhecimento necessário, e não há a execução ou esta não é a apropriada, a dificuldade enquadra-se no grupo de dificuldades administrativas na fase de execução.

\subsubsection{2 $\quad$ Em empresas de médio porte}

Nas empresas de médio porte, as dificuldades vinculadas com escassez de recursos estão relacionadas principalmente com recursos tecnológicos ou com conhecimentos específicos. Não houve nenhum item relacionado com insuficiência quantitativa de recursos humanos ou de recursos físicos. Dessa forma, os itens apresentados relacionados com recursos tecnológicos e conhecimentos específicos foram:

- $\quad$ recursos tecnológicos

a) Necessidade de atualização constante do sistema e gerenciamento de versões;

b) Desencontro entre as práticas dos sistemas e das práticas específicas de um segmento;

c) Interface ruim com o usuário, que dificulta sua utilização;

d) Baixa adequação entre o sistema e o contexto empresarial do país;

e) Interfaces necessárias para adaptação dos sistemas existentes;

f) Perda de algumas funções essenciais dos negócios;

g) Excesso de customizações;

h) Vínculo com a empresa fornecedora, especificamente em relação à necessidade de atualização da versão descontinuada;

i) Alto custo das customizações; 
j) Dificuldade no atendimento pelo fornecedor (lento e inadequado).

Assim como nas empresas de pequeno porte, a maioria das dificuldades de escassez de recursos relacionada a recursos tecnológicos do sistema está relacionada principalmente aos entraves encontrados na adequação do sistema com as necessidades das organizações, em relação à integração com sistemas anteriores, customizações e retorno na utilização. Possíveis soluções apresentadas para as empresas de pequeno porte também podem servir para estas empresas.

- $\quad$ conhecimentos específicos

a) Tarefas de customização durante a implantação;

b) Inexperiência da equipe de suporte;

c) Alto custo da consultoria e treinamento;

d) Complexidade da customização;

e) Falta de suporte adequado;

f) Dependência de um único fornecedor;

g) Carência de pessoas qualificadas e experientes;

h) Falta de capacitação dos funcionários;

i) Necessidade constante de manutenção e aprimoramento;

j) Custo alto na contratação de profissionais com experiência e com bons conhecimentos sobre negócios;

k) Consultoria para acompanhamento do projeto cara;

l) Funcionários sem qualificação técnica para dar suporte;

m) Funcionários sem qualificação técnica para utilizar o sistema.

Este grupo também apresenta semelhanças com as empresas de pequeno porte, onde a maioria das limitações refere-se principalmente a conhecimentos técnicos na implantação do software e na utilização do sistema. Pela incidência de problemas relacionados a esses dois assuntos, percebe-se a importância e atenção que lhes deve ser atribuída no início do projeto de implantação dos sistemas.

\subsection{Em empresas de grande porte}


Nas empresas de grande porte, assim como nas de médio, as dificuldades apresentadas vinculadas à escassez de recursos estão relacionadas principalmente com recursos tecnológicos e de conhecimentos específicos. As dificuldades encontradas que são relacionadas com a escassez de recursos humanos e físicos são muito genéricos, não indicando nenhuma conclusão específica.

- $\quad$ Recursos humanos

Alto volume de trabalho envolvido na instalação.

- $\quad$ Recursos físicos

Escassez de recursos computacionais.

- $\quad$ Recursos tecnológicos (ou do sistema)

a) Sistema de contabilidade inadequado;

b) Sistema não provê todas as informações necessárias às decisões em relação aos produtos e clientes;

c) Escopo do sistema restringe-se aos custos operacionais, não a cadeia de valores;

d) Pacotes de ERP incompletos ou pouco robustos;

e) Problemas de integração;

f) Problemas de baixa performance do sistema;

g) Perda de funcionalidades existentes em sistemas anteriores;

h) Excesso de telas e campos a serem digitados;

i) Excesso de dados no banco de dados, gerando problemas de performance.

Diferente do grupo de empresas pequenas e médias, nas empresas de grande porte não foram citados muitos problemas relacionados a customizações e às necessidades das empresas, ficando as dificuldades ligadas principalmente em relação às informações que podem ser obtidas pelo sistema.

- $\quad$ conhecimentos específicos 
a) Elevado custo de consultoria;

b) Conhecimento técnico inadequado ou insuficiente;

c) Problemas técnicos associados à metodologia de custeio;

d) Falta de adequados recursos da equipe de contadores;

e) Falta de pessoal competente em gestão de custos;

f) Problemas de parametrização;

g) Dificuldades para suporte, principalmente nos momentos iniciais da operação.

Em relação às dificuldades enfrentadas pelas empresas de grande porte ligadas à escassez de recursos de conhecimentos específicos, estas não diferem das empresas de outros portes, apresentando conhecimentos necessários à fase de implantação dos sistemas e para a operação dos sistemas.

Além dos itens apresentados nos grupos acima, foram encontrados na literatura itens referentes escassez de recursos, mas que não se enquadram em nenhuma das categorias listadas de recursos humanos, físicos, tecnológicos ou de conhecimentos específicos. Esses itens que tratam de escassez de recursos em geral são os seguintes:

a) Altos custos da implementação;

b) Existência de prioridades mais importantes para alocação dos recursos.

O item anterior está no grupo de escassez de recursos, por este ser deslocado da implementação do sistema para outros fins. Porém como não foi especificada qual a prioridade, não pôde ser categorizada entre os subgrupos de recursos humanos, físicos, tecnológicos ou de conhecimentos específicos.

\subsubsection{Fatores críticos}

Assim como as dificuldades, os fatores críticos apurados são classificados conforme a taxionomia apresentada a seguir, entre fatores críticos de natureza comportamental, administrativa e de escassez de recursos. O primeiro grupo, dos fatores críticos de natureza comportamental é apresentado em subgrupos de acordo com o que foi encontrado em empresas de pequeno, médio e grande porte. O segundo grupo, de natureza administrativa, 
além de ter os fatores críticos classificados de acordo com o porte da empresa, apresenta-os agrupados de acordo com a fase de planejamento, execução ou controle. No caso dos fatores críticos relacionados com a escassez de recursos, estes também são apresentados em outros grupos além do porte da empresa, e que determinam o tipo de recursos em escassez: humanos, físicos, tecnológicos e de conhecimentos específicos. Dessa forma, a apresentação dos fatores críticos encontrados na literatura é realizada da seguinte forma:

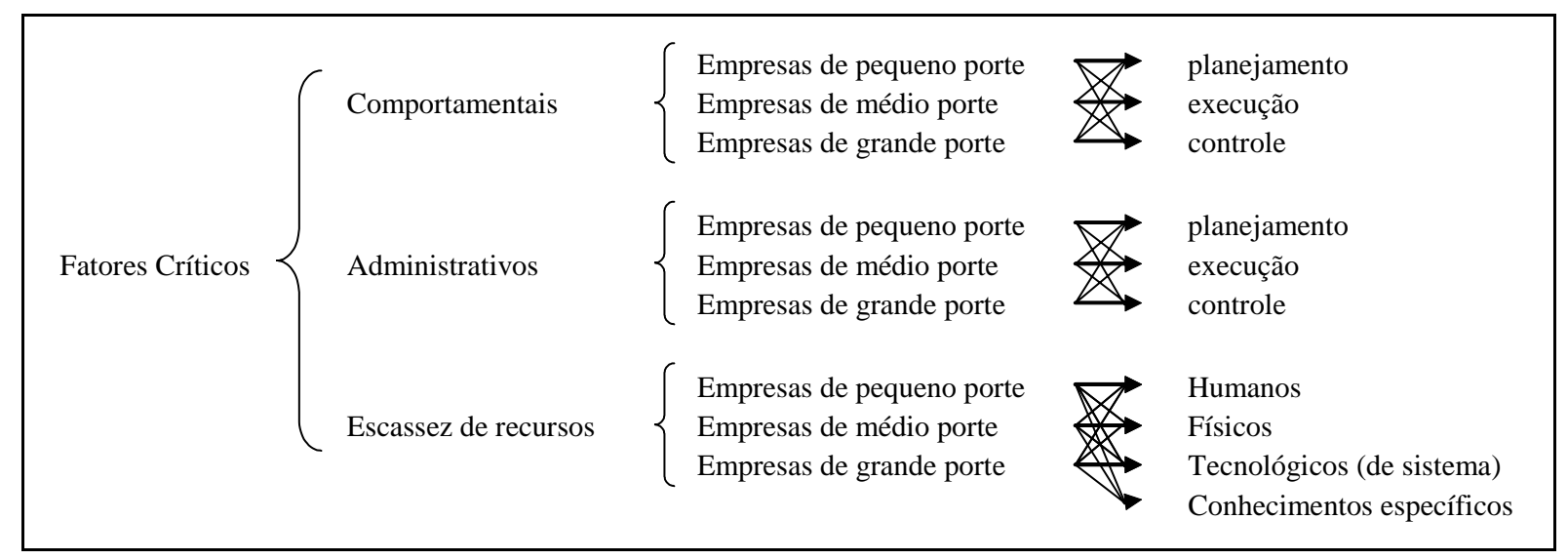

Diferente do grupo de dificuldades anteriormente apresentado, que se refere ao tema foco deste estudo, o grupo de fatores críticos à implantação de sistemas não será analisado e comentado a cada subgrupo, sendo apenas classificado de acordo com a estrutura apresentada. Apesar de não serem analisados individualmente, os fatores listados a seguir devem ser considerados na implantação de sistemas, devido sua importância. Além disso, podem ser analisados em conjunto com as dificuldades anteriormente apresentadas, por terem a mesma estrutura de categorização.

\subsubsection{Comportamentais}

Iniciando pelos fatores de natureza comportamental, considerados importantes na implementação de sistemas de custos, estes foram agrupados de acordo com o porte da empresa.

\subsection{Nas empresas de pequeno porte}

a) Apoio dos sócios; 
b) Ter o apoio e crença no valor do projeto por parte dos administradores;

c) Entendimento de que será provavelmente necessário mudar a organização;

d) Envolvimento dos usuários e obtenção de seu comprometimento;

e) Mudança organizacional originada pela implementação do sistema;

f) Comprometimento dos usuários;

g) Comprometimento da alta direção.

\subsection{Nas empresas de médio porte}

a) Envolvimento de profissionais com conhecimento do negócio e objetivos da empresa.

\subsection{Nas empresas de grande porte}

a) Centralização de poder;

b) Responsabilidade do trabalhador na coleta dos dados;

c) Satisfação dos empregados;

d) Apoio da alta gerência;

e) Comprometimento do funcionário com a organização;

f) Percepção da necessidade de mudança;

g) Competição interna;

h) Disposição dos funcionários para mudanças;

i) Total envolvimento dos funcionários;

j) Motivação dos funcionários;

k) Apoio irrestrito dos altos executivos da instituição para o projeto;

l) Comprometido com a mudança;

m) Resistência a mudanças.

\subsubsection{Administrativas}

\subsection{Nas empresas de pequeno porte}


- $\quad$ Planejamento

a) Importância da informação sobre custos atribuída pela gestão;

b) O grau de variedade dos produtos;

c) Haver um sistema anterior de informação implementado;

d) Definir os objetivos do sistema e quais as informações necessárias para atingir esses objetivos;

e) Ter uma equipe multidisciplinar (engenharia, produção e contabilidade);

f) Tamanho da equipe do projeto;

g) Características da estrutura de incentivos;

h) Escolha de um líder de projeto que possua habilidades de negociação e gerenciamento de projetos e experiência em realização de mudanças organizacionais;

i) Análise de processos da empresa.

- $\quad$ Execução

a) Preparar e envolver os empregados;

b) Conhecimento e comunicação dos benefícios e dificuldades dos sistemas para todos os níveis;

c) Treinamento dos usuários.

- Controle

a) Constatar as vantagens e as desvantagens da implantação.

\subsection{Nas empresas de médio porte}

- $\quad$ Planejamento

a) O redesenho dos processos;

b) Mudança de estrutura organizacional para estrutura baseada em processos; 
c) Perceber a amplitude e profundidade decorrente da implantação do ERP;

d) Analisar a estratégia da empresa e as necessidades de informação;

e) Realização da análise dos processos;

f) Previsão do tempo e custo da implantação;

g) Discussão de variáveis numéricas que afetam o custo como: preços dos sistemas, quantidade de módulos, números de licenças, quantidade de horas de consultoria, modificações, investimento em hardware e em treinamento.

Não houve nas empresas de médio porte fatores críticos de natureza administrativa relacionados com as fases de execução e controle.

\subsection{Nas empresas de grande porte}

- $\quad$ Planejamento

a) Definição de qual modelo de sistema de custeio é o mais adequado e que será utilizado;

b) Qual o nível de detalhamento que será necessário;

c) Diversidades de produtos;

d) Custos para contabilização;

e) Adequação de recursos necessários;

f) Informações decorrentes do sistema para decisões dos gerentes;

g) Compatibilidade com a estratégia da empresa;

h) Interação entre os setores das empresas;

i) Necessidade de um plano de implementação;

j) Compreensão da cultura da empresa em termos de sua capacidade para mudança e presteza;

k) Definição de responsabilidades.

- $\quad$ Execução

a) Comunicação interna;

b) Falta de clareza de objetivos; 
c) Ligação com avaliação e recompensa de performance;

d) Treinamento dos usuários;

e) Existência de comunicação inter e intra departamental;

f) Iniciar as mudanças com os processos prioritários para a implementação;

g) Manter a comunicação contínua com todos os níveis hierárquicos de usuários, de maneira compreensiva e não técnica, sobre o andamento e realizações do projeto;

h) Equipe equilibrada entre membros da tecnologia e das áreas de negócios;

i) Suporte aos usuários nas mudanças em seus trabalhos;

j) Obtenção de alterações e melhorias no sistema.

- Controle

Não foram citados fatores relacionados a controle nas empresas de grande porte.

\subsubsection{Escassez de Recursos}

\subsection{Nas empresas de pequeno porte}

- $\quad$ Recursos tecnológicos (ou do sistema)

a) Ter cálculos simples;

b) Sistema deve ser flexível e dinâmico;

c) Modelo de sistema que não necessite de alto investimento na coleta de dados;

d) Modelo de sistema que não necessite de uma séria reestruturação organizacional;

e) Adequação do sistema à empresa e funcionalidades disponíveis.

- $\quad$ Conhecimentos específicos

a) Haver alguém com experiência em implantação de sistemas ou obter auxílio externo;

b) Experiência do líder de projeto;

c) Profissionais com conhecimento técnico e de negócio; 


\subsection{Nas empresas de médio porte}

- $\quad$ Recursos físicos

a) Tecnologia necessária para o processamento do sistema.

- $\quad$ Recursos tecnológicos (ou do sistema)

a) Interface com outros sistemas;

b) Migração de dados de sistemas anteriores.

- $\quad$ Conhecimentos específicos

a) Ajustes após a implementação;

b) Equipe experiente e com bom conhecimento do negócio.

\subsection{Nas empresas de grande porte}

- $\quad$ Recursos tecnológicos

a) Complexidade do sistema para usuários;

b) Compatibilidade com sistemas existentes;

c) Melhora sobre sistema existente.

- $\quad$ Conhecimentos específicos

a) Especialização dos funcionários;

b) Conhecimento do processo;

c) Conhecimento técnico dos funcionários;

d) Capacidade de negociação sobre aspectos técnicos do gerente do projeto;

e) Assimilação das novas rotinas de trabalho cooperativas e integradas; 
f) Complexidade de parametrização.

Uma observação importante que deve ser apresentada é de que, dentre os fatores considerados críticos ou importantes encontrados na literatura, alguns não apresentaram características para serem classificadas nos grupos de fatores comportamentais, administrativos ou de escassez de recursos. Esses itens estão mais relacionados com o ambiente no qual a empresa está inserida, apresentando assim características contingenciais. Dessa forma, itens apresentados como fatores determinantes que não se encaixam aos grupos anteriormente apresentados são:

a) Incerteza ambiental;

b) Localização (ambiente econômico e social);

c) Porte da empresa ou tamanho da firma.

Esses itens foram citados principalmente nas empresas de pequeno porte, sendo que o porte da empresa também apareceu como sendo importante para empresas de grande porte. Além disso, apesar de serem apresentados neste estudo como exceção aos grupos anteriormente citados, existe a possibilidade de serem enquadrados no grupo de fatores críticos de natureza administrativa. Isso ocorre porque, ao existir esse fator relevante para a implementação do sistema, é necessário que haja uma ação por parte dos gestores em função de sua existência, seja no planejamento, na execução ou no controle. Dessa forma, dependendo do entendimento, poder-se-ia classificá-las no grupo de fatores administrativos.

Por outro lado, como contra-argumentação à afirmação anterior, pode-se supor que todos os fatores críticos apresentados, independente de ser de natureza comportamental, administrativa ou de escassez de recursos, necessitem de uma ação por parte dos gestores. Devido essa indefinição esses itens foram apresentados num grupo à parte.

\subsection{Análise dos grupos}

Pela análise da revisão de literatura, podem ser apresentadas algumas observações referentes às incidências de fatores nos grupos, conforme apresentado abaixo: 
Iniciando pelas dificuldades, as quais foram classificadas em comportamentais, administrativas e de recursos, em relação aos fatores comportamentais, verifica-se que estes estão presentes em todos os portes de empresa, e com quantidade de incidências semelhantes. Ainda, pode-se afirmar que a maioria dessas dificuldades comportamentais está relacionada a problemas de resistência, os quais são diversos como: ao uso, à cobrança, à mudança, entre outros.

Em relação às dificuldades relacionadas a fatores administrativos, apesar de que em todos os portes de empresas tenham apresentado este tipo de dificuldade, percebe-se que nas empresas de grande porte a quantidade desses problemas foi menor do que os demais grupos, sendo ainda menor na fase de planejamento, quando classificadas em fases de planejamento, execução e controle. Além disso, ao analisar as dificuldades administrativas relacionadas ao grupo de empresas de médio porte, a quantidade de fatores apresentados foi maior do que nos demais grupos (21 contra 15 nas pequenas e 14 nas grandes).

Ao analisar as dificuldades encontradas relacionadas à escassez de recursos, verifica-se que basicamente as dificuldades estão relacionadas a fatores tecnológicos do sistema e de conhecimentos específicos. São poucos os itens apresentados que tratam de recursos físicos ou humanos. Nas empresas de médio porte, inclusive, esses dois grupos não apresentaram nenhum item na revisão de literatura, contendo apenas itens de natureza tecnológica e de conhecimentos específicos.

Os itens encontrados referentes dificuldades relacionadas a recursos tecnológicos, ou de sistema, são semelhantes em todos os portes de empresa. Resumidamente estão relacionados a problemas de integração com sistemas anteriores e a customizações necessárias para adequação com a empresa. A maioria das dificuldades encontradas neste grupo está de alguma forma relacionada às necessidades da empresa que o sistema não oferece. A implementação acaba sendo prejudica devido às mudanças e adequações que acabam sendo necessárias. 


\section{ESTUDO DE CASO}

\subsection{A empresa}

A empresa analisada é de médio porte, segundo as definições constantes no Capítulo 4, com cerca de 200 funcionários, e faturamento bruto anual em torno de US\$ 30 milhões. Sua atividade é industrial, do ramo de embalagens plásticas, não sendo de composição societária familiar, a qual teve início de suas atividades no ano de 1992, ao se juntar com um parceiro local. Daquela data até o ano de 1997, a responsabilidade pela gestão estava com o sócio local. Nesta data a empresa atual adquiriu a parte deste sócio, passando a ser integralmente uma multinacional, iniciando-se a transferência do modelo da matriz. As entrevistas foram realizadas com o controller da empresa, que foi o responsável pela implantação do sistema, e que teve o auxílio de um analista de custos.

\subsection{Situação anterior à implantação}

Anteriormente ao sistema atual de apuração de custos, o controle era mais simples e realizado através de planilhas eletrônicas. Apesar de haver um sistema integrado de gestão anterior, diferente do atual, não havia uma interação de todos os seus módulos, incluindo-se o de custos. Porém, mesmo sem haver uma integração completa, a engenharia industrial já possuía a maioria dos dados referente à produção, como "tempo de máquina, peso de frascos, fichas técnicas, listas de produção, etc.”. Apesar da necessidade de se ter um novo sistema de custeio já ter sido identificada anteriormente, o motivo principal pela sua adoção em substituição ao anterior foi, segundo a empresa, "uma transposição do modelo usado pela matriz".

\subsection{A implantação do sistema}

O atual sistema de custos está em uso há seis anos e foi implementado simultaneamente ao novo sistema ERP, da empresa SAP. Não houve um projeto que tenha envolvido uma análise 
estruturada das opções de fornecedores desses softwares, assim como contatos para coleta de referências, visto que o fornecedor do sistema foi determinado pela matriz. Consultoria local foi utilizada, mas exclusivamente para configuração de aspectos tributários, durante a implementação, a qual não teve interrupção até seu término.

\subsubsection{Fase pré-implementação}

O processo de pré-implementação, iniciado pela a identificação da necessidade de um sistema de custos até a decisão pelo fornecedor, teve duas etapas. Iniciou-se no ano de 1997 com a decisão da implantação, mas como a matriz estava priorizando a implementação em outros países, a empresa optou pela utilização temporária de outra opção de menor custo, com planilhas à parte para controle de custos. No final do ano de 2001, iniciou-se a implantação do novo sistema integrado completo.

\subsubsection{Fase de implementação}

A fase de implementação, do período desde a definição do projeto até o início de funcionamento do sistema, começou no mês de março daquele ano, até o mês de agosto, mês em que o mesmo foi colocado em operação. Nesse período, houve a visita de uma pessoa da matriz, "para analisar alguns processos internos, requisitos de hardware e solicitar a disponibilização de diversas informações”.

\subsubsection{Fose pós-implementação}

O processo de pós-implementação, desde o início da operacionalização do sistema, até a sua utilização rotineira, durou aproximadamente até meados de 2003, quando foi detectada a necessidade de alguns relatórios externos, em complemento às opções disponíveis até então. Nessa época, as atividades já eram realizadas rotineiramente, sem questionamentos sobre a utilização do sistema.

\subsection{Dificuldades}




\subsubsection{Principais dificuldades}

Em relação às dificuldades que foram citadas pelo entrevistado, nas questões abertas, estas se referem principalmente ao período após o início de funcionamento do sistema. Na fase inicial, até a sua operacionalização, não foram encontradas muitas barreiras, sendo considerada "relativamente simples, dado que se realizou apenas um roll out do modelo adotado pela matriz, sem qualquer adaptação local”.

Os problemas enfrentados estavam relacionados, principalmente, à etapa posterior ao início da utilização do sistema, sendo que as principais barreiras enfrentadas pela empresa, ou que dificultaram a continuidade da implantação, foram:

a) Não consideração de características locais, como nas diferenças de conceitos de custos fixos e variáveis entre matriz e filial. Como exemplo, a matriz considera a mão-de-obra como inteiramente variável, embora na filial isso não refletisse a realidade;

b) Pouco treinamento dos colaboradores no funcionamento do modelo adotado pela matriz;

c) Barreira lingüística na comunicação dos usuários com o pessoal de suporte da matriz.

Dentre os três itens, os dois primeiros foram considerados pelo controller como tendo sido de grande dificuldade, e o terceiro como de média dificuldade. Ao questionar sobre a existência de projetos ou planejamentos específicos para solucionar os problemas na época, cada caso teve uma situação distinta. No caso da primeira dificuldade, ainda hoje existe o problema, sendo realizadas as adaptações necessárias. Em relação ao segundo item, não puderam ser tomadas muitas ações no curto prazo. Como o sistema de custos não podia ser implantado isoladamente antes do sistema ERP completo, mesmo que parcialmente implantado, o treinamento só pôde ser realizado após o término da implantação completa. Em médio prazo, os usuários acabaram por absorver o modelo sem um projeto específico de treinamento. Em relação à terceira dificuldade, segundo o entrevistado: “Cogitamos trazer tradutores externos para ajudar, mas eles não conheciam os conceitos ou o modelo. Terminamos optando por centralizar o processo nas poucas pessoas que conheciam o idioma. No médio prazo, estas pessoas foram os multiplicadores do modelo”. 
Apesar de não terem sido desenvolvidos projetos específicos para a solução dos problemas, estes foram contornados dentro das condições e possibilidades do momento. Nesse sentido, o estudo de caso não forneceu informações sobre possíveis soluções que poderiam ser utilizadas como modelo ou para um direcionamento em estudos posteriores. Porém, a insuficiência de treinamento é citada diversas vezes na revisão de literatura, coincidindo com a dificuldade enfrentada pela empresa. Sendo assim, ao menos nessa questão, pode-se sugerir que, como solução, sejam oferecidos todos os treinamentos necessários aos funcionários.

Ao questionar sobre a previsibilidade das dificuldades enfrentadas, assim como das possíveis soluções, a resposta foi de que tinham conhecimento da existência dessas barreiras, mas que, dentro do contexto da empresa, não havia muito que fazer. Em relação ao insuficiente treinamento e à barreira lingüística, a opção apresentada pelo entrevistado foi de ter “contratado uma pessoa, com bons conhecimentos conceituais e de inglês, e mantê-la por três meses na matriz nos EUA atuando em outra área de negócio para absorver o modelo”. Porém, para colocar em prática essa alternativa, o valor do investimento ultrapassaria o planejado. Além disso, segundo o entrevistado, “todos os recursos disponíveis na área contábil foram alocados ao projeto”.

a) A primeira dificuldade apresentada é de natureza administrativa, não sendo comportamental nem de escassez de recursos. Em relação ao grupo de escassez de recursos, não pode fazer parte deste grupo por não haver uma escassez de recursos físicos nem humanos, assim como não há uma deficiência tecnológica do sistema ou falta de conhecimento específico. Dessa forma, a não consideração de características locais pode ser considerada uma falha administrativa, especificamente na fase de planejamento, pois esta deveria ter sido considerada pela empresa no início do projeto. Apesar de não ter sido encontrada na literatura, dificuldade idêntica à apresentada pela empresa, pode-se verificar alguns itens semelhantes, ou de alguma forma relacionados ao problema, como por exemplo: práticas administrativas impostas pela controladora; não aderência do sistema aos processos da empresa; baixa adequação com o contexto empresarial do país e desencontro de práticas específicas;

b) A segunda dificuldade enfrentada pela empresa do estudo é um dos itens que faz parte da inexatidão das ciências humanas, formando, conforme mencionado, uma interseção 
entre os grupos de categorias utilizados neste estudo. Inicialmente, o pouco treinamento oferecido poderia ser considerado como uma escassez de recursos de conhecimentos específicos, mas é considerada como uma dificuldade de ordem administrativa, uma vez que a sua necessidade é conhecida, mas deveria ter sido fornecido em maior quantidade. Como se refere a uma ação que deveria ser realizada pelos gestores, essa dificuldade está relacionada à fase de execução. Conforme comentado, esta é uma dificuldade encontrada na literatura diversas vezes, especificamente nas empresas de pequeno e médio porte;

c) A terceira dificuldade enfrentada pela empresa refere-se à escassez de recursos de conhecimentos específicos, no caso o conhecimento da língua inglesa. Esse foi o fator limitante entre os usuários da filial com o pessoal de suporte fornecido pela matriz. Assim como no item anterior, percebe-se aqui a influência do grupo administrativo, especificamente no planejamento. Da mesma forma que os dois itens anteriores, a ausência de conhecimentos necessários para a implementação é fator presente na literatura.

\subsubsection{Demais dificuldades}

Além das dificuldades apresentadas nas questões abertas como sendo as principais, foram identificadas pela empresa, através dos questionários, outras possíveis limitações. Com essas questões, a empresa pôde identificar problemas que não foram citados nas questões abertas, mas que também foram relevantes na implementação. Dentro da escala sugerida no questionário, de zero a cinco, conforme o grau de dificuldade encontrada da implantação, foram considerados nas listas abaixo, os itens classificados pela empresa como quatro e cinco, que representam respectivamente os de grande de extrema dificuldade. A lista dos itens está segmentada de acordo com as categorias apresentadas, de dificuldades comportamentais, administrativas ou de recursos.

\subsubsection{Comportamentais}

Iniciando-se pelo grupo de dificuldades de natureza comportamentais, foram identificados e classificados pela empresa, como sendo de grande dificuldade enfrentada, os seguintes itens: 
a) Dificuldade de aprendizado;

b) Insegurança dos funcionários em relação ao manuseio e utilização do sistema.

Apesar do fato não ser suficiente para algum tipo de conclusão, observa-se que os dois itens identificados no estudo de caso e classificados como grandes dificuldades, fazem parte das dificuldades de empresa de médio porte constantes na revisão de literatura. Por outro lado, dois itens que constam na literatura como dificuldades comportamentais nas empresas de médio porte não foram identificados no estudo de caso, nem mesmo como sendo uma pequena dificuldade:

a) Falta de envolvimento da alta direção;

b) Resistência da alta direção e dos funcionários mais antigos que não têm conhecimentos de informática.

Todos os demais itens comportamentais encontrados na literatura para empresas de médio porte também foram identificados pela empresa, em maior ou menor escala. Cabe observar que, por ser a lista apresentada uma compilação do conjunto de todas as dificuldades encontradas na literatura em relação às empresas de médio porte, é de se esperar que nem todos os itens estejam presentes em todas as empresas do mesmo porte, uma vez que alguns itens são muito específicos, como por exemplo, o medo de perda do emprego.

\subsubsection{Escassez de recursos}

Em relação aos problemas de escassez de recursos (físicos, humanos, tecnológicos e de conhecimentos específicos) encontrados na literatura, aqueles que foram identificados no questionário pela empresa, e considerados como sendo de grande ou extrema dificuldade (escala quatro e cinco respectivamente) foram:
a) Dificuldade de transição para novos sistemas;
b) Complexidade de parametrização;
c) Necessidade de equipe experiente para conduzir a implantação;
d) Inexperiência da equipe de suporte; 
e) Complexidade da customização;

f) Falta de suporte adequado;

g) Problemas de parametrização;

h) Dificuldades para suporte, principalmente nos momentos iniciais da operação;

i) Alto volume de trabalho envolvido na instalação;

j) Dificuldades na obtenção de alterações e melhorias no sistema;

k) Desencontro entre as práticas dos sistemas e das práticas específicas de um segmento;

l) Sistema não provê todas as informações necessárias às decisões em relação aos produtos e clientes.

Assim como nas dificuldades comportamentais, a maioria dos itens de escassez de recursos, identificados pela empresa, faz parte das limitações constantes do grupo de empresas de médio porte. Apesar disso, da lista apresentada à empresa no questionário, para a classificação do grau de importância, alguns dos itens relacionados a empresas de médio porte não foram por ela identificados. Os que se enquadram nessa condição são:

a) Dependência de um único fornecedor;

b) Custo alto na contratação de profissionais com experiência e com bons conhecimentos sobre negócios;

c) Consultoria para acompanhamento do projeto cara;

d) Necessidade de atualização constante do sistema e gerenciamento de versões;

e) Interfaces necessárias para adaptação dos sistemas existentes;

f) Excesso de customizações;

g) Vínculo com a empresa fornecedora, especificamente em relação à necessidade de atualização da versão descontinuada;

h) Alto custo das customizações;

i) Dificuldade no atendimento pelo fornecedor.

Esses itens, apesar de serem relacionados à empresas de médio porte, não foram identificados pela empresa no seu processo de implementação. Cabe novamente a observação de que, como a lista contempla o que foi encontrado na literatura, é de se esperar que nem todas sejam identificadas por todas as empresas. 


\subsubsection{Administrativos}

Referente ao terceiro grupo, das dificuldades de natureza administrativas, os itens identificados na relação pela empresa como sendo de grande ou extrema dificuldade foram:

a) Falta de confiabilidade dos direcionadores;

b) Falha na comunicação entre os diversos níveis de usuários e entre equipes;

c) Falta de treinamentos;

d) Ausência de um plano e administração de testes integrados;

e) Sobrecarga de funções;

f) Falta de medidas anteriores de performance;

g) Treinamento inadequado;

h) Atividades incongruentes com os direcionadores de custos;

i) Visão superficial de processos.

Destes, somente o último item consta no grupo de dificuldades em empresas de médio porte da literatura. Os cinco primeiros itens foram encontrados na literatura relacionados às de pequeno porte, e os três seguintes às de grande porte. Ao analisar os demais itens da lista relacionada a empresas de médio porte que foi encontrada na literatura, verifica-se que muitos não foram identificados na empresa do estudo. Mesmo assim, por serem itens relacionados a fatores administrativos, têm grande variação dependendo da empresa. São apresentados a seguir esses pontos discordantes:

a) Sobrecarga de funções devido corte de pessoal;

b) Perda do foco com aumento de custo e prazo;

c) Ambiente familiar e não profissional;

d) Cálculo incorreto dos custos de implantação;

e) Implantação e serviços associados custam várias vezes o valor do software;

f) Orçamento limitado e menos sujeitos a revisões;

g) Utilização temporária do sistema novo e do antigo concomitantemente;

h) Falta de participação do fornecedor da seleção do hardware necessário.

Além das dificuldades apresentadas, consideradas como sendo de grande e extrema dificuldade, houve também uma grande quantidade de itens da lista, identificados na 
implantação do sistema da empresa, classificados como de pequena, considerável e média dificuldade, fazendo com que a maioria dos itens encontrados na revisão de literatura tenha sido identificada pela empresa, em maior ou menor escala.

Em resumo, o estudo de caso conseguiu identificar as principais dificuldades que teve na implementação do sistema de custos, além de mostrar que estas estavam de acordo com o que foi encontrado na literatura, em maior ou menor incidência. Das três principais, a primeira dificuldade encontrada, a qual se refere a adoção de práticas da matriz ou controladora, foi identificada no estudo bibliográfico, quando se trata de práticas impostas pela controladora, desencontro entre práticas do sistema com as de um segmento, ou como não aderência aos processos da empresa. O segundo item, referente ao pouco treinamento realizado, também está de acordo com a revisão de literatura, onde se encontram itens como treinamento inadequado ou a sua falta. O treinamento também está relacionado a outros diversos fatores limitantes, como: falta de capacitação de funcionários; resistência ao uso do sistema; dificuldade de aprendizado; dificuldade de adaptação ao novo sistema; alto custo da consultoria e treinamento; falta de suporte adequado, dentre outras. O terceiro item, que trata de conhecimentos específicos e de suporte, também consta da literatura, relacionado com outros diversos itens.

Das três dificuldades principais identificadas no estudo, duas são de natureza administrativa e uma é relacionada à escassez de recursos. As soluções encontradas para elas foram aplicadas de acordo com o desenvolvimento da implantação, sem um projeto específico para a suas soluções. No caso das diferenças de normas, até hoje são realizadas as adequações necessárias; o problema de treinamento foi solucionado em médio prazo com a utilização do sistema e conseqüente absorção do modelo; e na barreira lingüística foram utilizados os recursos disponíveis.

Por fim, ao analisar as dificuldades apresentadas nas respostas ao questionário como sendo de grande ou de extrema dificuldade, verifica-se que a maioria dos problemas enfrentados, assim como os apontados nas questões abertas, ou se encontra no grupo de dificuldades administrativas, ou no de escassez de recursos. Analisando os subgrupos dessas categorias, enquadram-se principalmente na fase de planejamento, no caso das administrativas, e de aspectos tecnológicos ou de conhecimentos específicos, no caso da escassez de recursos. 


\section{CONCLUSÕES E RECOMENDAÇÕES}

\subsection{Conclusões}

O estudo teve como foco a questão de pesquisa: "quais foram as principais dificuldades encontradas na implementação do sistema de custos, suas causas e soluções, na empresa de porte médio objeto de estudo?” O objetivo central, de identificar as principais dificuldades na empresa do estudo, foi alcançado, sendo elas: a não consideração de características locais da filial; pouco treinamento no funcionamento do modelo da matriz; barreira lingüística entre os usuários e o pessoal de suporte da matriz no exterior. As ações para a solução dos problemas e dificuldades enfrentados pela empresa foram efetuadas de acordo com as condições e possibilidades que o contexto da época permitia, conforme constam no Capítulo 6, não sendo desenvolvidos projetos específicos para a solução destes problemas.

Como objetivo secundário, pretendeu-se identificar na literatura as dificuldades e apresentálas de forma categorizada. Esse objetivo também foi alcançado, segregando-os inicialmente em dificuldades e fatores críticos, e posteriormente agrupando-os de acordo com características semelhantes, em grupos e subgrupos, conforme apresentado no Capítulo 5. A tipificação criada tem semelhança com outras categorizações apresentadas por demais autores, e verificou-se que ela pôde ser utilizada satisfatoriamente, considerando que poucos itens tiveram dúbio enquadramento. Tanto a lista elaborada, como sua tipificação, podem ser úteis em estudos posteriores, uma vez que se verificou a possibilidade de sua relação com casos práticos. Além disso, ambas podem ser úteis também para as organizações que vierem a implantar sistemas de custeio, verificando quais os tipos de dificuldades e fatores críticos mais enfrentados pelas empresas de seu porte.

Outro objetivo intermediário foi a comparação das dificuldades identificadas na empresa com as constantes na literatura. Conclui-se que os achados do estudo estão de acordo com o que foi visto na revisão bibliográfica, conforme comentado no Capítulo 6, tanto nos itens analisados isoladamente, como nos grupos que tiveram maior incidência, de fatores administrativos e de escassez de recursos. Verificou-se também que, da lista dos itens constantes nesses grupos, a maior parte foi identificada pela empresa analisada. 
Por fim, conclui-se que os achados do estudo, assim como os produtos por ele gerados, como as limitações enfrentadas pela empresa, a lista de dificuldades da literatura, a sua tipificação em diversos grupos, subgrupos e por porte de empresa, e a comprovação do seu possível alinhamento com casos práticos, têm grande utilidade tanto para o desenvolvimento do conhecimento como para uso prático nas organizações.

\subsection{Recomendações de estudos posteriores}

Considerando que o presente estudo possa ter agregado de alguma maneira, material para o desenvolvimento do conhecimento, a seguir são sugeridos estudos relacionados ao tema, para um maior aprofundamento no assunto.

Uma vez que, através da análise dos fatores encontrados na literatura, foram criados dois grupos distintos, o de dificuldades e o de fatores críticos, relacionados à implementação de sistemas de custos, pode-se fazer uma análise dos fatores críticos de forma mais aprofundada, pois neste estudo o objeto principal foi o grupo de dificuldades. A análise poderia considerar a mesma categorização utilizada e realizar testes empíricos para confrontação.

Outra sugestão seria o aprofundamento dos temas utilizados na classificação: o comportamental, o administrativo e de escassez de recursos, que têm várias ramificações, assim como os seus subgrupos, para a melhor compreensão das origens e possíveis ações para cada dificuldade apresentada.

E por fim, pesquisas com outras empresas devem ser realizadas, verificando se seus problemas e suas limitações também constam da lista de dificuldades elaboradas neste estudo, assim como questionários podem ser aplicados, para que se possa conseguir uma apuração de dados estatísticos de acordo com essa lista, que pode servir de modelo para estudos posteriores. 


\section{REFERÊNCIAS}

ADIZES, Ichak. Os ciclos de vida das organizações: Como e por que as empresas crescem e morrem e o que fazer a respeito. Pioneira: São Paulo. 1993

AFONSO, Paulo Sérgio Lima Pereira. Sistemas de custeio no âmbito da contabilidade de custos. Guimarães, 2002. Dissertação (Mestrado em engenharia). Escola de Engenharia da Universidade do Minho.

AL-AHMARI, Abdulrahman M. A. Implementing CIM systems in SMEs. International journal of computer applications in technology, vol. 15, n. 1/2/3, pp.122-127, 2002.

ALBUQUERQUE, Alexandre Farias. Gestão estratégica das informações internas na pequena empresa: estudo comparativo de casos em empresas do setor de serviços hoteleiros da região de Brotas - SP. São Carlos, 2004. Dissertação (Mestrado em Engenharia de Produção) - Escola de Engenharia de São Carlos da Universidade de São Paulo.

ANDRADE, Maria Margarida de. Como preparar trabalhos para cursos de pósgraduação. São Paulo: Atlas, 2002.

BANCROFT, N. H.; SEIP, H.; SPRENGEL, A. Implementing SAP R/3: How to introduce a large system into a large organization ( $2^{\text {nd }}$ ed.). Greenwich: Manning. 1998.

BERGAMINI, Cecília Whitaker. Psicologia aplicada à administração de empresas: Psicologia do comportamento organizacional. $4^{a}$. ed. São Paulo: Atlas, 2006.

BERTALANFFY, Ludwig von. Teoria geral dos sistemas. $3^{\mathrm{a}}$. ed. Petrópolis: Vozes, 1977.

BIO, Sergio Rodrigues. Desenvolvimento de sistemas contábeis-gerenciais: um enfoque comportamental e de mudança organizacional. São Paulo, 1987. Tese (Doutorado em Ciências Contábeis) - Programa de Pós-Graduação em Ciências Contábeis, Departamento de Contabilidade e Atuária, Faculdade de Economia, Administração e Contabilidade da Universidade de São Paulo.

BORINELLI, Márcio Luiz. Estrutura Conceitual básica de Controladoria: Sistematização à Luz da Teoria e da Práxis. São Paulo, 2006. Tese (Doutorado em Ciências Contábeis) - Programa de Pós-Graduação em Ciências Contábeis, Departamento de Contabilidade e Atuária, Faculdade de Economia, Administração e Contabilidade da Universidade de São Paulo.

BRASIL, Ministério do Desenvolvimento, Indústria e Comércio Exterior - Secretaria de Comércio Exterior - SECEX. www.desenvolvimento.gov.br último acesso em 27/09/2007. 
Ministério do Trabalho e emprego. RAIS - Relatório anual de informações sociais. www.mte.gov.br. Último acesso em 27/09/2007.

CATELLI, Armando (Org.). Controladoria: uma abordagem da gestão econômica Gecon. 2ª . ed. Atlas: São Paulo, 2001.

CHIEN, Shih-Wen et al. The influence of centrifugal and centripetal forces on ERP project success in small and medium-sized enterprises in China and Taiwan. International Journal of Production Economics. N. 107 p. 380-396, 2007.

DAVENPORT, Thomas $\mathrm{H}$. Putting the enterprise into the enterprise system. (information integration). Harvard business review. jul-aug 1998, vol. 76, issue 4.

DeLone, William H. Determinants of success for computer usage in small business. MIS Quarterly, mar-1988; vol.12, iss. 1, p. 51-61, 1988.

; McLean, Ephraim R. Information system success: the quest for the dependent variable. Information systems research, mar-1992, vol. 3, n. 1, 1992.

; The DeLone and McLean model of information system success: a tem year update. Journal of management information systems, spring-2003, vol. 19, no. 4, pp. 9-30, 2003.

Departamento Nacional de Registro do Comércio - DNRC. www.dnrc.gov.br último acesso em 27/09/2007.

DRURY, Colin; TAYLES, Mike. Cost system design for enhancing profitability. Management accounting, jan-1998, vol. 76, n. 1 , pp. 40, 1998.

DURAN, Orlando; RADAELLI, Lucas. Metodologia ABC: implantação numa microempresa. Gestão e Produção, vol. 7, n. 2, p. 118-135, ago-2000.

ECO, Humberto. Como se faz uma tese em ciências humanas. $7^{a}$. ed. Lisboa: Editorial Presença, 1998.

ESCOUTO, Rita Maria da Costa; SCHILLING, Luís Felipe. Proposta de metodologia de seleção de sistemas ERP para uma empresa de médio porte. In: SOUZA, Cesar Alexandre; SACCOL, Amarolinda Zanela (Org.). Sistemas ERP no Brasil: enterprise resource planning: teoria e casos. Atlas: São Paulo, 2008.

FAMÁ, Rubens; CARDOSO, Ricardo Lopes; FRARE, Eduardo. A implantação do sistema de custeio por atividades em um centro nacional de pesquisas: o caso LNLS - Laboratório nacional de Luz Síncroton. Cadernos da FACECA, Campinas, v.9, n.2, p.23-37, jul/dez 2000.

FASSOULA, E. D.; ROGERSON, J. H. Management tools for SMES. TQM \& Business Excellence, vol. 14, no. 10, dec-2003, 1143-1158, 2003.

GALEGALE, Napoleão Verardi. Proposta de um modelo de dados conceitual para o sistema de informação da gestão do caixa das empresas orientadas por 
unidades estratégias de negócios. São Paulo, 2000. Tese (Doutorado em Ciências Contábeis) - Programa de Pós-Graduação em Ciências Contábeis, Departamento de Contabilidade e Atuária, Faculdade de Economia, Administração e Contabilidade da Universidade de São Paulo.

GINZBERG, Michael J. An organizational contingencies view of accounting and information systems implementation. Accounting, organization and society, vol. 5 , n. 4, pp. 369-382, 1980.

GLAUTIER, M. W. E.; UNDERDOWN, B. Accounting theory and practice. $5^{\text {th }}$. ed. London: Pitman Publishing, 1995.

GOMES, Fabio Guedes. A Nova Economia Institucional e o (Sub) Desenvolvimento Econômico Brasileiro: limites e impossibilidades de interpretação. Anais do IX Encontro Nacional de Economia Política, Uberlândia, 2004.

GOSSELIN, Maurice. A review of Activity-Based Costing: technique, implementation, and consequences. In: CHAPMAN, Christopher S.; HOPWOOD, Anthony G.; SHIELDS, Michael D. (ed). Handbook of management accounting research. Elsevier: Amsterdam, 2007.

GUERREIRO, Reinaldo. Modelo conceitual de sistema de informação de gestão econômica: Uma contribuição à teoria da comunicação da contabilidade. São Paulo, 1989. Tese (Doutorado em Ciências Contábeis) - Programa de Pós-Graduação em Ciências Contábeis, Departamento de Contabilidade e Atuária, Faculdade de Economia, Administração e Contabilidade da Universidade de São Paulo.

A Teoria das Restrições e o Sistema de Gestão Econômica: Uma proposta de integração conceitual. Tese de livre docência, USP, São Paulo, 1995.

et al. Em busca de um melhor entendimento da contabilidade gerencial através da integração de conceitos da psicologia, cultura organizacional e teoria institucional. Revista contabilidade \& finanças, São Paulo, v. 3, p. 7-21, 2006.

GUNASEKARAN, A.; GRIEVE, R. J. Activity based costing in small and medium enterprises. Computers \& industrial engineering. Vol. 37 pp. 407-411, 1999.

HENDRICKSEN, Eldon S.; VAN BREDA, Michael F. Teoria da contabilidade. $5^{\mathrm{a}}$ ed. São Paulo: Atlas, 1999.

HOPPER, Trevor et al. Cost accounting in small and medium sized Japanese companies: an exploratory study. Accounting and Business Research, vol. 30 iss. 1, pp.73-86, 1999.

KASSAI, Silvia. As empresas de pequeno porte e a contabilidade. São Paulo, 1996. Dissertação (Mestrado em Ciências Contábeis) - Programa de PósGraduação em Ciências Contábeis, Departamento de Contabilidade e Atuária, Faculdade de Economia, Administração e Contabilidade da Universidade de São Paulo. 
As empresas de pequeno porte e a contabilidade. Caderno de estudos, São Paulo, Fipecafi, v.0, n.15, p.60-74, jan-jun, 1997.

; KASSAI, J. R. Sistema de custos para pequenas empresas: experiência de uma editora. Anais do IV Congresso Brasileiro de Custos, Fortaleza/CE, 1998.

KOTLER, P.; KELLER, K. L. Administração de Marketing. 12 a ed. São Paulo: Pearson Prentice Hall, 2006.

KRASNER, H. Ensuring E-Business Succes by Learning from ERP Failures. IT Pro, p. 22-27, jan-feb 2000.

KRUGLIANSKAS, Isak. Aspectos comportamentais relacionados com sistema de custos em instituições de pesquisa brasileiras. São Paulo, 1977. Dissertação (Mestrado em Administração) - Faculdade de Economia, Administração e Contabilidade da Universidade de São Paulo.

LAUDON, K. C.; LAUDON, J. P. Sistemas de Informação. $4^{\text {a }}$. ed. Rio de Janeiro: LTC Livros Técnicos e Científicos S.A., 1999.

MARTINS, Gilberto de Andrade. Manual para elaboração de monografias e dissertações. $2^{\text {a }}$. ed. São Paulo: Atlas, 1994.

Estudo de caso: uma estratégia de pesquisa. São Paulo: Atlas, 2006.

MARTINS, Eliseu. Contabilidade de custos. São Paulo: Atlas, 2003.

MASSUDA, J. C. Gestão de custos em pequenas empresas industriais de confecções: proposta de uma metodologia. Dissertação de mestrado em engenharia de produção da universidade federal de Santa Catarina. 2003.

MDIC - Ministério do desenvolvimento, indústria e comércio exterior - secretaria do desenvolvimento da produção - SDP www.desenvolvimento.gov.br acesso em $27 / 09 / 2007$

MEDEIROS, Edson Soares de. Metodologia para implementação do sistema de custeio baseado em atividades (abc) nos serviços logísticos da indústria de exploração e produção de petróleo: aplicação no provedor de transporte do órgão de exploração \& produção da Petrobrás na bacia de campos. Florianópolis, 1999. Dissertação (Mestrado em Engenharia de Produção), Universidade Federal de Santa Catarina.

MENDES, J. V.; ESCRIVÃO FILHO, E. Sistemas integrados de gestão (ERP) em pequenas e médias empresas: um confronto entre a teoria e a prática empresarial. In: SOUZA, Cesar Alexandre; SACCOL, Amarolinda Zanela (Org.). Sistemas ERP no Brasil: enterprise resource planning: teoria e casos. Atlas: São Paulo, 2008.

MORAES, João Vicente de. Sistemas de custos para pequenas empresas industriais. Florianópolis, 2002. Dissertação (Mestrado em Engenharia de Produção), Universidade Federal de Santa Catarina. 
NAKAGAWA, Massayuki. Gestão estratégica de custos: Conceitos, Sistemas e Implementação. São Paulo: Atlas, 1991.

NASCIMENTO, Silvério Antônio do. Sistema de custos em pequenas e médias empresas de confecção de vestuário com o uso de planilhas eletrônicas. Florianópolis, 2002. Dissertação (Mestrado em engenharia de produção), Universidade federal de Santa Catarina.

NEEDY, Kim LaScola et al. Implementing Activity-Based Costing systems in small manufacturing firms: a field study. Engineering Management Journal, mar-2003, vol. 15, n. 1, 2003.

NYSTROM, Paul C. Managerial resistance to a management system. Accounting, organizations and society, vol. 2, n. 4, pp. 317-322, 1977.

OZAKI, A. M.; VIDAL, A. G. R. Desafios da Implementação de Sistemas ERP: Um estudo de caso em uma empresa de médio porte. In: SOUZA, Cesar Alexandre; SACCOL, Amarolinda Zanela (Org.). Sistemas ERP no Brasil: enterprise resource planning: teoria e casos. Atlas: São Paulo, 2008.

OYADOMARI, J.C.T. et al. A institucionalização da VBM value based management como prática de contabilidade gerencial: uma análise à luz da NIS new institutional sociology. In: Anais 7o. Congresso USP de controladoria e contabilidade Universidade de São Paulo, São Paulo, 2007.

PADOVEZE, Clóvis Luís. Sistemas de informações contábeis: fundamentos e análise. São Paulo: Atlas, 1998.

PEREIRA, Carlos Daniel Schneider. Sistemas integrados de gestão empresarial: um estudo de caso de implementação de um sistema ERP em uma empresa seguradora brasileira. São Paulo, 2002. Dissertação (Mestrado em Ciências Contábeis) - Programa de Pós-Graduação em Ciências Contábeis, Departamento de Contabilidade e Atuária, Faculdade de Economia, Administração e Contabilidade da Universidade de São Paulo.

; RICCIO, Edson Luiz. Caso seguradora: insucesso na implementação de um sistema ERP. In: SOUZA, Cesar Alexandre; SACCOL, Amarolinda Zanela (Org.). Sistemas ERP no Brasil: enterprise resource planning: teoria e casos. Atlas: São Paulo, 2008.

PEREIRA, José Santos. Sistemas empresariais integrados - ERP na empresa contábil: um estudo de caso de mudança organizacional com uso da pesquisaação. São Paulo, 2003. Dissertação (Mestrado em Ciências Contábeis) - Programa de Pós-Graduação em Ciências Contábeis, Departamento de Contabilidade e Atuária, Faculdade de Economia, Administração e Contabilidade da Universidade de São Paulo.

PINOTTI, Antônio Jonas. Sistema informatizado para apuração de custos por atividades em pequenas e médias empresas de confecções. Florianópolis, 2003. 
Dissertação (Mestrado em Engenharia de Produção), Universidade federal de Santa Catarina.

POMPERMAYER, Cleonice Bastos. A influência de fatores organizacionais nos aspectos práticos dos sistemas de gestão de custos. Florianópolis, 2004. Tese (Doutorado em Engenharia de Produção), Universidade Federal de Santa Catarina. Florianópolis, 2004.

PRADO, E. F. S. A ortodoxia neoclássica. Estudos Avançados. São Paulo, v. 15, n. 41, 2001.

RIBEIRO, João A.; SCAPENS, Robert. W. Institutional theories in management accounting change. Contributions, issues and paths for development. Qualitative research in accounting \& management, v.3 n. 2, p.94-111, 2006.

RICCIO, Edson Luiz. Uma contribuição ao Estudo da Contabilidade como Sistema de Informação. São Paulo, 1989. Tese (Doutorado em Ciências Contábeis) - Programa de Pós-Graduação em Ciências Contábeis, Departamento de Contabilidade e Atuária, Faculdade de Economia, Administração e Contabilidade da Universidade de São Paulo.

Efeitos da tecnologia de informação na contabilidade: Estudo de casos de implementação de sistemas empresariais integrados - ERP. Tese de livre docência. FEA/USP, São Paulo, 2001.

ROCHA, Welington. Contribuição ao estudo de um modelo conceitual de sistema de informação de gestão estratégica. São Paulo, 1999. Tese (Doutorado em Ciências Contábeis) - Programa de Pós-Graduação em Ciências Contábeis, Departamento de Contabilidade e Atuária, Faculdade de Economia, Administração e Contabilidade da Universidade de São Paulo.

ROZTOCKI, Narcyz; NEEDY, Kim LaScola. Integrating activity-based costing and economic value added in manufacturing, Engineering Management Journal, Vol. 11 No. 2, Jun-99, pp. 17-22, 1999.

ROZTOCKI, Narcyz et al. A Procedure for Smooth Implementation of Activity Based Costing in Small Companies. Engineering Management Journal; Dec 2004; vol. 16, n. 4 pg. 19, 2004.

SANTOS, Antônio Marcos Flauzino. A implantação do custeio ABC em pequenas empresas de confecção. Florianópolis, 2002. Dissertação (Mestrado em Engenharia de Produção), Universidade federal de Santa Catarina.

SCAPENS, Robert W. Never mind the gap: towards an institutional perspective on management accounting practice. Management Accounting Research, 5, 301-321, 1994.

. Understanding management practices: a personal journey, The british accounting review, vol.38, pag.1-30, 2006. 
SCRAMIM, Fernando Cesar Leandro et al. Sistema informatizado para gestão de custos em laticínio de médio porte. Revista brasileira de agroinformática, Visçosa/MG, v. 4, n. 1, p. 13-27, 2002.

SEBRAE - Serviço Brasileiro de apoio às micro e pequenas empresas. www.sebraesp.com.br último acesso em 25/11/2007.

SOUTES, Dione Olesczuk. Uma investigação do uso de artefatos da Contabilidade Gerencial por empresas brasileiras. São Paulo, 2006. Dissertação (Mestrado em Ciências Contábeis) - Programa de Pós-Graduação em Ciências Contábeis, Departamento de Contabilidade e Atuária, Faculdade de Economia, Administração e Contabilidade da Universidade de São Paulo.

SOUZA, Cesar Alexandre de. Sistemas integrados de gestão empresarial: estudos de casos de implementação de sistemas ERP. Dissertação de mestrado em Administração. Faculdade de Economia, Administração e Contabilidade da Universidade de São Paulo. 2000. Paulo, 2008.

SACCOL, Amarolinda Zanela (Org.). Sistemas ERP no Brasil. Atlas: São

ZWICKER, Ronaldo. Ciclo de vida de sistemas ERP. Caderno de pesquisas em administração. $1^{\circ}$. trim-00, V.1, no. 11, 2000.

Sistemas ERP: Estudos de Casos Múltiplos em empresas brasileiras. In: SOUZA, Cesar Alexandre; SACCOL, Amarolinda Zanela (Org.). Sistemas ERP no Brasil: enterprise resource planning: teoria e casos. Atlas: São Paulo, 2008.

SUSSMANN, Antônio Gustavo. Panorama dos sistemas ERPs nas médias empresas da cadeia de suprimentos das indústrias de autopeças de uma cidade do interior de São Paulo. São Paulo, 2005. Dissertação (Mestrado em Ciências Contábeis) - Programa de Pós-Graduação em Ciências Contábeis, Departamento de Contabilidade e Atuária, Faculdade de Economia, Administração e Contabilidade da Universidade de São Paulo.

STAIR, Ralph M.; REYNOLDS, George W. Principles of information Systems. $4^{\text {th }}$. ed. Cambridge: Course Technology, 1999.

THEMISTOCLEOUS, Marinos et al. ERP and application integration: exploratory survey. Business process management journal. Vol. 7, no. 3, pp. 195-204, 2001.

TSAI, Wen-Hsien et al. The relationship between implementation variables and performance improvement of ERP systems. International journal of technology management, Vol. 38, No. 4, pp. 350-373, 2007.

VALENTE, Nelma Terezinha Zubek. Implementação de ERP em pequenas e médias empresas: um estudo de caso em empresa do setor de construção civil. São Paulo, 2004. Dissertação (Mestrado em Ciências Contábeis) - Programa de Pós-Graduação em Ciências Contábeis, Departamento de Contabilidade e Atuária, 
Faculdade de Economia, Administração e Contabilidade da Universidade de São Paulo.

VIEIRA, Verônica A. C. Implantação de sistemas integrados de gestão em pequenas e médias empresas: um estudo exploratório baseado em casos. Dissertação de Mestrado em Administração FEA/USP. 2004.

YIN, Robert K. Estudo de caso. 3 ed. Porto Alegre: Bookman, 2005.

ZAN, Adriano. Mudanças na contabilidade gerencial de uma organização: estudo de caso com diagnóstico institucional. São Paulo, 2006. Dissertação (Mestrado em Ciências Contábeis). Programa de Pós-Graduação em Ciências Contábeis, Departamento de Contabilidade e Atuária, Faculdade de Economia, Administração e Contabilidade da Universidade de São Paulo.

ZYLBERSZTAJN, Decio. Estruturas de Governança e Coordenação do Agribusiness: Uma Aplicação da Nova Economia das Instituições. São Paulo, 1995. Tese (Livre docência) - Faculdade de Economia, Administração e Contabilidade da Universidade de São Paulo.

ZWICKER, Ronaldo. pág. 15 a 17 Prefácio In: SOUZA, Cesar Alexandre; SACCOL, Amarolinda Zanela (Org.). Sistemas ERP no Brasil: enterprise resource planning: teoria e casos. Atlas: São Paulo, 2008.

; SOUZA, Cesar Alexandre. Sistemas ERP: conceituação, ciclo de vida e estudos de casos comparados. In: SOUZA, Cesar Alexandre; SACCOL, Amarolinda Zanela (Org.). Sistemas ERP no Brasil: enterprise resource planning: teoria e casos. Atlas: São Paulo, 2008. 


\section{APÊNDICES}

APÊNDICE 1: QUESTIONÁRIO

APÊNDICE 2: DIFICULDADES E FATORES CRÍTICOS POR PORTE DE EMPRESA E POR TIPO DE SISTEMAS

APÊNDICE 3: DIFICULDADES E FATORES CRÍTICOS CLASSIFICADOS POR GRUPO E SUBGRUPO

APÊNDICE 4: CARTA DE APRESENTAÇÃO 


\section{APÊNDICE 1: QUESTIONÁRIO}

\section{PARTE A}

\section{I - CARACTERIZAÇÃO DA EMPRESA}

1) Qual o número médio de funcionários da empresa na época da implementação do sistema de custeio?

2) Qual o faturamento bruto anual em dólares americanos na época da implementação?

3) Qual o ramo de atividade da empresa?

4) Qual o ano de início das atividades da empresa?

5) A composição societária é familiar? Se sim, quais os cargos ocupados por membros da família?

\section{II - PROCESSO DE IMPLEMENTAÇÃO}

6) Quem é (foi) o principal responsável pelo projeto de implementação?

7) Houve mais alguma pessoa chave no processo, e com poder de decisão sobre a implementação, envolvidas diretamente com o processo? Se sim, quem?

8) Em qual fase está a implementação? Início, meio, fim, ou já foi finalizada? Quais as datas de início e fim?

9) O que levou a empresa a decidir pela implementação do sistema de custeio?

10) Já havia um sistema de informações integrado sendo utilizado (ERP)?

11) Se sim, o sistema de custos faz parte do sistema de informações integrado?

12) A implantação do sistema de custos foi simultânea ao sistema ERP?

13) Houve um projeto para a implantação do sistema que tenha envolvido uma análise estruturada da escolha do fornecedor, dos custos e dos prazos, com contatos para coleta de referências?

14) Houve a auxílio de consultoria externa?

15) Se sim, em qual fase (pré-implementação / implementação / pós-implementação)?

16) Houve a interrupção do processo de implementação? Se sim, em qual fase e por qual motivo?

17) Quanto tempo durou todo o processo de pré-implementação, desde a identificação da necessidade de um sistema de custos até a decisão pelo fornecedor? 
18) Quanto tempo durou o processo da implementação em si, desde a definição do projeto até o início do funcionamento do sistema?

19) Quanto tempo durou o processo pós-implementação, desde o início do funcionamento do sistema até a aceitação e utilização rotineira do sistema.

\section{III - DIFICULDADES}

20) Quais foram as principais dificuldades encontradas na fase inicial da implementação do sistema de custos, desde a identificação da necessidade de um sistema de custos até a decisão de escolha do fornecedor?

21) Quais foram as principais dificuldades encontradas na fase principal da implementação, desde a definição do projeto de implementação (caso tenha existido), até o início de funcionamento do sistema?

22) Quais foram as principais dificuldades encontradas na fase final da implementação do sistema de custos, desde o início de funcionamento do sistema até a aceitação e utilização rotineira do sistema?

23) Classifique as dificuldades citadas nas três questões anteriores, de acordo com o seguinte critério:

\begin{tabular}{|l|l|}
\hline 1 & Pequena dificuldade \\
\hline 2 & Considerável dificuldade \\
\hline 3 & Média Dificuldade \\
\hline 4 & Grande dificuldade \\
\hline 5 & Extrema dificuldade \\
\hline
\end{tabular}

24) Tente apontar as causas e soluções encontradas para as dificuldades apresentadas.

\section{IV - FATORES IMPORTANTES OU CRÍTICOS DE SUCESSO}

25) Cite fatores que considere como importantes e devam ser considerados na implementação de sistemas de custeio.

26) Classifique os fatores citados de acordo com o grau de importância que eles tiveram na implementação do sistema de custeio da sua empresa.

\begin{tabular}{|l|l|}
\hline 1 & Pouco importante \\
\hline 2 & Considerável importância \\
\hline 3 & Importante \\
\hline 4 & Muito importante \\
\hline 5 & Extremamente importante \\
\hline
\end{tabular}




\section{PARTE B}

\section{I - DIFICULDADES DE IMPLEMENTAÇÃO NO SISTEMA DE CUSTEIO}

Classifique os fatores a seguir de acordo com o que foi identificado na implementação de sistemas de custeio da empresa.

\begin{tabular}{|l|l|}
\hline 0 & Não identificado \\
\hline 1 & Pequena dificuldade \\
\hline 2 & Considerável dificuldade \\
\hline 3 & Média Dificuldade \\
\hline 4 & Grande dificuldade \\
\hline 5 & Extrema dificuldade \\
\hline
\end{tabular}

\section{COMPORTAMENTAIS}

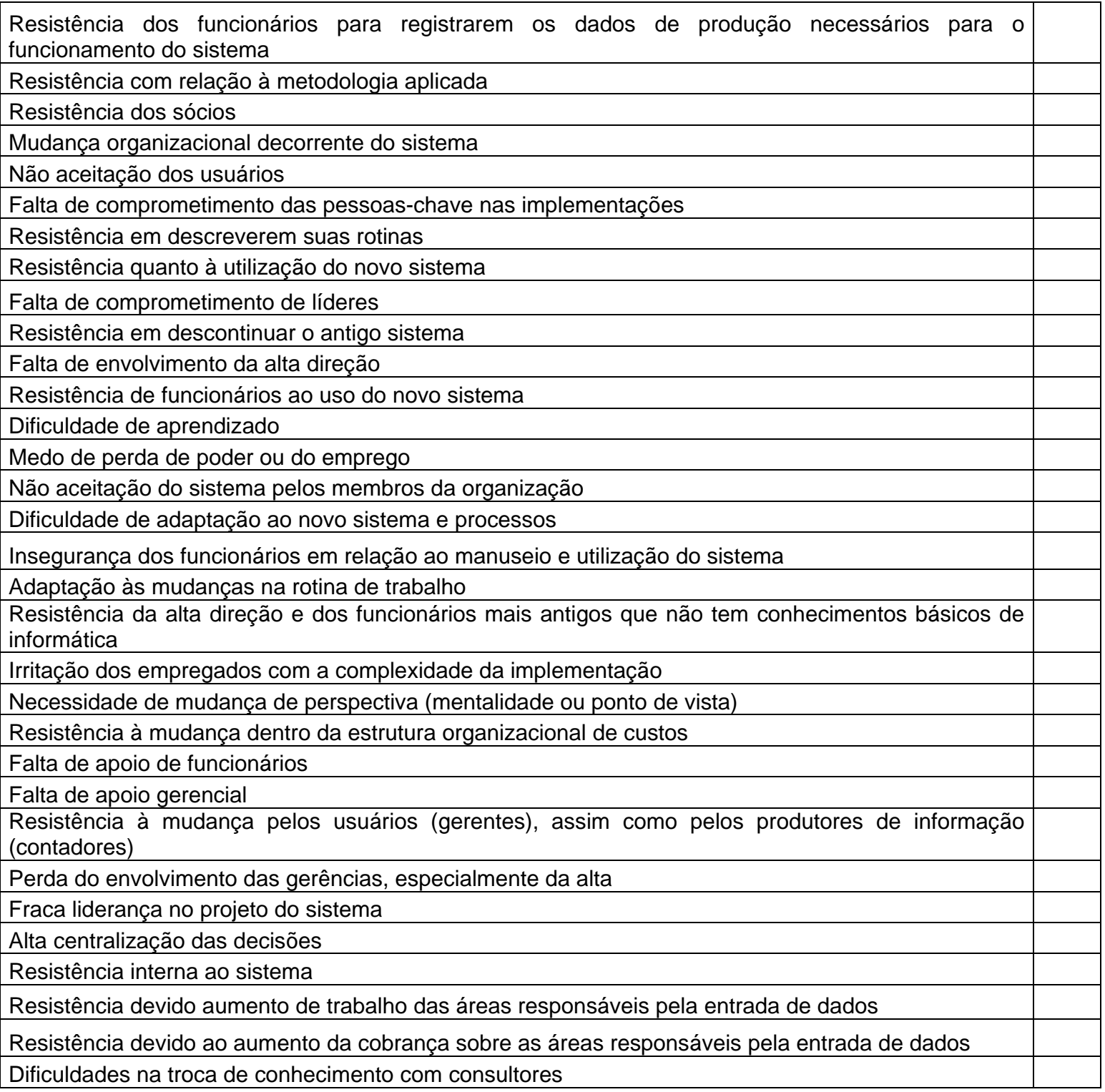




\section{RECURSOS}

Dificuldade de transição para novos sistemas

Falta de pessoas especializadas

Problemas de parametrização

Complexidade de parametrização

Equipe experiente para conduzir a implantação

Necessidade de consultoria externa para treinamento

Falta de capacitação dos funcionários

Falta de conhecimento prévio de contabilidade pelos usuários

Tarefas de customização durante a implantação Inexperiência da equipe de suporte

Alto custo da consultoria e treinamento

Complexidade da customização

Falta de suporte adequado

Dependência de um único fornecedor

Carência de pessoas qualificadas e experientes

Falta de capacitação dos funcionários

Necessidade constante de manutenção e aprimoramento

Custo alto na contratação de profissionais com experiência e com bons conhecimentos sobre negócios

Consultoria para acompanhamento do projeto cara

Funcionários sem qualificação técnica para dar suporte

Funcionários sem qualificação técnica para utilizar o sistema

Elevado custo de consultoria

Conhecimento técnico inadequado ou insuficiente

Problemas técnicos associados à metodologia de custeio

Falta de adequados recursos da equipe de contadores

Falta de pessoal competente em gestão de custos

Problemas de parametrização

Dificuldades para suporte, principalmente nos momentos iniciais da operação

Falta de recursos técnicos

Falta de adequados recursos de TI

Falta de infra-estrutura de $\mathrm{TI}$

Escassez de recursos computacionais

Altos custos da implementação

Custo alto para coleta e processamento de dados necessários e na forma correta

Falta de recursos humanos

Alto volume de trabalho envolvido na instalação

Investimento alto para melhorias do sistema (customizações)

Pacotes incompletos ou pouco robustos

Problemas de integração

Problemas de baixa performance do sistema

Alto custo das atualizações das versões e das adaptações das customizações realizadas

Dificuldades na obtenção de alterações e melhorias no sistema

Necessidade de atualização constante do sistema e gerenciamento de versões

Desencontro entre as práticas dos sistemas e das práticas específicas de um segmento

Interface ruim com o usuário, que dificulta sua utilização

Baixa adequação entre o sistema e o contexto empresarial do país

Interfaces necessárias para adaptação dos sistemas existentes

Perda de algumas funções essenciais dos negócios

Excesso de customizações

Vínculo com a empresa fornecedora, especificamente em relação à necessidade de atualização da versão descontinuada

Alto custo das customizações

Dificuldade no atendimento pelo fornecedor (lento e inadequado) 
Falta de confiabilidade nas informações extraídas do sistema Sistema de contabilidade inadequado

Sistema não provê todas as informações necessárias às decisões em relação aos produtos e clientes

Escopo do sistema restringe-se aos custos operacionais, não a cadeia de valores

Pacotes de ERP incompletos ou pouco robustos

Problemas de integração

Problemas de baixa performance do sistema

Perda de funcionalidades existentes em sistemas anteriores

Excesso de telas e campos a serem digitados

Excesso de dados no banco de dados, gerando problemas de performance

\section{ADMINISTRATIVOS}

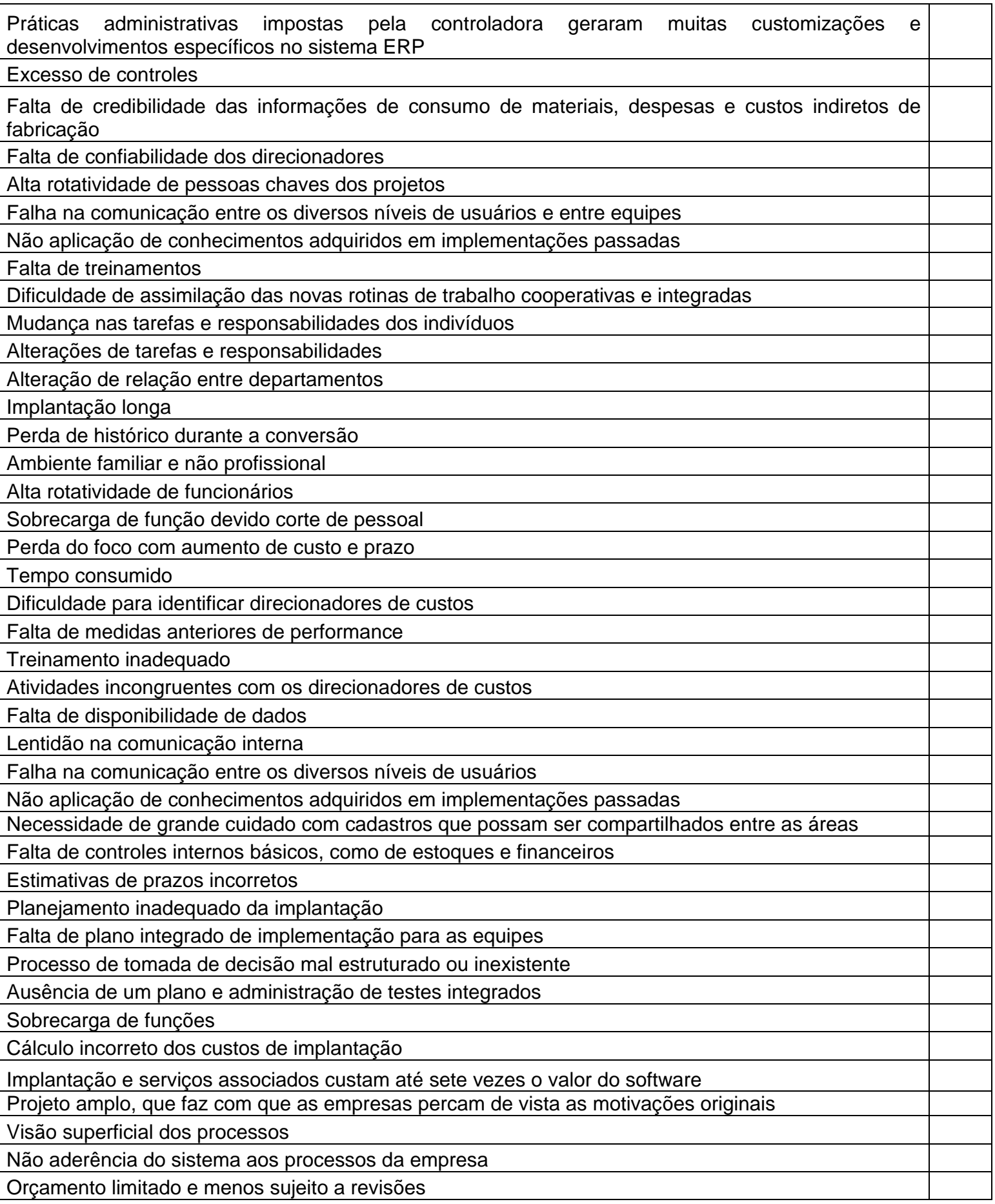


Utilização temporária do sistema novo e do antigo concomitantemente

Planejamento de projeto inadequado

Falta de participação do fornecedor na seleção do hardware necessário

Sub-avaliação da resistência dos empregados.

Sistema compete com outros sistemas já existentes

Falta de um plano integrado de desenvolvimento/implementação para as equipes

Processo de tomada de decisões mal estruturado ou inexistente 


\section{APÊNDICE 2: DIFICULDADES E FATORES CRÍTICOS POR PORTE DE EMPRESA E POR TIPO DE SISTEMAS}

\section{Dificuldades}

I.I. Nas empresas de pequeno porte

\section{I.I.I. Sistemas de Custos}

i. $\quad$ Falta de credibilidade das informações de consumo de materiais, despesas e custos indiretos de fabricação;

ii. $\quad$ Falta de confiabilidade dos direcionadores;

iii. $\quad$ Falta de controles internos básicos, como de estoques e financeiros;

iv. Resistência dos funcionários para registrarem os dados de produção necessários para o funcionamento do sistema

v. $\quad$ Resistência com relação à metodologia aplicada;

vi. Resistência dos sócios em expor resultados de suas áreas

vii. $\quad$ Falta de recursos técnicos;

viii. Falta de adequados recursos de TI;

ix. $\quad$ Custo alto para coleta e processamento de dados necessários e na forma correta

x. Investimento alto para melhorias do sistema (customizações)

\section{I.I.II Sistemas ERP}

i. Práticas administrativas impostas pela controladora geraram muitas customizações e desenvolvimentos específicos no sistema ERP

ii. Alta rotatividade de pessoas chaves dos projetos;

iii. $\quad$ Falha na comunicação entre os diversos níveis de usuários e entre equipes

iv. Não aplicação de conhecimentos adquiridos em implementações passadas

v. $\quad$ Falta de treinamentos;

vi. Dificuldade de assimilação das novas rotinas de trabalho cooperativas e integradas;

vii. Estimativas de prazos incorretos;

viii. $\quad$ Planejamento inadequado da implantação;

ix. $\quad$ Falta de plano integrado de implementação para as equipes

x. $\quad$ Processo de tomada de decisão mal estruturado ou inexistente

xi. $\quad$ Ausência de um plano e administração de testes integrados

xii. Sobrecarga de funções

xiii. Mudança organizacional decorrente do sistema;

xiv. Falta de comprometimento das pessoas-chave nas implementações

xv. Resistência a mudanças;

xvi. Resistência em descreverem suas rotinas;

xvii. Resistência quanto à utilização do novo sistema;

xviii. Falta de comprometimento de líderes;

xix. Resistência em descontinuar o antigo sistema;

xx. Dificuldade de transição para novos sistemas;

xxi. Falta de pessoas especializadas;

xxii. Problemas de parametrização

xxiii. Complexidade de parametrização

xxiv. Necessidade de equipe experiente para conduzir a implantação

xxv. Necessidade de consultoria externa para treinamento

xxvi. Falta de capacitação dos funcionários

xxvii. Falta de conhecimento prévio de contabilidade pelos usuários; 
xxviii. Falta de infra-estrutura de TI;

xxix. Falta de recursos humanos;

xxx. Pacotes incompletos ou pouco robustos

xxxi. Problemas de integração

xxxii. Problemas de baixa performance do sistema

xxxiii. Alto custo das atualizações das versões e das adaptações das customizações realizadas

xxxiv. Dificuldades na obtenção de alterações e melhorias no sistema;

I.II. Em empresas de médio porte

\section{I.II.I. Sistemas ERP}

i. $\quad$ Excesso de controles

ii. Mudança nas tarefas e responsabilidades dos indivíduos

iii. Alterações de tarefas e responsabilidades

iv. $\quad$ Alteração de relação entre departamentos

v. Implantação longa

vi. $\quad$ Perda de histórico durante a conversão

vii. Ambiente familiar e não profissional;

viii. Alta rotatividade de funcionários

ix. $\quad$ Sobrecarga de função devido corte de pessoal

x. $\quad$ Perda do foco com aumento de custo e prazo

xi. $\quad$ Falta de confiabilidade nas informações extraídas do sistema

xii. Cálculo incorreto dos custos de implantação

xiii. Implantação e serviços associados custam até sete vezes o valor do software

xiv. Projeto amplo, que faz com que as empresas percam de vista as motivações originais

xv. $\quad$ Planejamento de um projeto para essa adaptação

xvi. V Visão superficial dos processos;

xvii. $\quad$ Não aderência do sistema aos processos da empresa;

xviii. Orçamento limitado e menos sujeito a revisões;

xix. $\quad$ Utilização temporária do sistema novo e do antigo concomitantemente;

xx. Planejamento de projeto inadequado

xxi. $\quad$ Falta de participação do fornecedor na seleção do hardware necessário

xxii. Falta de envolvimento da alta direção

xxiii. Resistência de funcionários ao uso do novo sistema;

xxiv. Dificuldade de aprendizado;

xxv. $\quad$ Medo de perda de poder ou do emprego;

xxvi. Não aceitação do sistema pelos membros da organização;

xxvii. Dificuldade de adaptação ao novo sistema e processos

xxviii. Insegurança dos funcionários em relação ao manuseio e utilização do sistema

xxix. Adaptação às mudanças na rotina de trabalho

xxx. Resistência da alta direção e dos funcionários mais antigos que não tem conhecimentos básicos de informática

xxxi. Tarefas de customização durante a implantação

xxxii. Inexperiência da equipe de suporte

xxxiii. Alto custo da consultoria e treinamento

xxxiv. Complexidade da customização

xxxv. Falta de suporte adequado

xxxvi. Dependência de um único fornecedor

xxxvii. Carência de pessoas qualificadas e experientes; 
xxxviii. Falta de capacitação dos funcionários;

xxxix. Necessidade constante de manutenção e aprimoramento;

xl. Custo alto na contratação de profissionais com experiência e com bons conhecimentos sobre negócios

xli. Consultoria para acompanhamento do projeto cara

xlii. Funcionários sem qualificação técnica para dar suporte

xliii. Funcionários sem qualificação técnica para utilizar o sistema

xliv. Necessidade de atualização constante do sistema e gerenciamento de versões

xlv. Desencontro entre as práticas dos sistemas e das práticas específicas de um segmento

xlvi. Interface ruim com o usuário, que dificulta sua utilização

xlvii. Baixa adequação entre o sistema e o contexto empresarial do país

xlviii. Interfaces necessárias para adaptação dos sistemas existentes

xlix. Perda de algumas funções essenciais dos negócios

l. $\quad$ Excesso de customizações

li. Vínculo com a empresa fornecedora, especificamente em relação à necessidade de atualização da versão descontinuada;

lii. Alto custo das customizações

liii. Dificuldade no atendimento pelo fornecedor (lento e inadequado)

I.III. Em empresas de grande porte

\section{I.III.I. Sistemas de Custos}

i. Tempo consumido;

ii. $\quad$ Dificuldade para identificar direcionadores de custos;

iii. $\quad$ Falta de medidas anteriores de performance;

iv. Treinamento inadequado;

v. Atividades incongruentes com os direcionadores de custos;

vi. $\quad$ Falta de disponibilidade de dados;

vii. $\quad$ Lentidão na comunicação interna;

viii. Sub-avaliação da resistência dos empregados.

ix. $\quad$ Sistema compete com outros sistemas já existentes;

x. $\quad$ Irritação dos empregados com a complexidade da implementação;

xi. $\quad$ Necessidade de mudança de perspectiva (mentalidade ou ponto de vista);

xii. Resistência à mudança dentro da estrutura organizacional de custos;

xiii. $\quad$ Falta de apoio de funcionários;

xiv. Falta de apoio gerencial;

xv. Resistência à mudança pelos usuários (gerentes), assim como pelos produtores de informação (contadores);

xvi. Perda do envolvimento das gerências, especialmente da alta;

xvii. $\quad$ Fraca liderança no projeto do sistema;

xviii. Alta centralização das decisões;

xix. Elevado custo de consultoria;

xx. Conhecimento técnico inadequado ou insuficiente;

xxi. Problemas técnicos associados à metodologia de custeio;

xxii. $\quad$ Falta de adequados recursos da equipe de contadores;

xxiii. Falta de pessoal competente em gestão de custos;

xxiv. Escassez de recursos computacionais;

xxv. Altos custos da implementação;

xxvi. Alto volume de trabalho envolvido na instalação; 
xxvii. Sistema de contabilidade inadequado;

xxviii. Sistema não provê todas as informações necessárias às decisões em relação aos produtos e clientes;

xxix. Escopo do sistema restringe-se aos custos operacionais, não a cadeia de valores;

xxx. Existência de prioridades mais importantes para alocação dos recursos;

\section{I.III.II. Sistemas ERP}

i. $\quad$ Falha na comunicação entre os diversos níveis de usuários

ii. Não aplicação de conhecimentos adquiridos em implementações passadas

iii. Necessidade de grande cuidado com cadastros que possam ser compartilhados entre as áreas;

iv. $\quad$ Falta de um plano integrado de desenvolvimento/implementação para as equipes

v. $\quad$ Processo de tomada de decisões mal estruturado ou inexistente

vi. Resistência interna ao sistema;

vii. Resistência devido aumento de trabalho das áreas responsáveis pela entrada de dados;

viii. Resistência devido ao aumento da cobrança sobre as áreas responsáveis pela entrada de dados;

ix. Dificuldades na troca de conhecimento com consultores;

x. Problemas de parametrização

xi. Dificuldades para suporte, principalmente nos momentos iniciais da operação;

xii. $\quad$ Pacotes de ERP incompletos ou pouco robustos

xiii. Problemas de integração

xiv. $\quad$ Problemas de baixa performance do sistema

xv. Perda de funcionalidades existentes em sistemas anteriores;

xvi. Excesso de telas e campos a serem digitados;

xvii. Excesso de dados no banco de dados, gerando problemas de performance;

II) Fatores críticos ou importantes

II.I. Nas empresas de pequeno porte

\section{II.I.I Sistemas de Custos}

i. $\quad$ Constatar as vantagens e as desvantagens da implantação;

ii. $\quad$ Preparar e envolver os empregados;

iii. Importância da informação sobre custos atribuída pela gestão;

iv. $\quad$ O grau de variedade dos produtos;

v. $\quad$ Haver um sistema anterior de informação implementado;

vi. Definir os objetivos do sistema e quais as informações necessárias para atingir esses objetivos;

vii. $\quad$ Ter uma equipe multidisciplinar (engenharia, produção e contabilidade);

viii. $\quad$ Apoio dos sócios;

ix. $\quad$ Ter o apoio e crença no valor do projeto por parte dos administradores;

x. Haver alguém com experiência em implantação de sistemas ou obter auxílio externo;

xi. Ter cálculos simples;

xii. Sistema deve ser flexível e dinâmico;

xiii. Modelo de sistema que não necessite de alto investimento na coleta de dados;

xiv. Modelo de sistema que não necessite de uma séria reestruturação organizacional;

xv. $\quad$ Necessitar de poucos recursos; 


\section{II.I.II. Sistemas ERP}

i. Conhecimento e comunicação dos benefícios e dificuldades dos sistemas para todos os níveis

ii. Treinamento dos usuários

iii. Tamanho da equipe do projeto;

iv. $\quad$ Características da estrutura de incentivos;

v. Escolha de um líder de projeto que possua habilidades de negociação e gerenciamento de projetos e experiência em realização de mudanças organizacionais

vi. $\quad$ Análise de processos da empresa

vii. Entendimento de que será provavelmente necessário mudar a organização

viii. Envolvimento dos usuários e obtenção de seu comprometimento

ix. $\quad$ Mudança organizacional originada pela implementação do sistema

x. $\quad$ Comprometimento dos usuários

xi. Comprometimento da alta direção

xii. Experiência do líder de projeto;

xiii. Profissionais com conhecimento técnico e de negócio

xiv. Adequação do sistema à empresa e funcionalidades disponíveis

II.II. Nas empresas de médio porte

i. $\quad$ O redesenho dos processos;

ii. Mudança de estrutura organizacional para estrutura baseada em processos;

iii. $\quad$ Perceber a amplitude e profundidade decorrente da implantação do ERP;

iv. $\quad$ Analisar a estratégia da empresa e as necessidades de informação;

v. Realização da análise dos processos;

vi. $\quad$ Previsão do tempo e custo da implantação;

vii. Discussão de variáveis numéricas que afetam o custo como: preços dos sistemas, quantidade de módulos, números de licenças, quantidade de horas de consultoria, modificações, investimento em hardware e em treinamento;

viii. Envolvimento de profissionais com conhecimento do negócio e objetivos da empresa;

ix. $\quad$ Ajustes após a implementação;

$\mathrm{x}$. $\quad$ Equipe experiente e com bom conhecimento do negócio;

xi. Tecnologia necessária para o processamento do sistema;

xii. Interface com outros sistemas;

xiii. Migração de dados de sistemas anteriores;

II.III. Nas empresas de grande porte

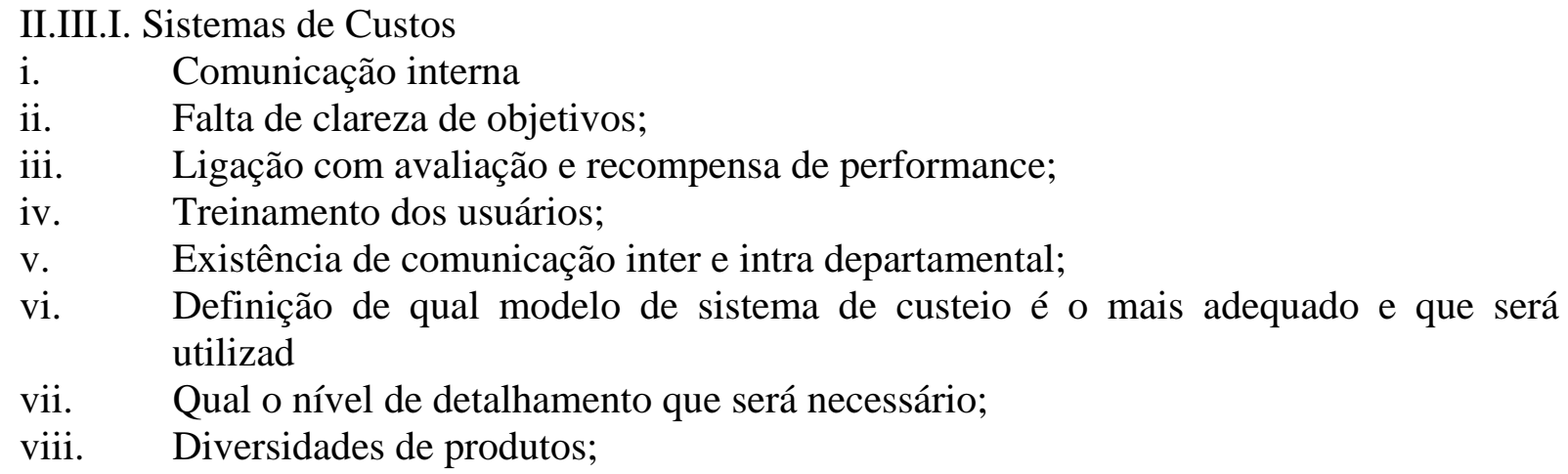


ix. $\quad$ Custos para contabilização;

x. $\quad$ Adequação de recursos necessários;

xi. Informações decorrentes do sistema para decisões dos gerentes;

xii. Compatibilidade com a estratégia da empresa;

xiii. Interação entre os setores das empresas;

xiv. Centralização de poder;

Xv. Responsabilidade do trabalhador na coleta dos dados;

xvi. Satisfação dos empregados;

xvii. Apoio da alta gerência;

xviii. Comprometimento do funcionário com a organização;

xix. $\quad$ Percepção da necessidade de mudança;

xx. Competição interna;

xxi. Disposição dos funcionários para mudanças;

xxii. Total envolvimento dos funcionários;

xxiii. Especialização dos funcionários;

xxiv. Conhecimento do processo;

xxv. Complexidade do sistema para usuários;

xxvi. Compatibilidade com sistemas existentes;

xxvii. Melhora sobre sistema existente;

\section{II.III.I. Sistemas ERP}

i. $\quad$ Treinamento de usuários;

ii. Iniciar as mudanças com os processos prioritários para a implementação;

iii. Manter a comunicação contínua com todos os níveis hierárquicos de usuários, de maneira compreensiva e não técnica, sobre o andamento e realizações do projeto;

iv. $\quad$ Equipe equilibrada entre membros da tecnologia e das áreas de negócios

v. $\quad$ Suporte aos usuários nas mudanças em seus trabalhos.

vi. $\quad$ Obtenção de alterações e melhorias no sistema;

vii. $\quad$ Necessidade de um plano de implementação;

viii. Compreensão da cultura da empresa em termos de sua capacidade para mudança e presteza

ix. Definição de responsabilidades

x. $\quad$ Motivação dos funcionários;

xi. Apoio irrestrito dos altos executivos da instituição para o projeto;

xii. Comprometido com a mudança

xiii. Resistência a mudanças;

xiv. Conhecimento técnico dos funcionários;

xv. Capacidade de negociação sobre aspectos técnicos do gerente do projeto;

xvi. Assimilação das novas rotinas de trabalho cooperativas e integradas;

xvii. Complexidade de parametrização 


\section{APÊNDICE 3: DIFICULDADES E FATORES CRÍTICOS CLASSIFICADOS POR GRUPO E SUBGRUPO}

\begin{tabular}{|c|c|c|}
\hline \multicolumn{3}{|l|}{ I. Dificuldades } \\
\hline \multicolumn{3}{|c|}{ I.I. Nas empresas de pequeno porte } \\
\hline comportamentais & & Falta de comprometimento das pessoas-chave nas implementações \\
\hline comportamentais & & Falta de comprometimento de líderes \\
\hline comportamentais & & Mudança organizacional decorrente do sistema \\
\hline comportamentais & & Resistência a mudanças \\
\hline comportamentais & & Resistência com relação à metodologia aplicada \\
\hline comportamentais & & $\begin{array}{l}\text { Resistência dos funcionários para registrarem os dados de produção } \\
\text { necessários para o funcionamento do sistema }\end{array}$ \\
\hline comportamentais & & Resistência dos sócios em expor resultados de suas áreas \\
\hline comportamentais & & Resistência em descontinuar o antigo sistema \\
\hline comportamentais & & Resistência em descreverem suas rotinas \\
\hline comportamentais & & Resistência quanto à utilização do novo sistema \\
\hline administrativos & planejamento & Ausência de um plano e administração de testes integrados \\
\hline administrativos & planejamento & Estimativas de prazos incorretos \\
\hline administrativos & planejamento & Falta de controles internos básicos, como de estoques e financeiros \\
\hline administrativos & planejamento & Falta de plano integrado de implementação para as equipes \\
\hline administrativos & planejamento & Planejamento inadequado da implantação \\
\hline administrativos & planejamento & Processo de tomada de decisão mal estruturado ou inexistente \\
\hline administrativos & planejamento & Sobrecarga de funções \\
\hline administrativos & execução & Alta rotatividade de pessoas chaves dos projetos \\
\hline administrativos & execução & $\begin{array}{l}\text { Dificuldade de assimilação das novas rotinas de trabalho cooperativas } \\
\text { e integradas }\end{array}$ \\
\hline administrativos & execução & $\begin{array}{l}\text { Falha na comunicação entre os diversos níveis de usuários e entre } \\
\text { equipes }\end{array}$ \\
\hline administrativos & execução & Falta de confiabilidade dos direcionadores \\
\hline administrativos & execução & $\begin{array}{l}\text { Falta de credibilidade das informações de consumo de materiais, } \\
\text { despesas e custos indiretos de fabricação }\end{array}$ \\
\hline administrativos & execução & Falta de treinamentos \\
\hline administrativos & execução & $\begin{array}{l}\text { Não aplicação de conhecimentos adquiridos em implementações } \\
\text { passadas }\end{array}$ \\
\hline administrativos & controle & $\begin{array}{l}\text { Práticas administrativas impostas pela controladora geraram muitas } \\
\text { customizações e desenvolvimentos específicos no sistema ERP }\end{array}$ \\
\hline escassez de recursos & humanos & $\begin{array}{l}\text { Custo alto para coleta e processamento de dados necessários e na } \\
\text { forma correta }\end{array}$ \\
\hline escassez de recursos & humanos & Falta de recursos humanos \\
\hline escassez de recursos & físicos & Falta de adequados recursos de TI \\
\hline escassez de recursos & físicos & Falta de infra-estrutura de TI \\
\hline escassez de recursos & físicos & Falta de recursos técnicos \\
\hline escassez de recursos & tecnológicos & $\begin{array}{l}\text { Alto custo das atualizações das versões e das adaptações das } \\
\text { customizações realizadas }\end{array}$ \\
\hline escassez de recursos & tecnológicos & Dificuldades na obtenção de alterações e melhorias no sistema \\
\hline escassez de recursos & tecnológicos & Investimento alto para melhorias do sistema (customizações) \\
\hline escassez de recursos & tecnológicos & Pacotes incompletos ou pouco robustos \\
\hline escassez de recursos & tecnológicos & Problemas de baixa performance do sistema \\
\hline escassez de recursos & tecnológicos & Problemas de integração \\
\hline escassez de recursos & conhecimentos específicos & Complexidade de parametrização \\
\hline
\end{tabular}




\begin{tabular}{|c|c|c|}
\hline escassez de recursos & | conhecimentos específicos & Dificuldade de transição para novos sistemas \\
\hline escassez de recursos & conhecimentos específicos & Falta de capacitação dos funcionários \\
\hline escassez de recursos & conhecimentos específicos & Falta de conhecimento prévio de contabilidade pelos usuários \\
\hline escassez de recursos & conhecimentos específicos & Falta de pessoas especializadas \\
\hline escassez de recursos & conhecimentos específicos & Necessidade de consultoria externa para treinamento \\
\hline escassez de recursos & conhecimentos específicos & Necessidade de equipe experiente para conduzir a implantação \\
\hline escassez de recursos & conhecimentos específicos & Problemas de parametrização \\
\hline \multicolumn{3}{|c|}{ I.II. Em empresas de médio porte } \\
\hline comportamentais & & Adaptação às mudanças na rotina de trabalho \\
\hline comportamentais & & Dificuldade de adaptação ao novo sistema e processos \\
\hline comportamentais & & Dificuldade de aprendizado \\
\hline comportamentais & & Falta de envolvimento da alta direção \\
\hline comportamentais & & $\begin{array}{l}\text { Insegurança dos funcionários em relação ao manuseio e utilização do } \\
\text { sistema }\end{array}$ \\
\hline comportamentais & & Medo de perda de poder ou do emprego \\
\hline comportamentais & & Não aceitação do sistema pelos membros da organização \\
\hline comportamentais & & $\begin{array}{l}\text { Resistência da alta direção e dos funcionários mais antigos que não } \\
\text { tem conhecimentos básicos de informática }\end{array}$ \\
\hline comportamentais & & Resistência de funcionários ao uso do novo sistema \\
\hline administrativos & planejamento & Cálculo incorreto dos custos de implantação \\
\hline administrativos & planejamento & $\begin{array}{l}\text { Falta de participação do fornecedor na seleção do hardware } \\
\text { necessário }\end{array}$ \\
\hline administrativos & planejamento & $\begin{array}{l}\text { Implantação e serviços associados custam até sete vezes o valor do } \\
\text { software }\end{array}$ \\
\hline administrativos & planejamento & Não aderência do sistema aos processos da empresa \\
\hline administrativos & planejamento & Orçamento limitado e menos sujeito a revisões \\
\hline administrativos & planejamento & Planejamento de projeto inadequado \\
\hline administrativos & planejamento & Planejamento de um projeto para essa adaptação \\
\hline administrativos & planejamento & $\begin{array}{l}\text { Projeto amplo, que faz com que as empresas percam de vista as } \\
\text { motivações originais }\end{array}$ \\
\hline administrativos & planejamento & $\begin{array}{l}\begin{array}{l}\text { Utilização temporária do sistema novo e } \\
\text { concomitantemente }\end{array} \\
\end{array}$ \\
\hline administrativos & planejamento & Visão superficial dos processos \\
\hline administrativos & execução & Alta rotatividade de funcionários \\
\hline administrativos & execução & Alteração de relação entre departamentos \\
\hline administrativos & execução & Alterações de tarefas e responsabilidades \\
\hline administrativos & execução & Ambiente familiar e não profissional \\
\hline administrativos & execução & Falta de confiabilidade nas informações extraídas do sistema \\
\hline administrativos & execução & Implantação longa \\
\hline administrativos & execução & Mudança nas tarefas e responsabilidades dos indivíduos \\
\hline administrativos & execução & Perda de histórico durante a conversão \\
\hline administrativos & execução & Perda do foco com aumento de custo e prazo \\
\hline administrativos & execução & Sobrecarga de função devido corte de pessoal \\
\hline administrativos & controle & Excesso de controles \\
\hline escassez de recursos & tecnológicos & Alto custo das customizações \\
\hline escassez de recursos & tecnológicos & Baixa adequação entre o sistema e o contexto empresarial do país \\
\hline escassez de recursos & tecnológicos & $\begin{array}{l}\text { Desencontro entre as práticas dos sistemas e das práticas específicas } \\
\text { de um segmento }\end{array}$ \\
\hline escassez de recursos & tecnológicos & Dificuldade no atendimento pelo fornecedor (lento e inadequado) \\
\hline escassez de recursos & tecnológicos & Excesso de customizações \\
\hline escassez de recursos & tecnológicos & Interface ruim com o usuário, que dificulta sua utilização \\
\hline
\end{tabular}




\begin{tabular}{|c|c|c|}
\hline escassez de recursos & tecnológicos & Interfaces necessárias para adaptação dos sistemas existentes \\
\hline escassez de recursos & tecnológicos & $\begin{array}{l}\text { Necessidade de atualização constante do sistema e gerenciamento de } \\
\text { versões }\end{array}$ \\
\hline escassez de recursos & tecnológicos & Perda de algumas funções essenciais dos negócios \\
\hline escassez de recursos & tecnológicos & $\begin{array}{l}\text { Vínculo com a empresa fornecedora, especificamente em relação à } \\
\text { necessidade de atualização da versão descontinuada }\end{array}$ \\
\hline escassez de recursos & conhecimentos específicos & Alto custo da consultoria e treinamento \\
\hline escassez de recursos & conhecimentos específicos & Carência de pessoas qualificadas e experientes \\
\hline escassez de recursos & conhecimentos específicos & Complexidade da customização \\
\hline escassez de recursos & conhecimentos específicos & Consultoria para acompanhamento do projeto cara \\
\hline escassez de recursos & conhecimentos específicos & $\begin{array}{l}\text { Custo alto na contratação de profissionais com experiência e com } \\
\text { bons conhecimentos sobre negócios }\end{array}$ \\
\hline escassez de recursos & conhecimentos específicos & Dependência de um único fornecedor \\
\hline escassez de recursos & conhecimentos específicos & Falta de capacitação dos funcionários \\
\hline escassez de recursos & conhecimentos específicos & Falta de suporte adequado \\
\hline escassez de recursos & conhecimentos específicos & Funcionários sem qualificação técnica para dar suporte \\
\hline escassez de recursos & conhecimentos específicos & Funcionários sem qualificação técnica para utilizar o sistema \\
\hline escassez de recursos & conhecimentos específicos & Inexperiência da equipe de suporte \\
\hline escassez de recursos & conhecimentos específicos & Necessidade constante de manutenção e aprimoramento \\
\hline escassez de recursos & conhecimentos específicos & Tarefas de customização durante a implantação \\
\hline \multicolumn{3}{|c|}{ I.III. Em empresas de grande porte } \\
\hline comportamentais & & Alta centralização das decisões \\
\hline comportamentais & & Dificuldades na troca de conhecimento com consultores \\
\hline comportamentais & & Falta de apoio de funcionários \\
\hline comportamentais & & Falta de apoio gerencial \\
\hline comportamentais & & Fraca liderança no projeto do sistema \\
\hline comportamentais & & Irritação dos empregados com a complexidade da implementação \\
\hline comportamentais & & $\begin{array}{l}\text { Necessidade de mudança de perspectiva (mentalidade ou ponto de } \\
\text { vista) }\end{array}$ \\
\hline comportamentais & & Perda do envolvimento das gerências, especialmente da alta \\
\hline comportamentais & & Resistência à mudança dentro da estrutura organizacional de custos \\
\hline comportamentais & & $\begin{array}{l}\text { Resistência à mudança pelos usuários (gerentes), assim como pelos } \\
\text { produtores de informação (contadores) }\end{array}$ \\
\hline comportamentais & & $\begin{array}{l}\text { Resistência devido ao aumento da cobrança sobre as áreas } \\
\text { responsáveis pela entrada de dados }\end{array}$ \\
\hline comportamentais & & $\begin{array}{l}\text { Resistência devido aumento de trabalho das áreas responsáveis pela } \\
\text { entrada de dados }\end{array}$ \\
\hline comportamentais & & Resistência interna ao sistema \\
\hline administrativos & planejamento & $\begin{array}{l}\text { Falta de um plano integrado de desenvolvimento/implementação para } \\
\text { as equipes }\end{array}$ \\
\hline administrativos & planejamento & Processo de tomada de decisões mal estruturado ou inexistente \\
\hline administrativos & planejamento & Sistema compete com outros sistemas já existentes \\
\hline administrativos & planejamento & Sub-avaliação da resistência dos empregados. \\
\hline administrativos & execução & Atividades incongruentes com os direcionadores de custos \\
\hline administrativos & execução & Dificuldade para identificar direcionadores de custos \\
\hline administrativos & execução & Falha na comunicação entre os diversos níveis de usuários \\
\hline administrativos & execução & Falta de disponibilidade de dados \\
\hline administrativos & execução & Falta de medidas anteriores de performance \\
\hline administrativos & execução & Lentidão na comunicação interna \\
\hline administrativos & execução & $\begin{array}{l}\text { Não aplicação de conhecimentos adquiridos em implementações } \\
\text { passadas }\end{array}$ \\
\hline
\end{tabular}




\begin{tabular}{|c|c|c|}
\hline administrativos & execução & $\begin{array}{l}\text { Necessidade de grande cuidado com cadastros que possam ser } \\
\text { compartilhados entre as áreas }\end{array}$ \\
\hline administrativos & execução & Tempo consumido \\
\hline administrativos & execução & Treinamento inadequado \\
\hline escassez de recursos & humanos & Alto volume de trabalho envolvido na instalação \\
\hline escassez de recursos & físicos & Escassez de recursos computacionais \\
\hline escassez de recursos & tecnológicos & $\begin{array}{l}\text { Escopo do sistema restringe-se aos custos operacionais, não a cadeia } \\
\text { de valores }\end{array}$ \\
\hline escassez de recursos & tecnológicos & $\begin{array}{l}\text { Excesso de dados no banco de dados, gerando problemas de } \\
\text { performance }\end{array}$ \\
\hline escassez de recursos & tecnológicos & Excesso de telas e campos a serem digitados \\
\hline escassez de recursos & tecnológicos & Pacotes de ERP incompletos ou pouco robustos \\
\hline escassez de recursos & tecnológicos & Perda de funcionalidades existentes em sistemas anteriores \\
\hline escassez de recursos & tecnológicos & Problemas de baixa performance do sistema \\
\hline escassez de recursos & tecnológicos & Problemas de integração \\
\hline escassez de recursos & tecnológicos & Sistema de contabilidade inadequado \\
\hline escassez de recursos & tecnológicos & $\begin{array}{l}\text { Sistema não provê todas as informações necessárias às decisões em } \\
\text { relação aos produtos e clientes }\end{array}$ \\
\hline escassez de recursos & conhecimentos específicos & Conhecimento técnico inadequado ou insuficiente \\
\hline escassez de recursos & conhecimentos específicos & $\begin{array}{l}\text { Dificuldades para suporte, principalmente nos momentos iniciais da } \\
\text { operação }\end{array}$ \\
\hline escassez de recursos & conhecimentos específicos & Elevado custo de consultoria \\
\hline escassez de recursos & conhecimentos específicos & Falta de adequados recursos da equipe de contadores \\
\hline escassez de recursos & conhecimentos específicos & Falta de pessoal competente em gestão de custos \\
\hline escassez de recursos & conhecimentos específicos & Problemas de parametrização \\
\hline escassez de recursos & conhecimentos específicos & Problemas técnicos associados à metodologia de custeio \\
\hline escassez de recursos & geral & Altos custos da implementação \\
\hline escassez de recursos & geral & $\begin{array}{l}\begin{array}{l}\text { Existência de prioridades mais importantes para alocação dos } \\
\text { recursos }\end{array} \\
\end{array}$ \\
\hline \multicolumn{3}{|c|}{ II Fatores críticos ou importantes } \\
\hline \multicolumn{3}{|c|}{ II.I. Nas empresas de pequeno porte } \\
\hline comportamentais & & Apoio dos sócios \\
\hline comportamentais & & Comprometimento da alta direção \\
\hline comportamentais & & Comprometimento dos usuários \\
\hline comportamentais & & $\begin{array}{l}\begin{array}{l}\text { Entendimento de que será provavelmente necessário mudar a } \\
\text { organização }\end{array} \\
\end{array}$ \\
\hline comportamentais & & Envolvimento dos usuários e obtenção de seu comprometimento \\
\hline comportamentais & & Mudança organizacional originada pela implementação do sistema \\
\hline comportamentais & & $\begin{array}{l}\text { Ter o apoio e crença no valor do projeto por parte dos } \\
\text { administradores }\end{array}$ \\
\hline administrativos & planejamento & Análise de processos da empresa \\
\hline administrativos & planejamento & Características da estrutura de incentivos \\
\hline administrativos & planejamento & $\begin{array}{l}\text { Definir os objetivos do sistema e quais as informações necessárias } \\
\text { para atingir esses objetivos }\end{array}$ \\
\hline administrativos & planejamento & $\begin{array}{l}\text { Escolha de um líder de projeto que possua habilidades de negociação } \\
\text { e gerenciamento de projetos e experiência em realização de mudanças } \\
\text { organizacionais }\end{array}$ \\
\hline administrativos & planejamento & Haver um sistema anterior de informação implementado \\
\hline administrativos & planejamento & Importância da informação sobre custos atribuída pela gestão \\
\hline administrativos & planejamento & O grau de variedade dos produtos \\
\hline
\end{tabular}




\begin{tabular}{|c|c|c|}
\hline administrativos & planejamento & Tamanho da equipe do projeto \\
\hline administrativos & planejamento & $\begin{array}{l}\begin{array}{l}\text { Ter uma equipe multidisciplinar (engenharia, produção e } \\
\text { contabilidade) }\end{array} \\
\end{array}$ \\
\hline administrativos & execução & $\begin{array}{l}\text { Conhecimento e comunicação dos benefícios e dificuldades dos } \\
\text { sistemas para todos os níveis }\end{array}$ \\
\hline administrativos & execução & Preparar e envolver os empregados \\
\hline administrativos & execução & Treinamento dos usuários \\
\hline administrativos & controle & Constatar as vantagens e as desvantagens da implantação \\
\hline escassez de recursos & tecnológicos & Adequação do sistema à empresa e funcionalidades disponíveis \\
\hline escassez de recursos & tecnológicos & $\begin{array}{l}\text { Modelo de sistema que não necessite de alto investimento na coleta } \\
\text { de dados }\end{array}$ \\
\hline escassez de recursos & tecnológicos & $\begin{array}{l}\text { Modelo de sistema que não necessite de uma séria reestruturação } \\
\text { organizacional }\end{array}$ \\
\hline escassez de recursos & tecnológicos & Sistema deve ser flexível e dinâmico \\
\hline escassez de recursos & tecnológicos & Ter cálculos simples \\
\hline escassez de recursos & conhecimentos específicos & Experiência do líder de projeto \\
\hline escassez de recursos & conhecimentos específicos & $\begin{array}{l}\text { Haver alguém com experiência em implantação de sistemas ou obter } \\
\text { auxílio externo }\end{array}$ \\
\hline escassez de recursos & conhecimentos específicos & Profissionais com conhecimento técnico e de negócio \\
\hline \multicolumn{3}{|c|}{ II.II. Nas empresas de médio porte } \\
\hline comportamentais & & $\begin{array}{l}\text { Envolvimento de profissionais com conhecimento do negócio e } \\
\text { objetivos da empresa }\end{array}$ \\
\hline administrativos & planejamento & Analisar a estratégia da empresa e as necessidades de informação \\
\hline administrativos & planejamento & $\begin{array}{l}\text { Discussão de variáveis numéricas que afetam o custo como: preços } \\
\text { dos sistemas, quantidade de módulos, números de licenças, } \\
\text { quantidade de horas de consultoria, modificações, investimento em } \\
\text { hardware e em treinamento }\end{array}$ \\
\hline administrativos & planejamento & $\begin{array}{l}\text { Mudança de estrutura organizacional para estrutura baseada em } \\
\text { processos }\end{array}$ \\
\hline administrativos & planejamento & O redesenho dos processos \\
\hline administrativos & planejamento & $\begin{array}{l}\text { Perceber a amplitude e profundidade decorrente da implantação do } \\
\text { ERP }\end{array}$ \\
\hline administrativos & planejamento & Previsão do tempo e custo da implantação \\
\hline administrativos & planejamento & Realização da análise dos processos \\
\hline escassez de recursos & físicos & Tecnologia necessária para o processamento do sistema \\
\hline escassez de recursos & tecnológicos & Interface com outros sistemas \\
\hline escassez de recursos & tecnológicos & Migração de dados de sistemas anteriores \\
\hline escassez de recursos & conhecimentos específicos & Ajustes após a implementação \\
\hline escassez de recursos & conhecimentos específicos & Equipe experiente e com bom conhecimento do negócio \\
\hline \multicolumn{3}{|c|}{ II.III. Nas empresas de grande porte } \\
\hline comportamentais & & Apoio da alta gerência \\
\hline comportamentais & & Apoio irrestrito dos altos executivos da instituição para o projeto \\
\hline comportamentais & & Centralização de poder \\
\hline comportamentais & & Competição interna \\
\hline comportamentais & & Comprometido com a mudança \\
\hline comportamentais & & Comprometimento do funcionário com a organização \\
\hline comportamentais & & Disposição dos funcionários para mudanças \\
\hline comportamentais & & Motivação dos funcionários \\
\hline comportamentais & & Percepção da necessidade de mudança \\
\hline
\end{tabular}




\begin{tabular}{|c|c|c|}
\hline comportamentais & & Resistência a mudanças \\
\hline comportamentais & & Responsabilidade do trabalhador na coleta dos dados \\
\hline comportamentais & & Satisfação dos empregados \\
\hline comportamentais & & Total envolvimento dos funcionários \\
\hline administrativos & planejamento & Adequação de recursos necessários \\
\hline administrativos & planejamento & Compatibilidade com a estratégia da empresa \\
\hline administrativos & planejamento & $\begin{array}{l}\text { Compreensão da cultura da empresa em termos de sua capacidade } \\
\text { para mudança e presteza }\end{array}$ \\
\hline administrativos & planejamento & Custos para contabilização \\
\hline administrativos & planejamento & $\begin{array}{l}\text { Definição de qual modelo de sistema de custeio é o mais adequado e } \\
\text { que será utilizado }\end{array}$ \\
\hline administrativos & planejamento & Definição de responsabilidades \\
\hline administrativos & planejamento & Diversidades de produtos \\
\hline administrativos & planejamento & Informações decorrentes do sistema para decisões dos gerentes \\
\hline administrativos & planejamento & Interação entre os setores das empresas \\
\hline administrativos & planejamento & Necessidade de um plano de implementação \\
\hline administrativos & planejamento & Qual o nível de detalhamento que será necessário \\
\hline administrativos & execução & Comunicação interna \\
\hline administrativos & execução & $\begin{array}{l}\text { Equipe equilibrada entre membros da tecnologia e das áreas de } \\
\text { negócios }\end{array}$ \\
\hline administrativos & execução & Existência de comunicação inter e intra departamental \\
\hline administrativos & execução & Falta de clareza de objetivos \\
\hline administrativos & execução & $\begin{array}{l}\text { Iniciar as mudanças com os processos prioritários para a } \\
\text { implementação }\end{array}$ \\
\hline administrativos & execução & Ligação com avaliação e recompensa de performance \\
\hline administrativos & execução & $\begin{array}{l}\text { Manter a comunicação contínua com todos os níveis hierárquicos de } \\
\text { usuários, de maneira compreensiva e não técnica, sobre o andamento } \\
\text { e realizações do projeto }\end{array}$ \\
\hline administrativos & execução & Obtenção de alterações e melhorias no sistema \\
\hline administrativos & execução & Suporte aos usuários nas mudanças em seus trabalhos. \\
\hline administrativos & execução & Treinamento de usuários \\
\hline administrativos & execução & Treinamento dos usuários \\
\hline escassez de recursos & tecnológicos & Compatibilidade com sistemas existentes \\
\hline escassez de recursos & tecnológicos & Complexidade do sistema para usuários \\
\hline escassez de recursos & tecnológicos & Melhora sobre sistema existente \\
\hline escassez de recursos & conhecimentos específicos & Assimilação das novas rotinas de trabalho cooperativas e integradas \\
\hline escassez de recursos & conhecimentos específicos & $\begin{array}{l}\text { Capacidade de negociação sobre aspectos técnicos do gerente do } \\
\text { projeto }\end{array}$ \\
\hline escassez de recursos & conhecimentos específicos & Complexidade de parametrização \\
\hline escassez de recursos & conhecimentos específicos & Conhecimento do processo \\
\hline escassez de recursos & conhecimentos específicos & Conhecimento técnico dos funcionários \\
\hline escassez de recursos & conhecimentos específicos & Especialização dos funcionários \\
\hline
\end{tabular}




\section{APÊNDICE 4: CARTA DE APRESENTAÇÃO}

Carta de Apresentação

São Paulo,

À

Empresa

Sr.

Cargo

Prezados Senhores,

Como mestrando do Programa de Pós-graduação em Controladoria e Contabilidade da Faculdade de Economia, Administração e Contabilidade da Universidade de São Paulo, solicito a sua participação em um estudo acadêmico realizado para analisar as dificuldades de implantação de um sistema de custos em médias empresas.

Apesar da ciência da existência dessas dificuldades, são raros os estudos que as abordem com foco neste porte de empresas. A finalidade deste estudo é de tentar identificar essas dificuldades, assim como suas causas e possíveis soluções. Com isso, espera-se aumentar o conhecimento sobre o assunto, aliando a teoria acadêmica com a prática encontrada nas empresas, auxiliando futuros pesquisadores e pessoas envolvidas na implantação desse tipo de sistema.

Para o estudo não será necessário o fornecimento de informações sigilosas ou estratégicas da empresa, tanto contábeis como financeiras. As informações solicitadas referem-se a aspectos relacionados somente com o processo de implantação do sistema de custo, e a aspectos organizacionais. A identificação da empresa também não será fornecida, assim como dos respondentes, a não ser que respectivamente autorizadas.

Ao término do estudo, caso seja de interesse de V.Sa.s, este estará à disposição para consulta.

Agradecemos antecipadamente a colaboração de V.Sa.s, lembrando que suas informações auxiliarão o desenvolvimento científico em relação à compreensão das organizações brasileiras.

Atenciosamente,

Roberto Suzuki 